\title{
Liquid Metal Temperature Measurement (Sodium) State-of-the-Art-Study
}

by

J.S. Hochheiser

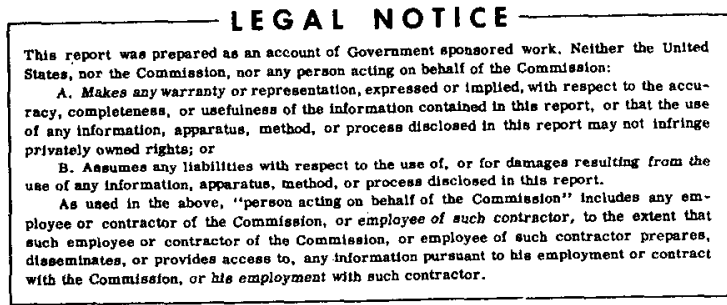

\section{Liquid Metal Engineering Center} Operated for

the U.S. Atomic Energy Commission by Atomics International A Division of North American Rockwell Corporation

Contract: AT(04-3)-700

Issued: May 31, 1968 


\section{DISCLAIMER}

This report was prepared as an account of work sponsored by an agency of the United States Government. Neither the United States Government nor any agency Thereof, nor any of their employees, makes any warranty, express or implied, or assumes any legal liability or responsibility for the accuracy, completeness, or usefulness of any information, apparatus, product, or process disclosed, or represents that its use would not infringe privately owned rights. Reference herein to any specific commercial product, process, or service by trade name, trademark, manufacturer, or otherwise does not necessarily constitute or imply its endorsement, recommendation, or favoring by the United States Government or any agency thereof. The views and opinions of authors expressed herein do not necessarily state or reflect those of the United States Government or any agency thereof. 


\section{DISCLAIMER}

Portions of this document may be illegible in electronic image products. Images are produced from the best available original document. 
-

•
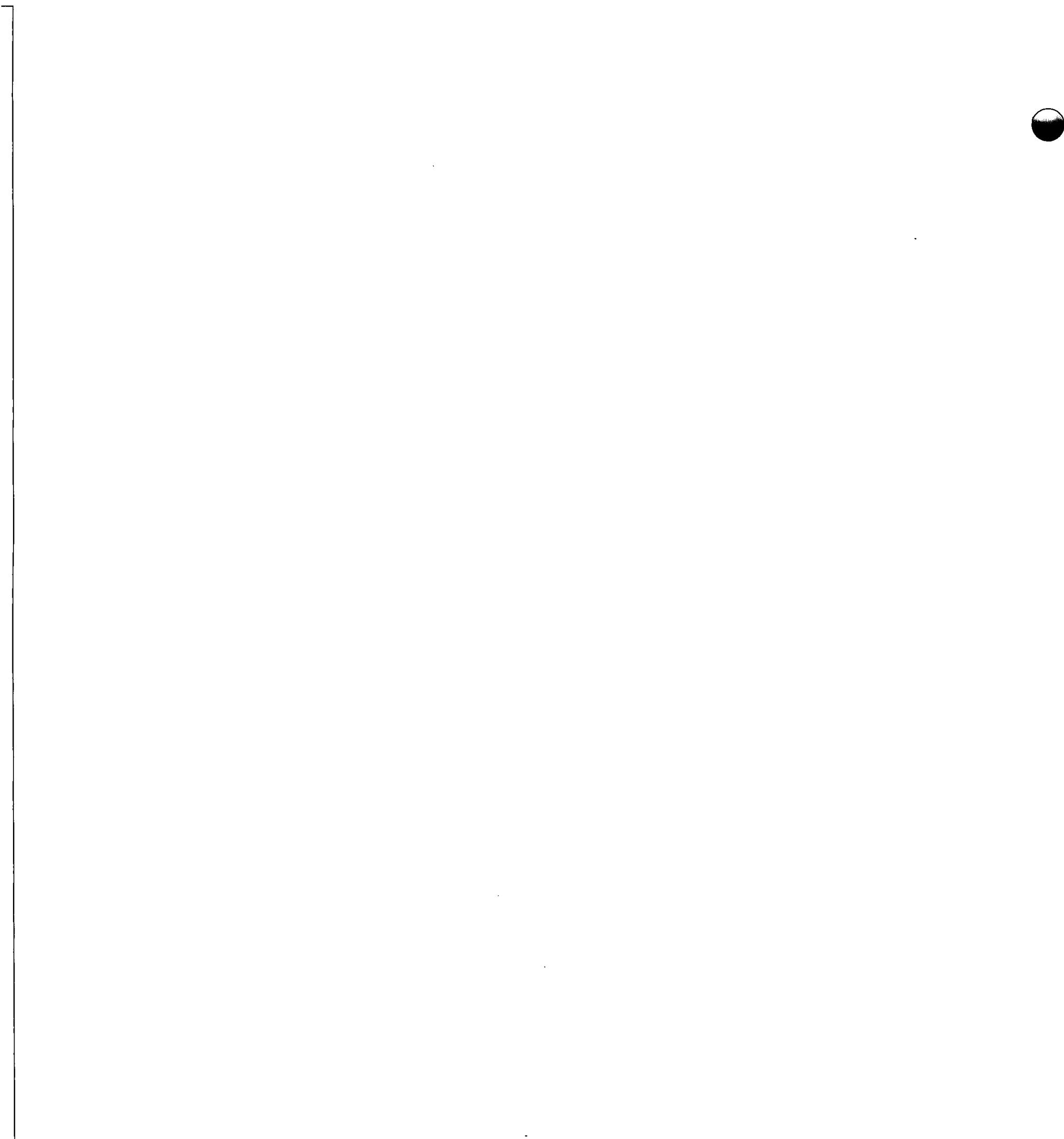

.

.

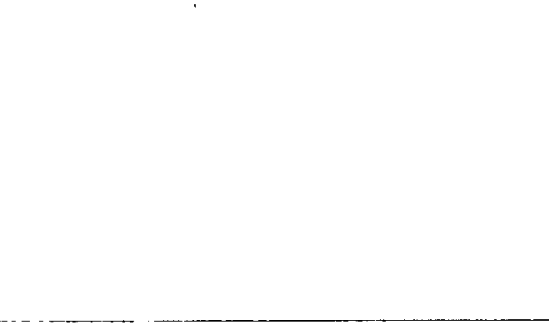




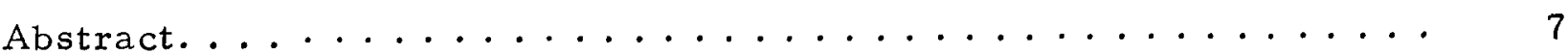

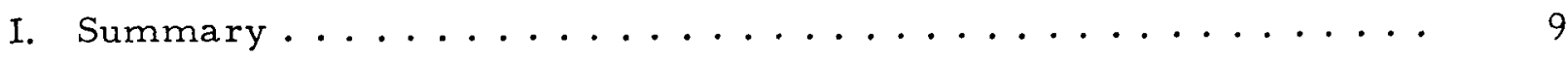

II. Int roduction . ........................ 11

III. Behavior of Materials with Temperature ............ 15

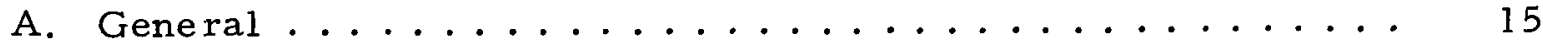

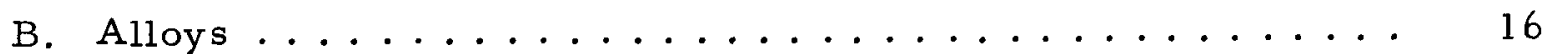

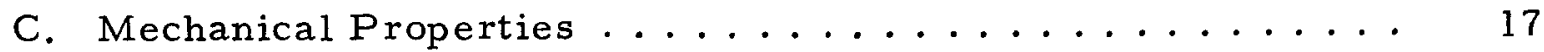

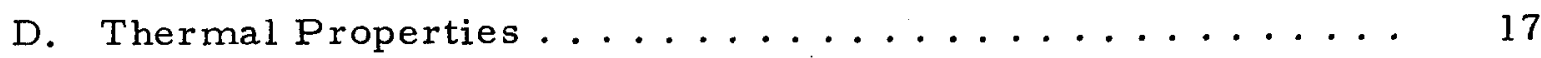

E. Chemical Properties .................. 17

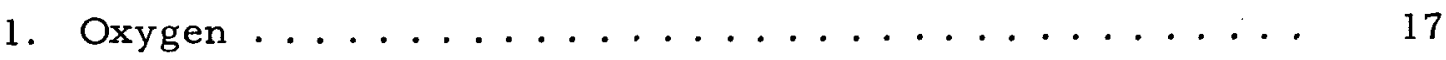

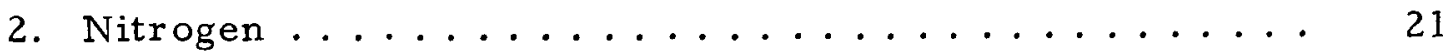

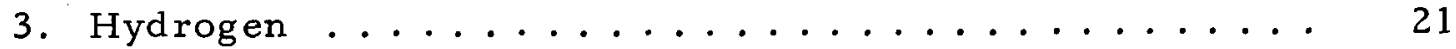

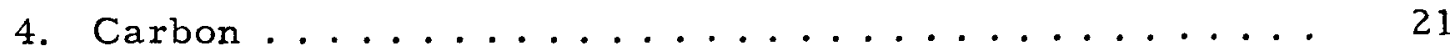

F. Electrical Properties ................... 22

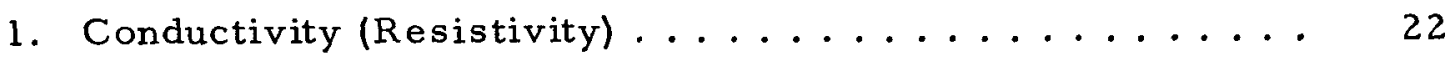

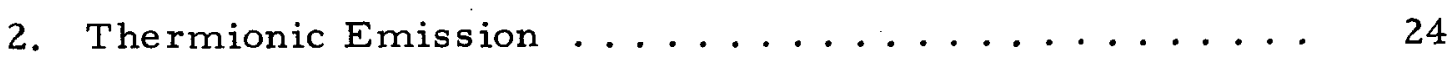

IV. Reference Standards and Calibration ............... 27

A. National Bureaur of Standards (NBS) Accuracy of

Realization of the Thermodynamic Temperature Scale . . . 27

B. Practical Temperature Scales Employed by NBS for the Calibration of Temperature-Measuring Instruments . . . . . 27

C. NBS Photometric Standards ................ 30

D. Calibration of Temperature-Measurement Instruments . . . . 32

V. Temperature Measurement Techniques and Instruments . . . . . 37

A. Thermoelectric Thermometry .............. 37

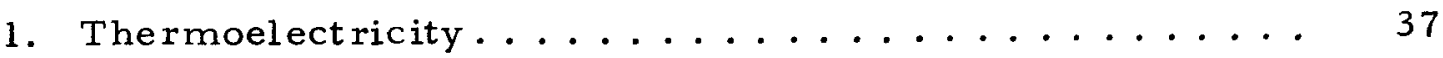

2. Advantages and Limitations of Thermocouples ...... 38

3. Mea surement and Calibration .............. 39

4. Thermocouple Fabrication ............... 44

5. Thermocouple Installation ............... 45

6. Thermocouple Materials ............... 48 
B. Resistance Thermometry ................ 52

1. Metals .......................... 54

2. Semiconductors ..................... 54

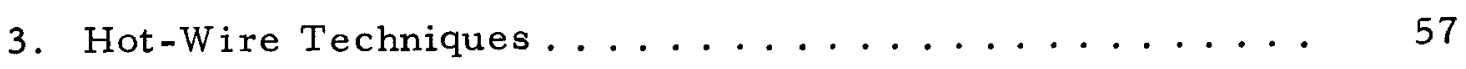

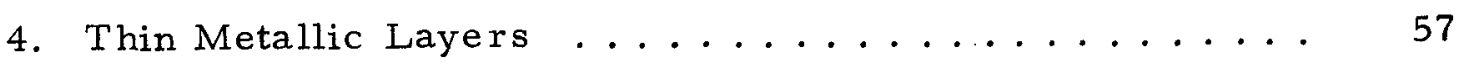

5. Oxides .................... 57

C. Radiation Pyrometry ................. 57

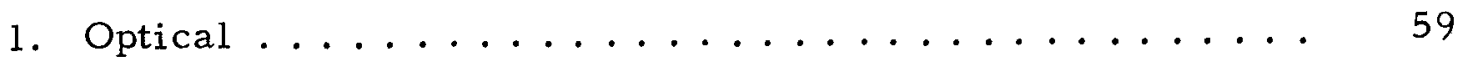

2. Emission Spectroscopy ............... 62

3. Infrared Photography ................ 63

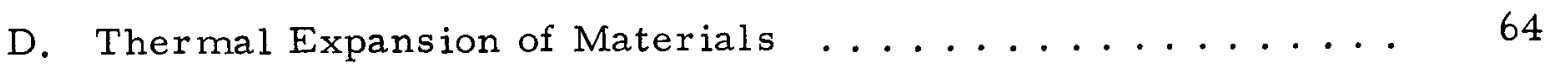

1. Liquid Thermometers ................. 64

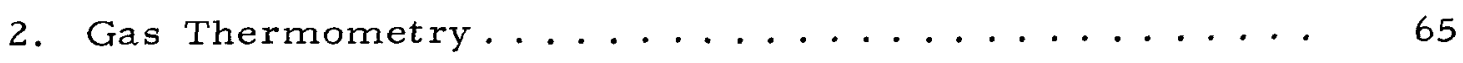

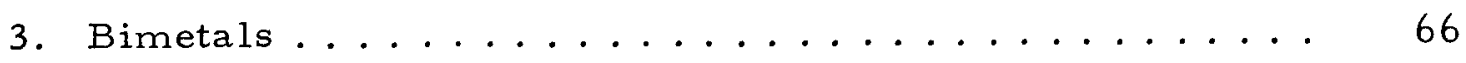

4. Filled System Thermometers . . . . . . . . . 67

E. Variations in Dielectric Constants. . . . . . . . . . 67

F. Thermionic Emission . . . . . . . . . . . . 68

G. Acoustic ............................... 69

1. Velocity of Sound in Gas . . . . . . . . . . . . 69

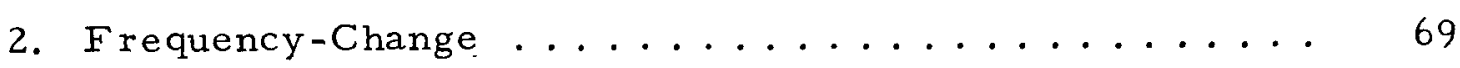

3. Phase-Relation.................. 70

4. Spark Gap ...................... 70

H. Thermochemical ................ 71

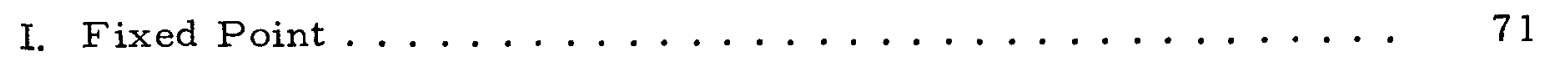

J. Phosphor Luminescence ................. 72

K. Noise Generated in Electrical Elements . . . . . . . . . 72

L. Diffusion. ......................... 73

M. Pneumatic Apparatus . . . . . . . . . . . . . . 75

N. Pyrometric Cones Tapes and Paints ............ 75

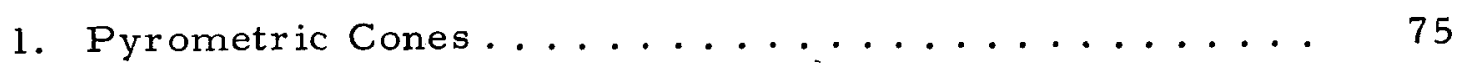

2. Tapes and Paints ................ 76 


\section{CONTENTS}

Page

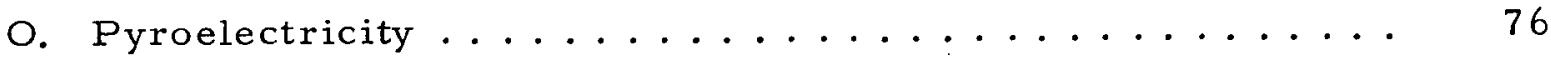

P. Microwave Resonant Cavities ............... 76

VI. Effects of Liquid Metal Reactor Environments on

Temperature Measurement Instruments . . . . . . . . . . . 79

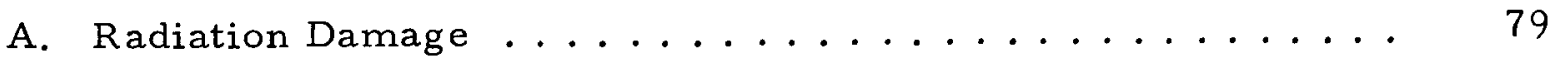

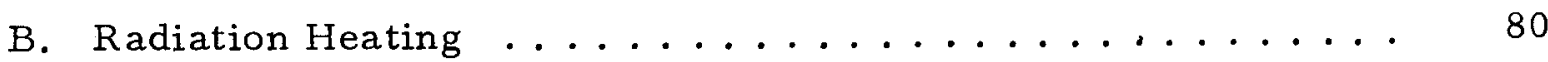

C. Differential Compton Circuits .............. 80

D. Ionization Chamber Effects ............... 80

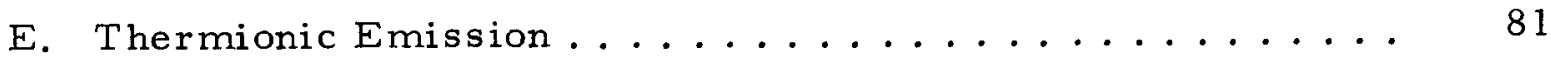

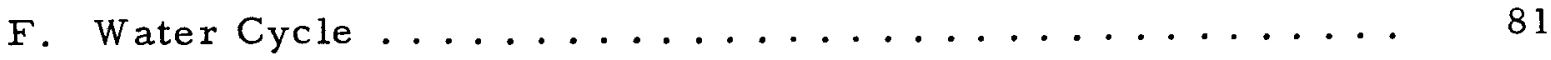

G. Electrostatic Effects ................... 81

H. Chemical Effects ................... 82

I. Vibration ..................... 82

VII. Literature Survey ....................... 83

A. Thermocouple Development for Project Rover, $2500^{\circ} \mathrm{C} \ldots . .83$

B. High Temperature Thermometry ............. 83

C. Fast Response Thermocouple................ 85

D. Fuel-Pin Temperature Measurement ........... 85

E. Thermocouple Stability and Reliability in Liquid Metal . . . . 85

F. Ther mocouple Development for a Lithium-Cooled Reactor. . $\quad 85$

G. The Effect of Pressure on Temperature Calibration ..... 85

H. Gradient Approach to Thermocouple Circuitry......... 86

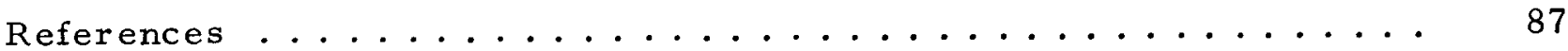

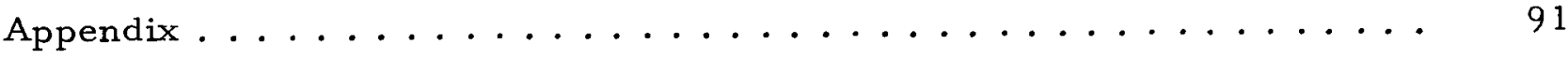

TABLE

1. Thermoelectric Series of Selected Metals and Alloys ......... 
Page

1. Relative Melting Points of Some Elements, Oxides, and

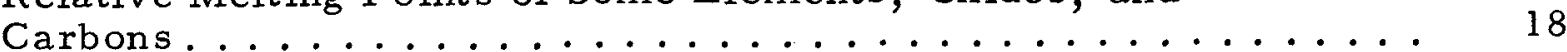

2. Melting Points of Metals, Alloys, and Ceramics .......... 19

3. Soldering, Brazing, and Welding Processes............ 20

4. Electrical Resistivity of Refractory Oxides . . . . . . . . . . 25

5. Electrical Resistance of Sintered Alumina . . . . . . . . . . 25

6. Accuracy of Realization of the Thermodynamic Temperature

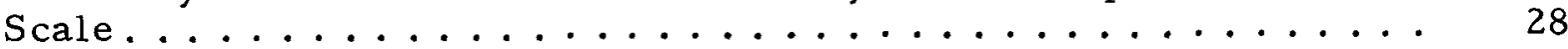

7. Calibration of Temperature-Measuring Instruments . . . . . . . 29

8. Precision and Accuracy of NBS Photometric Standards........ 31

9. Representative Ice-Bath Calibration Fixture. . . . . . . . . . 33

10. Cross-Section of Freezing Point Standard Cell (Aluminum) . . . . . 33

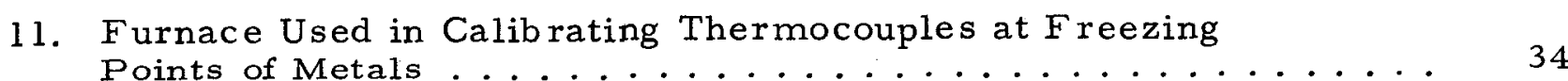

12. Schematic of Drift Test Facility .................. 35

13. Typical Ice Bath for Reference Junctions . . . . . . . . . . . . . 42

14. Differential Thermocouple $B A B$ and Meter M Measure the Temperature Difference $t_{3}-t_{1} \ldots \ldots \ldots . \ldots \ldots$

15. N Thermocouples in Series Acting as a Thermopile ......... 43

16. N Thermocouples in Parallel Providing a Measurement of the Temperature Mean Among $t_{1}, t_{2} \ldots t_{n} \ldots \ldots . \ldots . \ldots 4$

17. Single Thermocouple - Double-Bore Ceramic Insulators . . . . . 46

18. Single Thermocouple - Fish-Spine Ceramic Insulators . . . . . . 46

19. Double Thermocouple - Four-Hole Ceramic Insulators . . . . . . . 46

20. Exposed Loop Thermocouple .................... . 46

21. Gasket Thermocouple..................... 46

22. Mixture Thermocouple .................... 46

23. Shielded Thermocouple..................... 46

24. Sheathed Thermocouple ..................... . . 47

25. Thermo Electric Co., Inc., Patented Pipe Clamp Adapter . . . . . 47

26. Boron Graphite/Graphite Thermocouple, Coaxial Style. . . . . . 48

27. Resistance-Temperature Characteristics of Some Materials . . . . 53

28. Advanced Thermocouple Concepts ................ 54 


\begin{abstract}
A study of the available techniques and devices for making temperature measurements applicable to liquid metal (sodium) nuclear power reactors is presented. Included in this study is a review of the calibration and standards accuracies available, a study of the behavior of matter with temperature and with exposure to liquid metal reactor environments, and a literature survey as an aid to those who require details beyond the scope of this document. The Appendix carries a review of the fundamentals of temperature and temperature measurement theory plus a list of definitions.
\end{abstract}

LMEC -Memo-68-10 


\section{SUMMARY}

By far the majority of temperature measurements in liquid sodium reactors are made with thermocouples. At the extreme high end, e.g., 1000 to $5000^{\circ} \mathrm{F}$, tungsten/rhenium thermocouples provide the highest sensitivity with good sta bility. Combinations of W5Re/W26Re and W3Re/W25Re are preferable because of their better initial low temperature ductility than that of unalloyed tungsten. An advantage in using W5Re/W26Re is the availability of a ductile, compensated leadwire that matches the emf vs temperature characteristics from 32 to $1200^{\circ} \mathrm{F}$ within $\pm 0.11 \mathrm{mv}$.

The choice of electrical insulations narrows down to $\mathrm{BeO}$ and $\mathrm{ThO}_{2}$. $\mathrm{BeO}$ performs very well up to its melting temperature of about $4500^{\circ} \mathrm{F}$. $\mathrm{ThO}_{2}$ has a substantially higher melting temperature, $5972^{\circ} \mathrm{F}$; however, its electrical resistance decreases as the temperature approaches $4000^{\circ} \mathrm{F}$ and will result in an $8 \%$ reduction in emf at $5011^{\circ} \mathrm{F}$. The shunting effect of the decreased resis tance above $4200^{\circ} \mathrm{F}$ can be corrected for in the calibration of the thermocouple. Performance is reproducible and insensitive to thoria impurities and to immersion depth.

$\mathrm{W} 26 \mathrm{Re}$ is an alloy commercially available in the form of tubing used for sheathing. Tests indicate it is compatible with $\mathrm{PuO}_{2}-\mathrm{UO}_{2}$ fuel at temperatures up to $2700^{\circ} \mathrm{F}$ for times in excess of $500 \mathrm{hr}$. At temperatures in the vicinity of $5000^{\circ} \mathrm{F}$, however, the lifetime may be limited to several hours.

Chromel/Alumel thermocouples, insulated with $\mathrm{MgO}$ and sheathed with Inconel (0.012-in. -diameter wire, $0.062-\mathrm{in}$. OD $\times 0.009$-in. wall), a re used for measuring coolant temperatures. Such thermocouples will respond with a time constant of less than $0.1 \mathrm{sec}$.

The effect of neutron transmutation on tungsten/rhenium and Chromel/ Alumel the rmocouple signals is small but detectable.

Bare wire thermcouples (0.010-in. wires) will have response times of $100 \mathrm{~ms}$ or better. Sheathed thermocouples will have response times in the order of seconds, depending on size and construction. In measuring fuel, the response time is strongly influenced by the heat transfer coefficient between fuél and thermocouple, which may change substantially as the fuel cracks and 
sinters and forms central voids in-pile. Although smaller diameter thermocouple assemblies will exhibit faster response times, those with a larger diameter will give better life expectancy.

"Viewing" high temperature with optical measurement techniques has many advantages where the visibility makes this technique applicable. Optical pyrometers are, in fact, the standard for temperatures above $2000^{\circ} \mathrm{F}$. Infrared photography has provided large a rea and temperature gradient measurement at a glance in a single reading.

Platinum wire resistance thermometry provides the highest accuracy and repeatability up to about $1200^{\circ} \mathrm{F}$. The disadvantages are physical size and the fact that it is not a point sensor.

Other novel measuring techniques and devices have been explored, such as acoustic and microwave, to solve peculiar temperature measurement problems. Probably the most significant goal is arriving at a means for making reliable, long term (years) measurements with a device not subject to deterioration from the hostile attacks of the high temperature liquid sodium and its trace impurities. 


\section{INTRODUCTION}

In principle, nearly every property of a material which changes with temperature in a repeatable, well defined way can serve as a temperature measuring device. The variety of such devices are many. It is the purpose of this report to describe all the means that conceivably may be employed for temperature measurements in sodium reactor power generator systems or in liquid sodium test programs. In so doing, this document provides a full spectrum of temperature instrumentation, serving as a primer for those new to the field, and as a check list for those experienced in the field.

Furthermore, it is not the intention of this study to present a "cook book" of recipes for making temperature measurements but rathe $x$ to report developments in the state-of-the-art and the rationale behind the se developments. Bearing this thought in mind, it must be understood that making reliable temperature measurements for a long period of time in a hostile environment entails the integrated efforts of several disciplines, which encompass: the behavior of materials at temperature extremes; the effect of radiation on the instrumentation; techniques for calibration and standardization; the various temperature dependent physical phenomena; and such practical considerations as fabrication and installation. This report is divided into sections and subsections which treat each of these subjects separately.

Also, there has been much work done in recent years covering specific temperature measurement problems and their solutions. The details of these studies are too numerous to repeat here; therefore, a literature survey is included to direct the reader to further information of significant value. Finally, a list of references and an Appendix, which includes some generalized information, are added as a convenience to the reader.

\section{SOME PRECAUTIONARY NOTES}

Before selecting a method for making a temperature measurement some words of warning should be kept in mind. It is not enough to simply select and install the proper temperature measuring system (sensor, protective housing or sheath, read-out instrument, et al.) in order to determine the

LMEC-Memo-68-10 
temperature of a particular object or region. There are many ways that the true temperature of the object in question can deviate from the value indicated. Not the least of these is a consequence of the fact that no temperature measuring device can do more than relate the thermal state which it itself attains. In other words, the temperature differential between the sensitive portion of the transducer (e.g., the thermocouple junction) and the object must be minimized. It is not considered good practice, nor are the necessary data usually available, to correct the poor installation by the use of computed correction factors. Among the precautions to be observed, some of which are obvious, are those discussed in the following paragraphs.

When using thermometers (as opposed to pyrometers, see Definitions in the Appendix), provide good thermal contact between the thermometer and the medium being measured. (A colloidal suspension of silver and silicone grease has been used to improve thermal conductivity to the temperature sensor.) However, do not let the the rmometer perturb the conditions of the medium. A heavy-gage thermocouple wire or its thick-walled protection tube may conduct heat into or out of a small specimen. For example, in EBR-I (Mark III and IV) it was necessary to add a correction factor of $+40^{\circ} \mathrm{C}$ in measuring small diameter fuel slug temperatures at the center of the reactor at full power.

If the temperature being measured can vary rapidly, be sure that the response time of the thermometric device will allow it to follow the fluctuations.

A thermocouple that has given service over a period of time may appear to be in good condition, but the alloy of one leg may have diffused into the other leg. This would change the couple material composition, hence its calibration.

The effectiveness of the electrical insulation, afforded the wire of a thermocouple by its protection tube, is a strong function of the temperature and the tube material. It is rather surprising how rapidly some insulators degrade above temperatures of $1000^{\circ} \mathrm{C}$. This is an important factor to be considered in this temperature region.

While the effect of leadwire resistance in thermocouples is generally appreciated, the somewhat inverse effect of stray thermal emf's in resistance thermometers is sometimes overlooked. The flow of current through the resistance thermometer, an absolute requirement for its operation, must be

LMEC -Memo-68- 10 
minimized to avoid self-heating. This type of error can become appreciable if the thermometer is immersed in a medium where heat transfer is poor. An actual test using different currents is the simplest way to determine the extent of error, if any.

A problem sometimes overlooked with stainless steel sheathed thermocouples involves running calibration tests at temperatures above $1000^{\circ} \mathrm{F}$. At temperatures of 1000 to $1200^{\circ} \mathrm{F}$ the steel becomes permanently sensitized to stres s corrosion by halogens. After the test, chlorine and other halogens present in the air may start corrosion of the thermocouple, which will significantly affect its life in service.

As a postscript to the foregoing, it should be realized that, numerous as are the methods of thermometry, there are almost as many criteria to be applied in selecting one of these methods for a particular application. One may have to consider accuracy, stability, sensitivity, reproducibility, speed of response, reliability, life, linea rity of output, temperature range of useability, ease of reading, simplicity, safety, size and weight, adaptability to automatic recording and/or control, first cost and maintenance cost, etc. Perhaps in no other branch of measurement technology is it so important to "let the user beware". 
-

- 


\section{BEHAVIOR OF MATERIALS WITH TEMPERATURE}

A. GENERAL

It is commonly understood that as temperature rises materials melt, or lose so much strength that their structural value diminishes. However, these are not the only phenomena which affect the utility of materials. At high temperatures the cohesive forces which hold materials together weaken and mechanical as well as chemical and electrical stabilities a re decreased.

The examination of three typical materials, tungsten, silicon carbide and magnesium oxide, will serve to illustrate the mechanisms that can be expected at elevated temperatures.

In silicon carbide, a typical covalent "giant molecule," the cohesive forces are very strong at ordinary temperatures. At $300^{\circ} \mathrm{K}$ the probability is only $10^{-72}$ that a molecule will have enough energy to break one of its four electronpair bonds between atoms. At $3000^{\circ} \mathrm{K}$ this probability increases to the order of $10^{-7}$. At about $2100^{\circ} \mathrm{C} \mathrm{SiC} \mathrm{begins} \mathrm{to} \mathrm{undergo} \mathrm{a} \mathrm{phase} \mathrm{transition} \mathrm{from} \mathrm{the}$ cubic beta to the hexagonal alpha form. At $2400^{\circ} \mathrm{C}\left(4350^{\circ} \mathrm{F}\right)$ it decomposes. Similarly, the very hard diamond form of carbon undergoes a phase transition to graphite at 1600 to $1900^{\circ} \mathrm{C}$. The increased energy of the molecules makes it relatively easy to have enough energy concentrated in one band to break it; therefore, structures which are stable at lower temperatures do not endure at these higher temperatures.

Magnesium oxide is an ionic crystal, and electrostatic forces hold it together. As a result of thermal expansion, the average distance between ions grows and the cohesive forces become weaker. More important, the disruptive forces due to thermal motion and vibration of the ions increase greatly. Crystals rearrange into more stable and less deformed states (sintering). Free electrons and holes become more common, and the electrical resistivity drops continuously with rising temperature. Deformation of the crystals becomes easier and almost all the mechanical strength is lost. Thermal conductivity remains low, so that the thermal shock properties of the material are poor. Eventually (at $2200^{\circ} \mathrm{C}$ ) the vapor pressure becomes appreciable; since the vapor is composed of $\mathrm{MgO}$ molecules, this indicates a breakdown of the ionic crystal structure. The melting point is $2620^{\circ} \mathrm{C}\left(4750^{\circ} \mathrm{F}\right)$.

LMEC -Memo-68-10 
The mechanical phenomena in tungsten are more complex than in magnesium oxide, but the basic principle here too is the rearrangement of molecules to more stable forms. Powder metallurgy techniques rely on crystal growth, occurring well below the melting point, for the transformation of tungsten powder to bar tungsten. Actual tungsten materials, such as bars and wires, have been swaged and drawn after annealing, and the crystals have been broken up. Hence, exposure of tungsten wire, for example, to temperatures of the order of $2500^{\circ} \mathrm{C}$, causes extensive recrystallization. Grain boundaries, which were previously aligned parallel with the axis of the wire as a result of the drawing operation, now can be found running in a transverse direction; the strength of the wire (so exceptional before heating) is greatly reduced. After cooling, the frozen-in grain boundaries cause great brittleness. Non-sag wires have been perfected, in which an additive retards or directs the grain growth. In addition to mechanical transformation, the chemical reactivity of tungsten is greatly increased at high temperatures. Reaction with oxygen is instantaneous and violent. Tungsten will also react with carbon at temperatures more than $1000^{\circ} \mathrm{C}$ below its melting point. It is unstable in the presence of water vapor, molten oxidizing salts and other oxidizing media.

From this preliminary survey it is seen that all specifications must be greatly relaxed at high temperatures. In building temperature measuring devices designed to operate inside a nuclear reactor, extreme values of tensile strength, electrical resistivity, chemical inertness, etc., are not to be expected.

Since it is not the purpose of this study to repeat in detail material which is adequately covered in other documentation, the reader is directed to Vol. III of Reference 1 for further information on the mechanical, thermal, electrical and chemical properties of materials at high temperature. However, some of the more salient generalizations are included in the following text.

\section{B. ALLOYS}

Alloys of metals typically have melting temperatures somewhat below those of each of the element metals alone. The eutectic of an alloy is the point of maximum fusibility, or the combination ratio of the element metals which forms the lowest melting point alloy. 


\section{MECHANICAL PROPER TIES}

Perhaps the most striking of mechanical properties is creep: the change of dimensions under stress due to recrystallization and annealing phenomena. Creep is relatively low for tungsten. Molybdenum shows creep rates up to $1 \% / \mathrm{hr}$ under 12,500 psi at $2,000^{\circ} \mathrm{F}$.

Zirconia becomes plastic above $1300^{\circ} \mathrm{C}$. Many materials which have been subjected to high temperatures are brittle at room temperature.

\section{THERMAL PROPERTIES}

The thermal conductivity of metals does not change appreciably with temperature. The thermal conductivity of oxides generally decreases with elevated temperatures; $\mathrm{MgO}$ and $\mathrm{Al}_{2} \mathrm{O}_{3}$ decrease about an order of magnitude from 0 to $1500^{\circ} \mathrm{C} . \mathrm{ZrO}_{2}$ (stabilized) however, increases its thermal conductivity slightly with temperature. Figures 1,2, and 3 provide a handy reference of some of the thermal properties of some commonly used materials.

\section{E. CHEMICAL PROPERTIES}

Since the more complicated molecules dissociate at comparatively low temperatures, only the relatively simple compounds survive at very high temperatures. The chemical reactions which need to be taken into consideration are also few; essentially these are combinations of the elements with oxygen, nitrogen, hydrogen, and carbon. The converse reactions of dissociation of oxides, nitrides, hydrides, and carbides are also of concern, as are the solution process of one metal into another and the formation of a eutectic.

\section{Oxygen}

Carbon, molybdenum, tungsten, tantalum, rhenium, and all carbides and nitrides will react with oxygen at elevated temperature. The rate of oxidation depends on the nature of the oxide. If the oxide forms a coherent layer over the surface of the material, the rate-determining step is diffusion of oxygen through the oxide layer, and the amount of oxide formed will be proportional to the square root of the time. If the oxide is volatile $\left(\mathrm{MoO}_{3}, \mathrm{WO}_{3}\right)$ or forms a discontinuous layer (e.g., if its volume is smaller than that of the unoxidized material from which it is formed), the oxygen always has access to the metal surface and the amount of oxide formed is proportional to the time.

\section{LMEC-Memo-68-10}




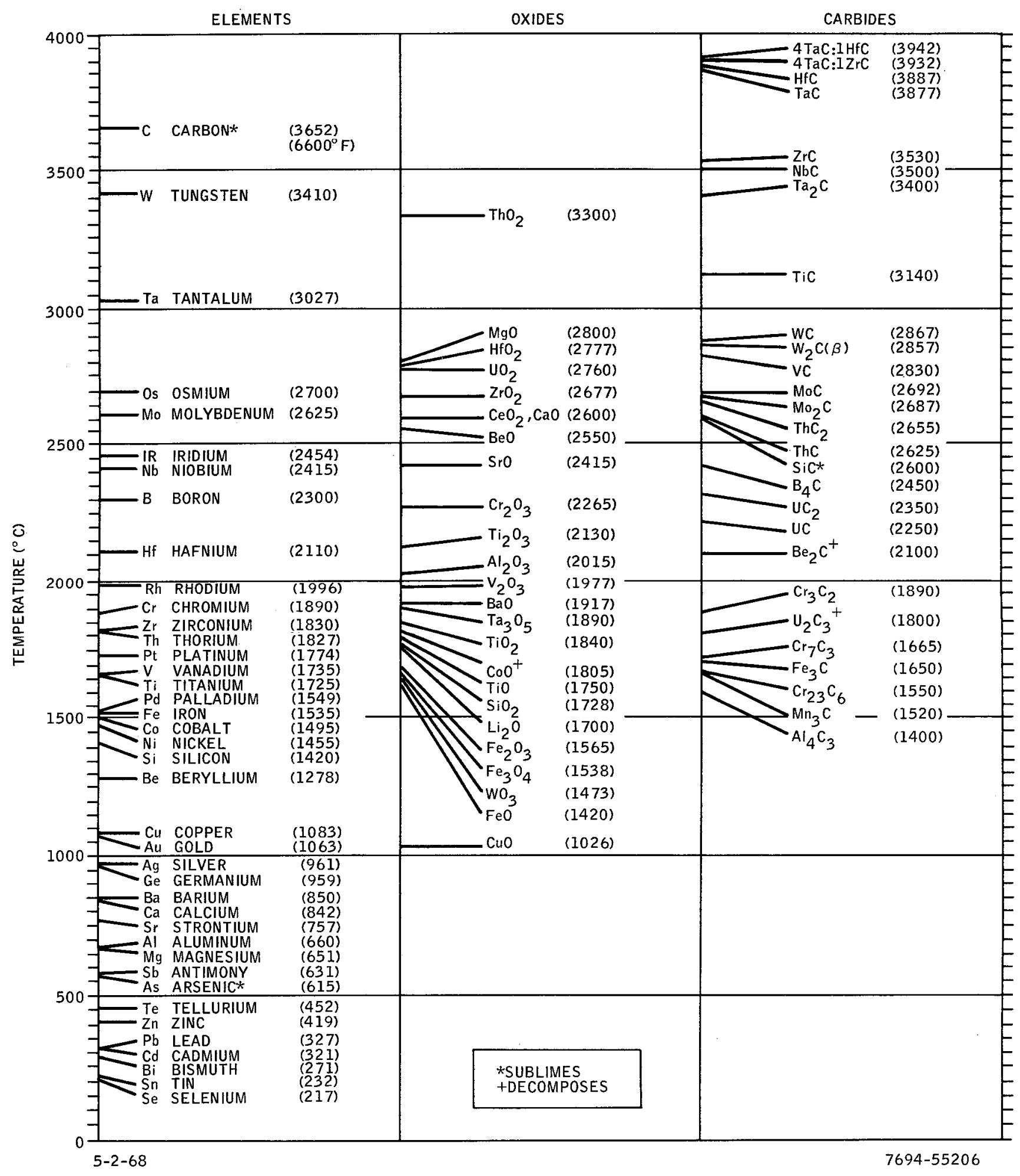

Figure 1. Relative Melting Points of Some Elements, Oxides, and Carbons

LMEC-Memo-68-10 


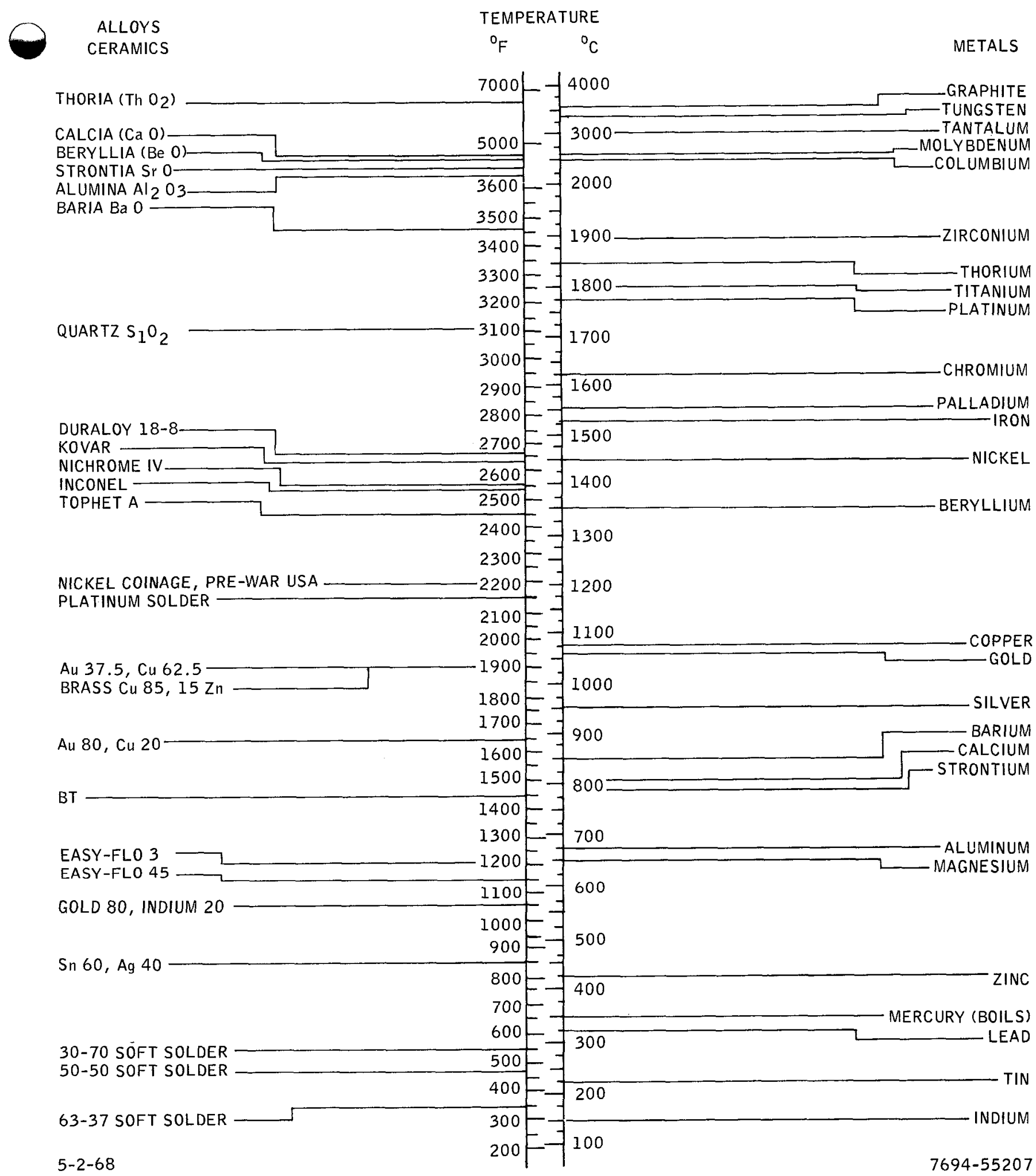

Figure 2. Melting Points of Metals, Alloys, and Ceramics

\section{LMEC-Memo-68-10}




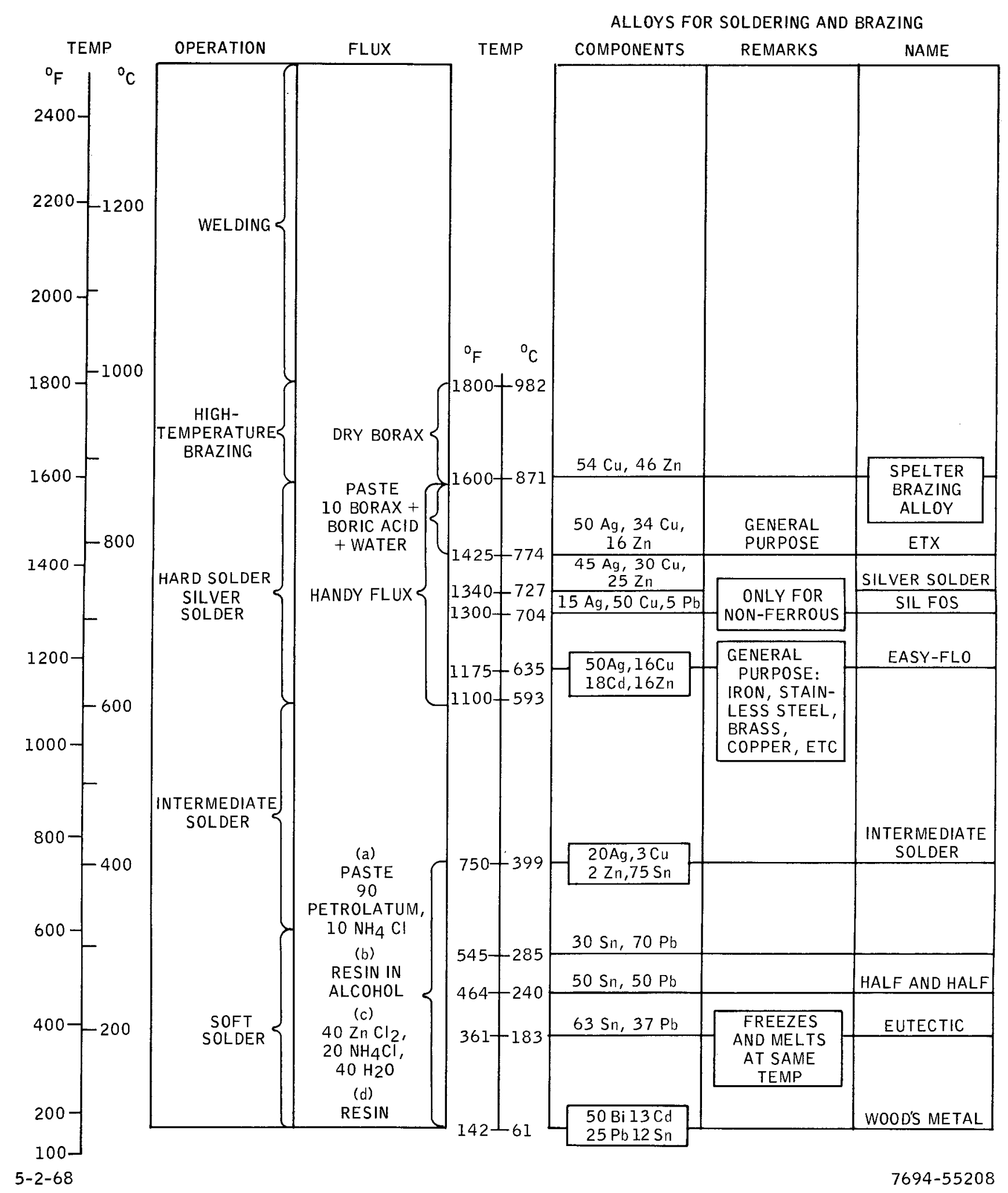

Figure 3. Soldering, Brazing, and Welding Processes

LMEC-Memo-68-10 
There is also a volume - diffusion mechanism which leads to formation of metallic interstitial suboxides such as $\mathrm{Mo}_{3} \mathrm{O}$.

\section{Nitrogen}

The formation of nitrides is due to the solid solution of nitrogen atoms. Two processes are therefore necessary: the catalyzed dissociation of nitrogen at the surface,

$$
1 / 2 \mathrm{~N}_{2}=\mathrm{N}
$$

and the diffusion of atoms from one interstitial position to another, deeper one. The former may be expected to go to an equilibrium, so that the concentration of nitrogen atoms is expected to be proportional to the square root of the partial pressure of nitrogen. The rate of the latter process is governed by an activation energy. At $2500^{\circ} \mathrm{K}$, the activation energy factors $e^{-\mathrm{E} / \mathrm{RT}}$ vary from $1.2 \times 10^{-4}$ for beta titanium to $1.1 \times 10^{-2}$ for thorium. Allowing for $10^{10}-10^{13}$ effective vibrations per second, it can be seen that the transport rate of $\mathrm{N}$ atoms will be rapid and will approach a straight diffusion process.

The nitrides of $\mathrm{Ti}, \mathrm{Zr}, \mathrm{Hf}, \mathrm{Th}, \mathrm{V}, \mathrm{Nb}$, and $\mathrm{Ta}$ are stable up to high temperatures. The nitrides of molybdenum and tungsten, on the other hand, do not appear to be stable at high temperatures.

\section{Hydrogen}

The activation energies for the diffusion of hydrogen through transition group metals are very low. Hydride formation should therefore occur easily at higher temperatures. Hydrides are very brittle and can be pulverized easily.

Metal oxides are hydrogen sensitive, and rough calculations indicate that $\mathrm{MgO}$ and $\mathrm{BeO}$ will have very appreciable dissociation pressures of metal vapor and $\mathrm{H}_{2} \mathrm{O}$ gas in the presence of 1 to 20 atm of hydrogen at 2000 to $2500^{\circ} \mathrm{K}$.

\section{Carbon}

Rates of carburization are not known. It is stated, however, that carburization of $\mathrm{Mo}$ and $\mathrm{W}$ is slow in the solid phase at temperatures under $2700^{\circ} \mathrm{C}$. Tantalum can be carburized in relatively thin layers. Most metals form single eutectics with their carbides. 
Obviously, the preceding information is only a very brief introduction to the chemistry of materials at high temperatures, with special attention to properties of solids, and those reactions which might lead to failure of structural elements of a temperature probe.

\section{F. ELECTRICAL PROPERTIES}

\section{Conductivity (Resistivity)}

A short way to describe the dependence of conductivity on temperature is as follows: for metallic substances, the conductivity drops with temperature, but not by many orders of magnitude; for semi-conductors and insulators, the conductivity rises much faster, and eventually all insulating properties break down.

The rising resistance in metals is due to increased interaction of electrons with the lattice of positive ions, as the latter is increasingly disturbed by thermal motion. The mean free path of the electron drops, and so does its mobility.

In non-metals, there are only a very few electrons in the conduction bands. Promotion of electrons to these bands requires an activation energy. Therefore, the entry of electrons into these bands requires an activation energy $E$, and the expression for the number of conduction electrons includes a term $\mathrm{e}^{-\mathrm{E} / \mathrm{RT}}$. Thus, when the temperature rises, the number of conduction electrons increases rapidly, and in some temperature range there will be a rather sharp drop in the resistance. When $\mathrm{E}$ is relatively low ( $\left.\mathrm{SiC}, \mathrm{ZrO}_{2}\right)$, the drop will come in the moderate temperature range. Such substances can be used as resistors in electric furnaces if preheated to a temperature at which they are no longer good insulators. Other materials ( $\mathrm{MgO}$ ) have high $\mathrm{E}$ and do not break down completely even at much higher temperatures.

Because of chemical and other surfaces processes, much of the increased conductivity of substances like $\mathrm{MgO}$ at high temperatures is surface conductivity. Therefore, conductivity tends to increase with increasing porosity.

Impurities can also greatly increase conductivity. There are at least two mechanisms for this. First, impurity atoms may furnish excess electrons to the conducting bands. In this way, very small amounts of impurities may greatly lower the resistance. Second, small amounts of impurities may for $\mathrm{m}$ 
a surface electrolytic zone if they react chemically with the substrate. This effect can be seen if an acid oxide, such as $\mathrm{SiO}_{2}$, is added to a basic oxide, such as $\mathrm{MgO}$.

Since many high temperature materials contain impurities, sometimes added deliberately to improve mechanical properties, reported conductivities (or resistivities) vary greatly. For metals, some values are:

\begin{tabular}{|c|c|c|}
\hline & $\left({ }^{\circ} \mathrm{C}\right)$ & $(\mu-\mathrm{ohm}-\mathrm{cm})$ \\
\hline \multirow[t]{4}{*}{ Tungsten } & 20 & 5.5 \\
\hline & 1200 & 40 \\
\hline & 2400 & 85 \\
\hline & 3240 & 118 \\
\hline \multirow[t]{4}{*}{ Molybdenum } & 20 & 5.1 \\
\hline & 1200 & 33 \\
\hline & 2000 & 60 \\
\hline & 2620 & 81 \\
\hline \multirow[t]{3}{*}{ Tantalum } & 20 & 15 \\
\hline & 1130 & 61 \\
\hline & 1730 & 80 \\
\hline \multirow[t]{2}{*}{$\underline{\text { Platinum }}$} & 0 & 11 \\
\hline & 1600 & 63 \\
\hline \multirow[t]{2}{*}{ TiN } & 20 & 21.7 \\
\hline & 2950 & 340 \\
\hline \multirow[t]{2}{*}{$\underline{\mathrm{ZrN}}$} & 20 & 13.6 \\
\hline & 2980 & 160 \\
\hline \multirow[t]{3}{*}{$\mathrm{Ta}_{2} \mathrm{~N}$} & 20 & 135 \\
\hline & 1480 & 104 \\
\hline & 2840 & 116 \\
\hline \multirow[t]{2}{*}{$\mathrm{w}_{2} \mathrm{C}$} & 20 & 80 \\
\hline & 2000 & 125 \\
\hline
\end{tabular}

LMEC-Me mo-68-10 
A general rule of thumb is that electrical resistivities of metallic substances tend to approach values around $200 \times 10^{-6} \mathrm{ohm}-\mathrm{cm}$ at high temperatures.

The resistivities of oxides are shown as a function of temperature in Figure 4. Figure 5 shows the effect of sintering on high temperature resistance of alumina. High-sintered materials, with less surface area, are seen to have better insulating properties. Note the inconsistencies in Figure 4, probably due to varying amounts of impurities as well as different histories of the material samples. Note also that in Figure $5 \log \mathrm{R}$ is linear with $1 / \mathrm{T}$, in line with the activation energy concept.

\section{Thermionic Emission}

Thermionic emission is another electrical property which must be given attention at high temperatures. The thermionic emission of carbides is less than that of the element metal. Some representative examples are tabulated as follows:

\begin{tabular}{lcc}
\multicolumn{1}{c}{ Material } & $\begin{array}{c}\text { Temperature } \\
\left({ }^{\circ} \mathrm{K}\right)\end{array}$ & $\begin{array}{c}\text { Current } \\
\left(\mathrm{ma} / \mathrm{cm}^{2}\right)\end{array}$ \\
\cline { 2 - 3 } Tungsten & 1800 & 0.045 \\
Tungsten & 2200 & 13.3 \\
Tungsten & 2600 & 716.0 \\
Tungsten & 3000 & $14,200.0$ \\
Tungsten & 3200 & $47,800.0$ \\
Tantalum & 2000 & 19.5 \\
TaC & 2000 & 0.32 \\
Molybdenum & 1900 & 1.0 \\
ThO $_{2}$ & 2000 & 11.0 \\
ThC $_{2}$ & 2000 & 4.0 \\
& &
\end{tabular}




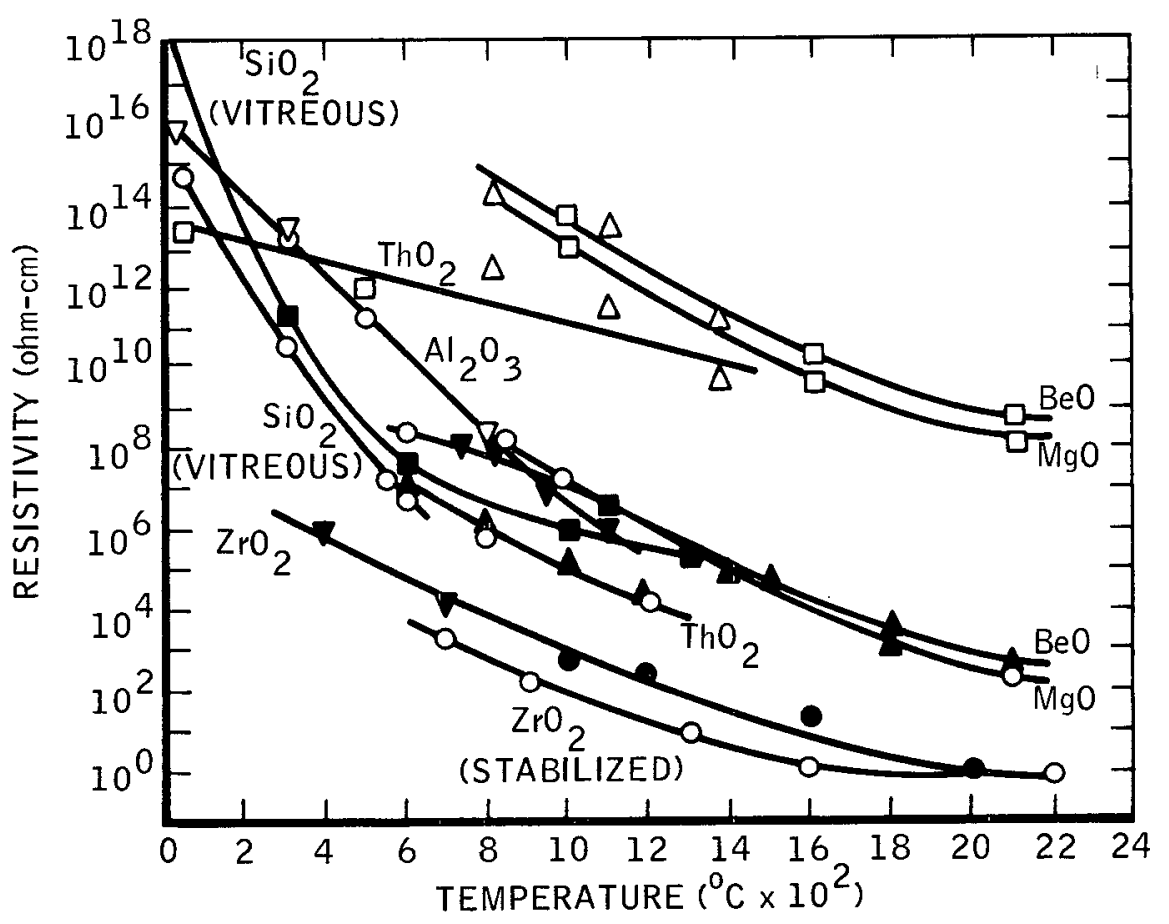

$5-2-68$

7694-55209

Figure 4. Electrical Resistivity of Refractory Oxides

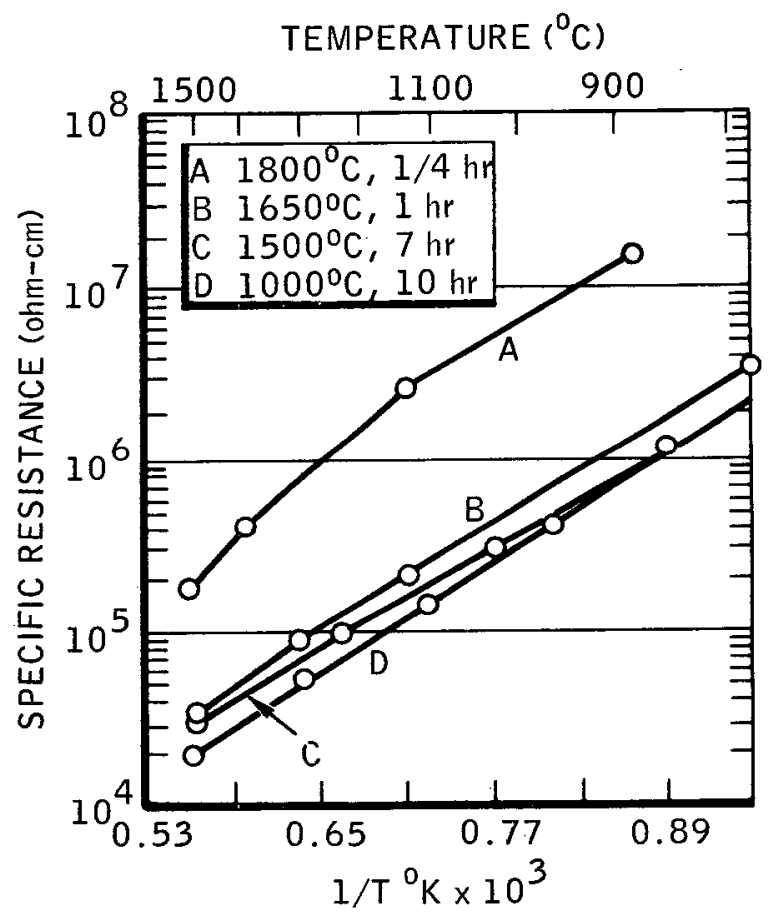

$5-2-68$

7694-55210

Figure 5. Electrical Resistance of Sintered Alumina

LMEC-Memo-68-10 
$\bullet$

$\theta$
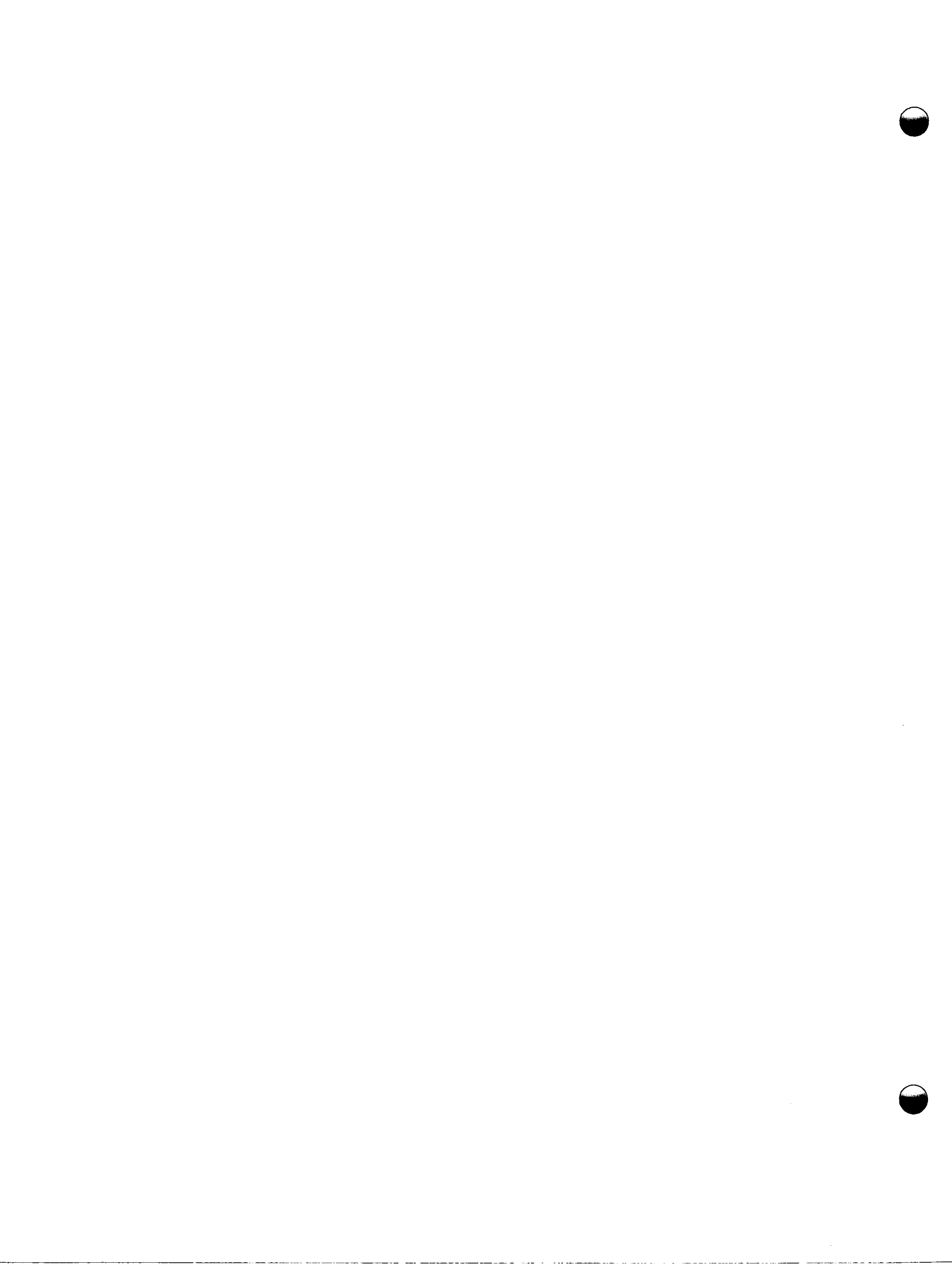


\section{REFERENCE STANDARDS AND CALIBRATION}

A. NATIONAL BUREAU OF STANDARDS (NBS) ACCURACY OF REALIZATION OF THE THERMODYNAMIC TEMPERATURE SCALE

While the Thermodynamic Kelvin Scale (TKS) is completely defined by assigning a value to the triple-point of water, this does not by itself enable one to realize the Scale at any other temperature. Using thermodynamic relations, however, the Scale is realized in different temperature ranges using the best available technique in each range. The Scale is put to practical use by determining the Kelvin temperatures of appropriate fixed points (freezing points, boiling points, etc.). Determinations are also made, between the fixed points, of the deviations from the TKS resulting from the properties of the practical instruments used for interpolation between fixed points. The temperature scale covered by Figure 6 , is divided into six ranges according to the techniques used for determining the rmodynamic temperatures.

\section{B. PRACTICAL TEMPERATURE SCA LES EMP LOYED BY NBS FOR THE CALIBRATION OF TEMPERATURE-MEASURING INSTR UMENTS}

At NBS the International Practical Temperature Scale (IPTS) is realized to serve as a common basis for defining temperatures in the United States. Below the lower limit of temperatures defined by the IPTS at $90^{\circ} \mathrm{K}\left(-183^{\circ} \mathrm{C}\right)$, a second scale, known as the NBS Provisional Scale of 1955 (NBS 1955 Scale), has been devised for use down to about $12^{\circ} \mathrm{K}$. In the range 2.0 to $5.22^{\circ} \mathrm{K}$ a third scale, known as the $\mathrm{T}_{58}$ Scale (helium 4 vapor pressure), is also maintained. Recently the gap between 5 and $12^{\circ} \mathrm{K}$ has been bridged by a scale based upon work with the newly developed NBS acoustic thermometer. Calibration services, provided for government agencies and private organizations and individuals, are based upon these scales.

The solid curves in the chart of Figure 7 represent the accuracy with which the three scales are realized, using the specified instruments of interpolation between the defining temperatures of the scales. The dashed lines shown as signed limits of error for widely used calibration services. These limits of error are largely judgment-type limits based upon estimated magnitudes of the known sources of error. In nearly all cases there are insufficient data of a 


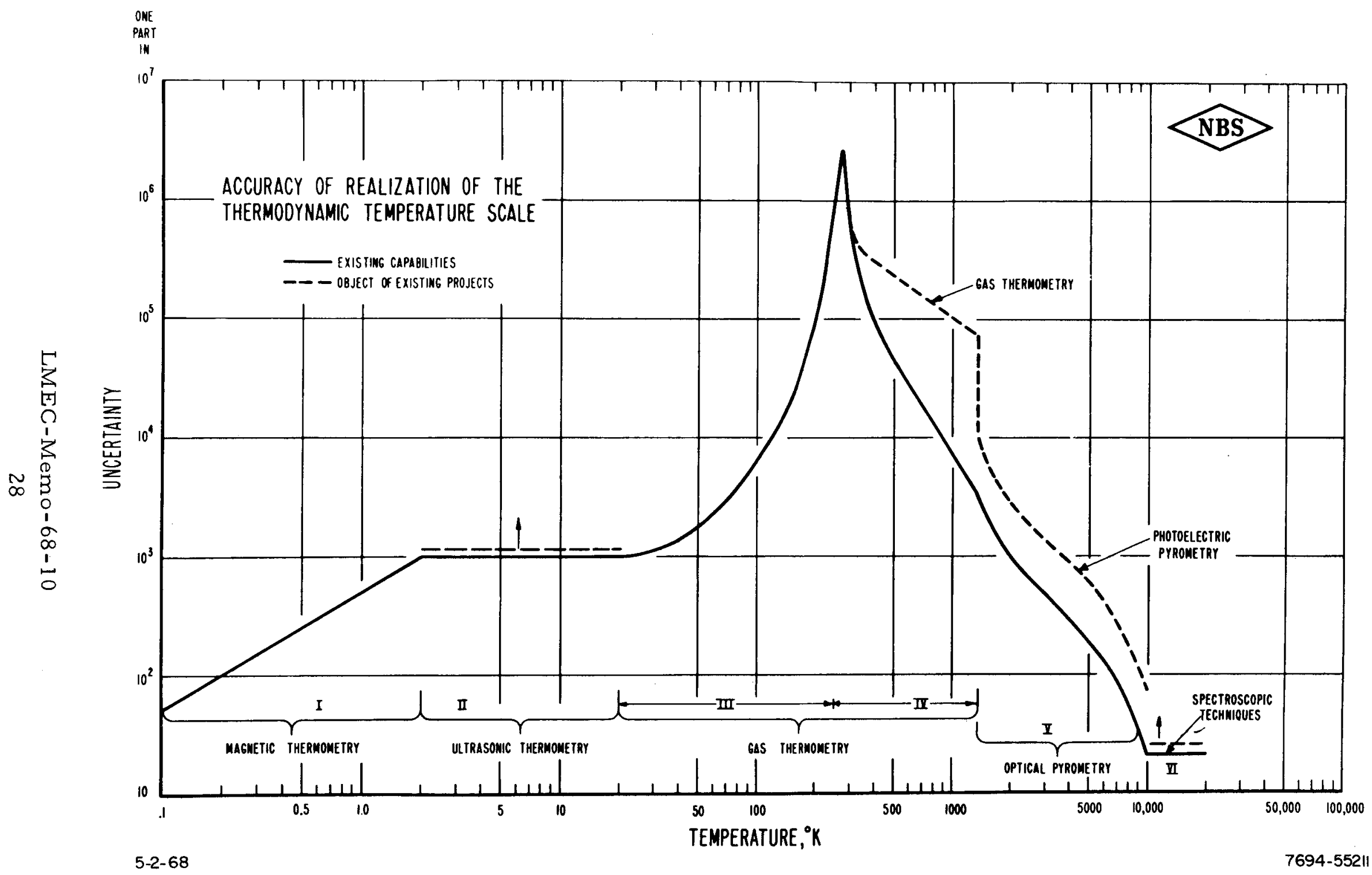

Figure 6. Accuracy of Realization of the Thermodynamic Temperature Scale 


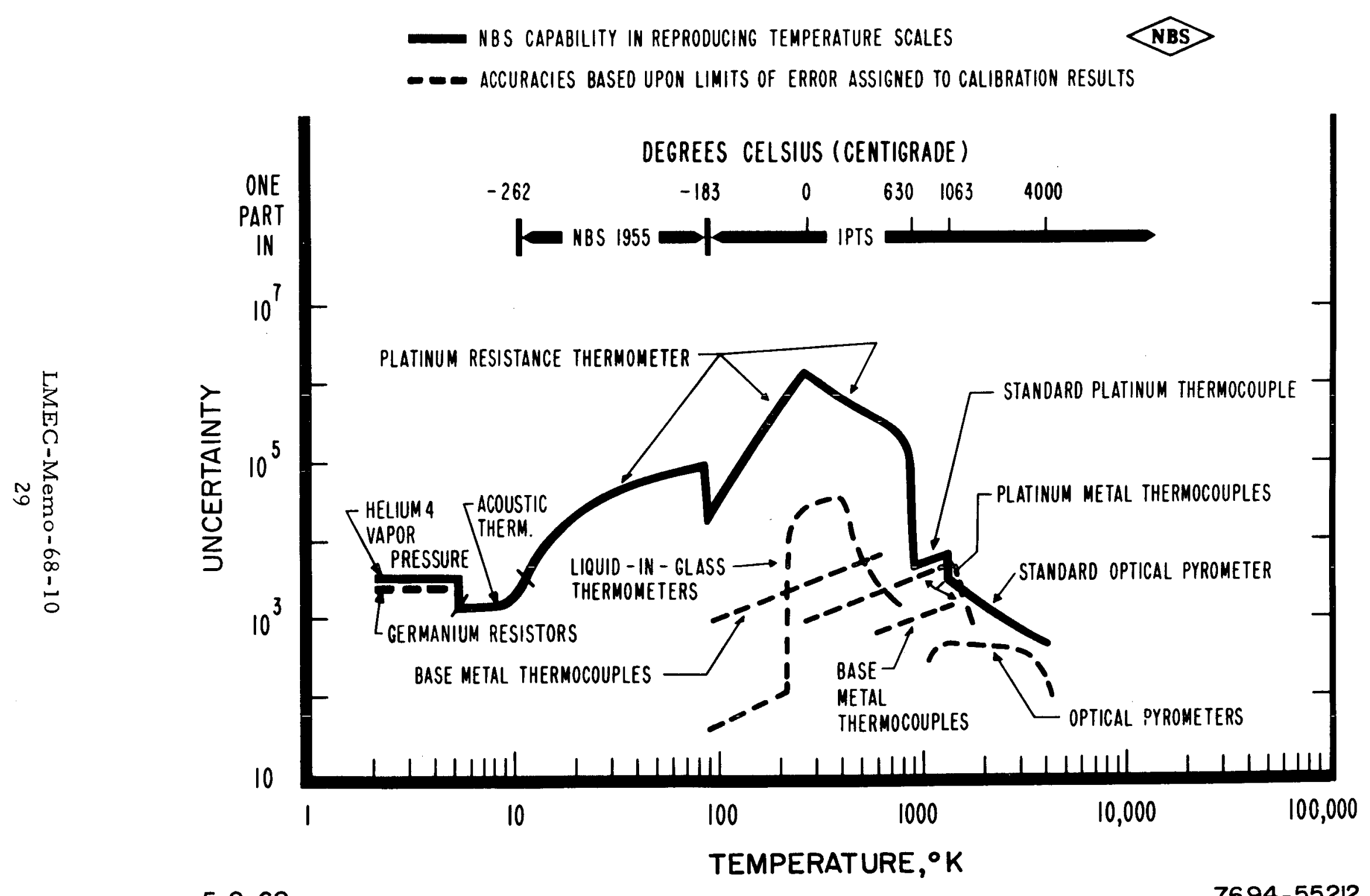

$5-2-68$

Figure 7. Calibration of Temperature-Measuring Instruments 
kind which will permit statistical analys is of the contribution of a particular potential source of error.

In several temperature ranges, work is currently in progress whose purpose is the improvement and extension of calibration services for temperaturemeasuring instruments. At $-183^{\circ} \mathrm{C}\left(90^{\circ} \mathrm{K}\right)$, the temperature of the oxygen point, apparatus is being developed which will materially improve the accuracy with which this point on the IPTS is realized. For use at high temperatures, a photoelectric pyrometer has been developed which will improve the NBS realization of the IPTS above $1063^{\circ} \mathrm{C}\left(1945^{\circ} \mathrm{F}\right.$ ) (gold point). This instruments permits the more accurate calibration of commercial photoelectric pyrometers which are now becoming available. In addition, the development of standards and facilities for the calibration of high-temperature thermocouples is at an advanced stage.

\section{NBS PHOTOMETRIC STANDARDS}

The current system of photometric units and standards is based on the luminance (candela $/ \mathrm{cm}^{2}$ ) of a blackbody at the temperature of freezing platinum $\left(2042^{\circ} \mathrm{K}\right)$, which is reproducible to within about $0.5 \%$. The candela is defined as the luminous intensity of $1 / 60^{\text {th }}$ of $1 \mathrm{~cm}^{2}$ of projected area of such a radiator. The luminous flux of other standard sources (rate of energy radiation in lumens) is the integral of the product of monochromatic luminance times its relative luminous efficiency, taken over all wavelengths of visible spectrum, and conventionally refer red to the equivalent color temperature of a fictitious blackbody. The uncertainty of luminous intensity of a standard source (flux reaching unit area of a unit sphere) is also plotted against color temperature, since that is a more important influence than the variation of intensity with the inverse square of distance. Fluorescent lamp standards, which have mercury lines superimposed on a continuum, are so different in spectral distribution from thermal radiators relative to which they are calibrated that their photometric assignments are uncertain by about $2 \%$, with the uncertainty in the photometric assignments of incandescent lamp standards between these two values of uncertainty. Figure 8 is a graphic illustration of these uncertainties.

Together with other national standardizing laboratories, NBS is investigating the feasibility of placing the system of photometric units and standards on a radiometric base in which radiant flux of a given wavelength in the visible

\section{LMEC-Memo-68-10}




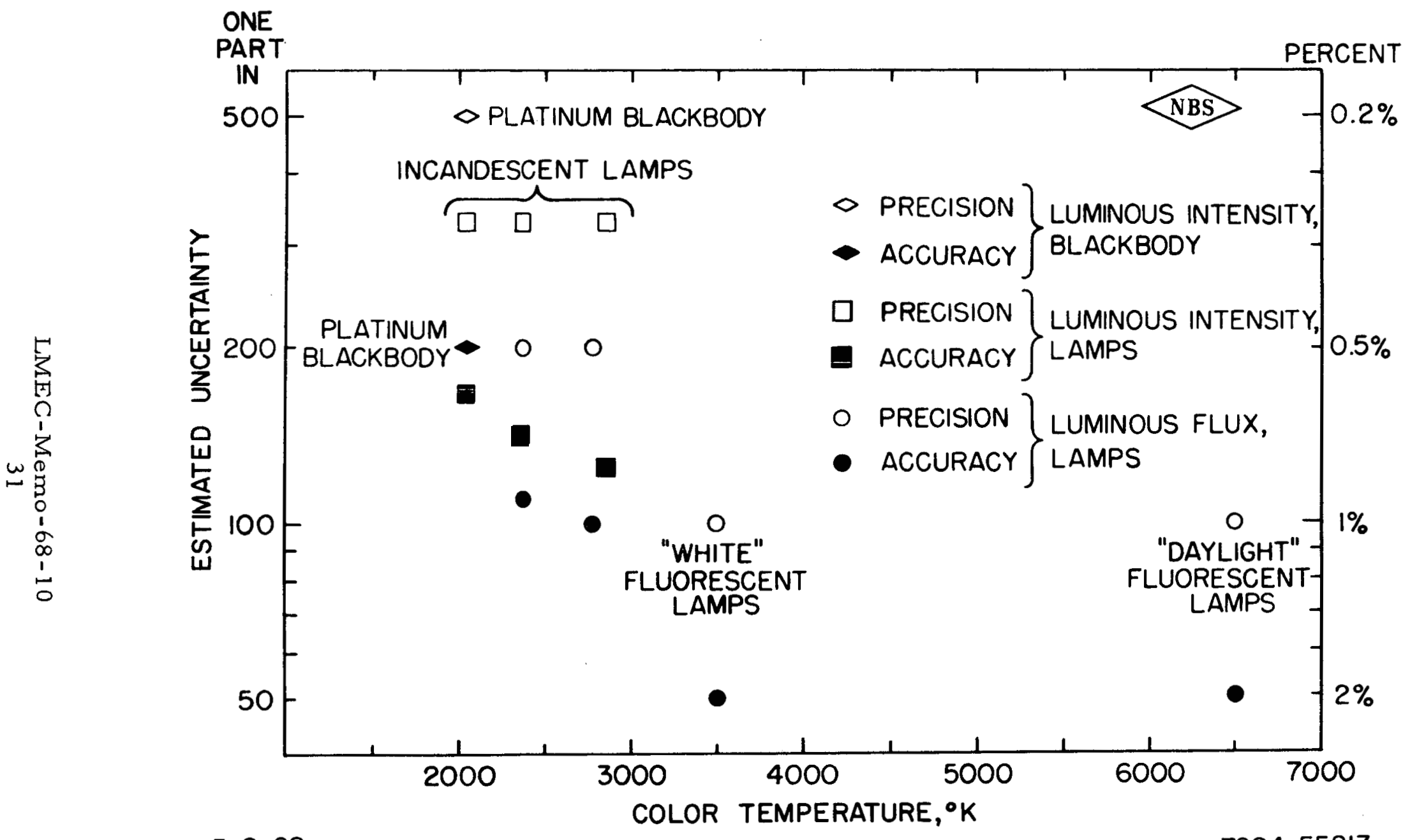

$5-2-68$

$7694-55213$

Figure 8. Precision and Accuracy of NBS Photometric Standards 
region of the spectrum would be assigned a value of luminous efficacy (for example, $680 \mathrm{lu} / \mathrm{w}$ at 555 nanometers). The goal is to attain a reproducibility better than about 0.25 . In addition, NBS is investigating a radiometric procedure for assigning photometric values to fluorescent lamps which, it is hoped, will reduce the uncertainty of these values to less than $1 \%$.

\section{CALIBRATION OF TEMPERATURE-MEASUREMENT INSTRUMENTS}

Calibration is defined as the process of transferring information by comparison; the more direct the comparison, the more reliable the calibration. In calibrating temperature measurement devices the basic question to be asked is: when a given environment is at a certain thermodynamic state (the state defined by the PV = RT relationship) what does the test thermometric device indicate?

The most accepted method currently employed for calibrating thermometric devices is to use a constant temperature bath (e.g., oil bath, ice bath, salt bath) to provide the calibration environment. The calibrating bath should be one of high thermal inertia (high heat content) so that minor exte mal perturbations will not significantly affect the calibrating environment, and so that the heat loss can be controlled to a high degree of precision. A representative ice-bath calibration fixture is illustrated in Figure 9.

The calibration temperatures (see Figure 1) are obtained by employing a calib ration point cell, such as a triple point (water) cell or an aluminum cell (see Figure 10), in a temperature bath. The primary standards and devices to be calibrated are placed in the cell in such a manner as to ensure an isother mal condition within the cell. For temperatures at the melting points of metals, for instance, the temperature of the bath is raised a few degrees above the calibration point and held there until all the metal in the cell is melted. The bath is then allowed to cool slowly. An isothermal condition will be obtained when the system arrives at the melting point temperature of the metal at which time the heat loss from the bath will be supplied by the heat of fusion of the metal. At this point the devices being calibrated will indicate a constant reading even though heat is still being removed from the system. Figure 11 illustrates a type of furnace used in metal freeze point calibration.

LMEC-Memo-68-10 


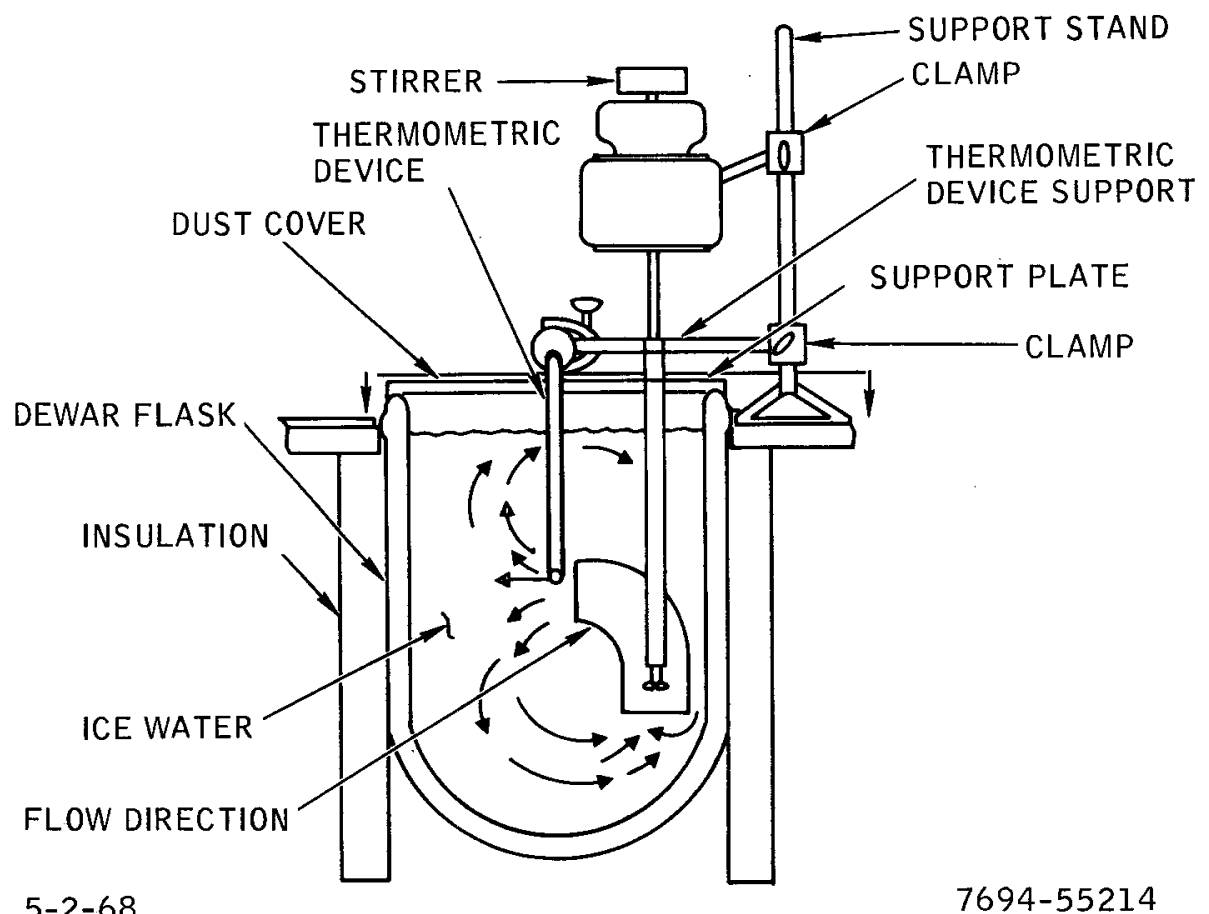

Figure 9. Representative Ice-Bath Calibration Fixture

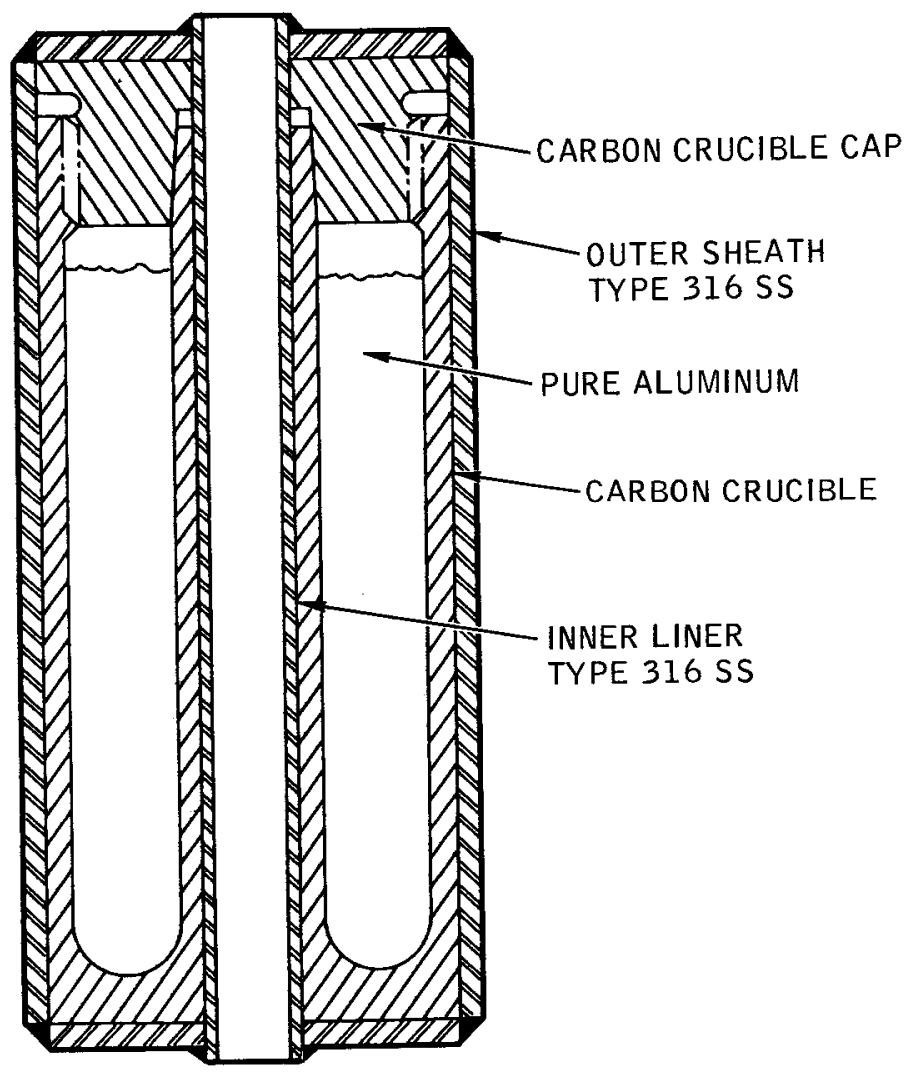

5-2-68

$7694-55215$

Figure 10. Cross-Section of Freezing Point Standard Cell (Aluminum)

LMEC-Memo-68-10 


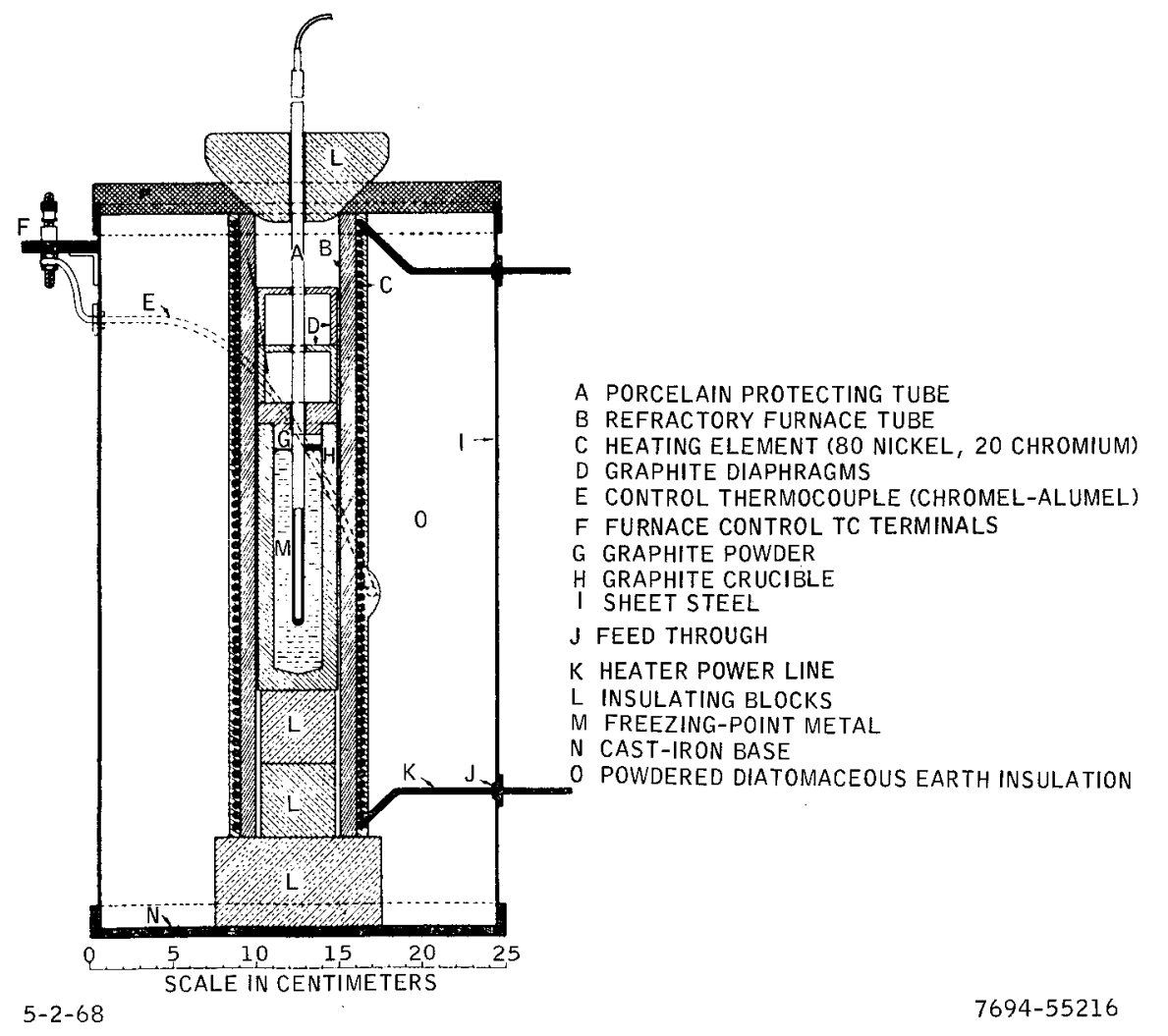
Figure 11. Furnace Used in Calibrating Thermocouples at Freezing Points of
Metals

By recording the readings of the devices being calibrated at a number of check points over the range of interest, a calibration curve can be arrived at from which intermediate temperature points may be interpolated. It is not within the scope of this report to define calibration procedures for any particular device. The preceding discussion is intended to provide the reader with an understanding of the basic principle involved. For further details see the specific Standards Laboratory Calibration Procedure for the device of interest. See Reference 2 for a further discussion of interpolation equations and response, recovery and heat-transfer considerations.

Calibration at extremely high temperatures generally requires a vacuum chamber with a view port for an optical pyrometer. Figure 12 illustrates a typical test facility for high temperature thermocouple test and calibration. 


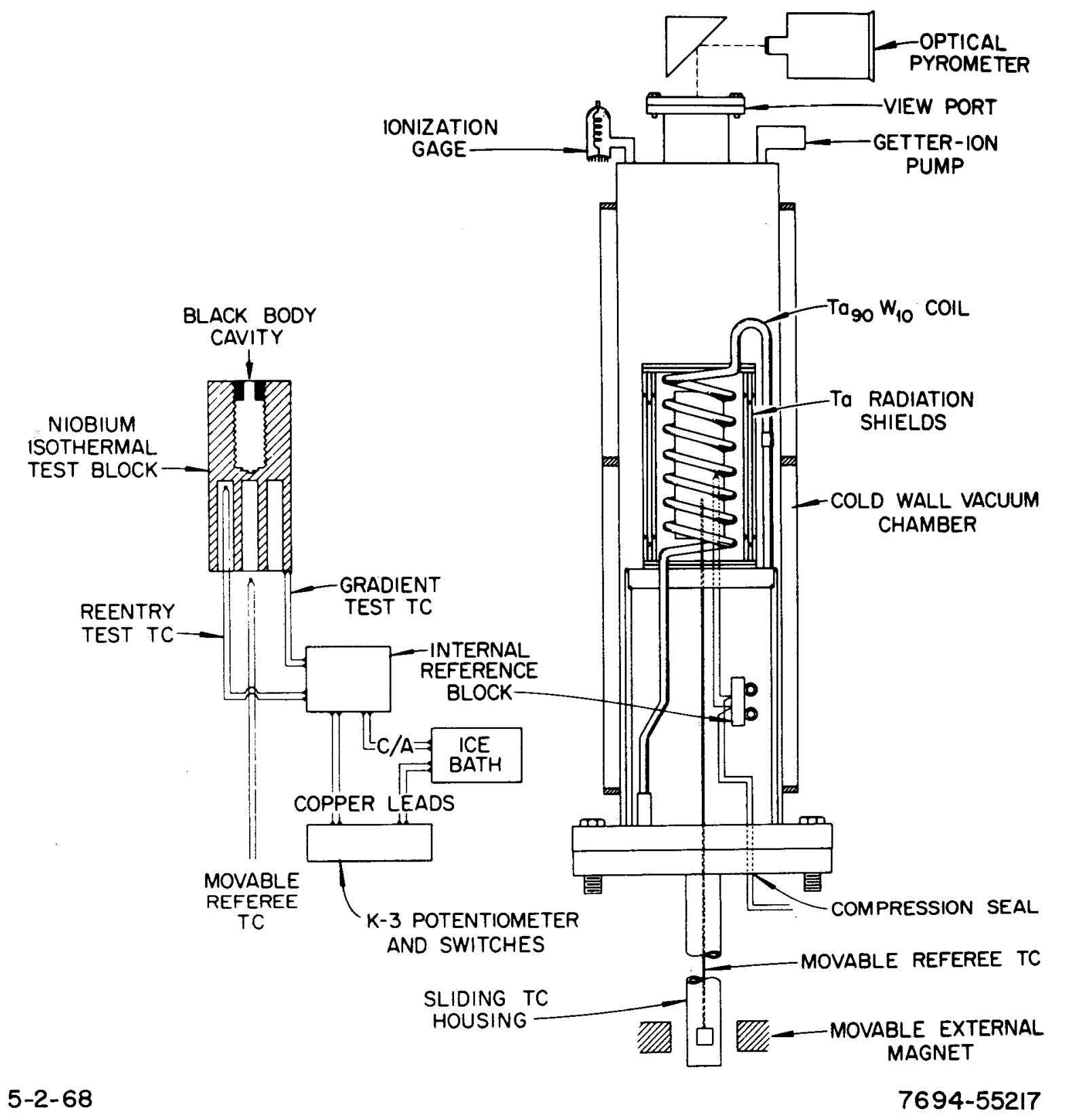

Figure 12. Schematic of Drift Test Facility

LMEC-Memo-68-10 


\section{TEMPERATURE MEASUREMENT TECHNIQUES AND INSTRUMENTS}

As stated previously, any matexial physical characteristic which varies reliably with temperature may be used as a temperature measurement device. This fact has given rise to numerous devices and techniques over the years. Some are highly specialized while others enjoy a wide scope of application. Some are designed to register one temperature, or a very narrow band, while others may be applicable over a very wide range, and still other techniques were developed for use at either extreme of the temperature range. While it is the intention of this document to be as inclusive as possible, the amount of space allocated to each technique will be generally proportional to its relative importance as applied to measurements in liquid metal high flux nuclear reactors.

\section{A. THERMOELECTRIC THERMOMETRY \\ 1. Thermoelectricity}

In 1821, Seebeck discovered the the rmoelectric emf named after him. Thermodynamically, the Seebeck effect is actually the algebraic sum of the Peltier and Thomson effects. Whenever the junctions formed of two dissimilar homogeneous materials are exposed to a temperature difference, an emf will be generated which is dependent on that temperature difference and also on the temperature level and the materials involved. Since this emf is measurable either by means of a millivoltmeter or potentiometer, it provides a means of measuring temperature differences. If a reference temperature such as an ice bath is established for one of the junctions, and the other junction is exposed to an environment at some unknown temperature, then the emf as read by the indicating instrument will vary directly, and only, with the unknown temperature. In order to take advantage of this thermoelectric thermometer, a successful effort has been made to establish many useful empirical relationships and to develop an advanced materials technology.

A thermocouple is a system of two wires, $A$ and $B$, welded together to form a measuring junction with the free end constituting the reference junction. Its successful use is based on the application of three fundamental laws, which have been established experimentally beyond a reasonable doubt. The three laws may be combined and stated as follows: the algebraic sum of the thermoelectric emf's generated in any given circuit containing any number of dissimilar

LMEC-Me mo-68-10 
homogeneous metals is a function only of the temperatures of the junctions. The important point is that the magnitude of the emf is independent of the presence of a third material as long as the junctions with the third material are at the same temperature.

For a more detailed discussion of thermoelectric theory and its governing laws see Reference 3, Section 6.

\section{Advantages and Limitations of Thermocouples}

Some of the advantages of the thermocouple are:

1) Stability

2) Lack of hysteretic effects in general

3) Small physical sampling size

4) Electrical signal generation

5) Flexibility as to physical size, orientation, positioning

6) Wide range of ope ration

7) Adaptability for measuring gas, liquid or solid temperatures

8) Insignificance of correction to readings

9) Resistance to corrosion, erosion, etc. Readings not affected until phase changes are essentially complete in the materials of which it is composed (for pure material couples)

10) Ease of application

11) Low cost of material generally

12) Large body of experimental technique exists.

Thermocouples retain many of their advantages even at very high temperatures, especially their stability under corrosive influences, as compared with most other techniques of temperature measurement. Therefore they appear to be most attractive high temperature measuring devices.

Among the disadvantages of the thermocouple are: the purely empirical calibration curves, cold junction corrections, special materials used in composition (such as alloys) which make drift of readings possible on change of composition, and relatively small dc electrical signal outputs.

$$
\text { LMEC -Me mo-68-10 }
$$


The main limitations on the use of thermocouples at high temperatures involve the useful lifetime of the sensing element and the rate of contamination or change of calibration. Each application and environmental condition will dictate the useful lifetime, and the accuracy desired will determine the allowable drift. Acceptable lifetimes may vary from seconds to years. For example, in measuring liquid metal temperatures it may be sufficient to read a temperature by a dip test, whereas in furnace applications thermocouples may have to be installed in inaccessible locations.

In the main it may be said that raising the operating temperature of a couple will shorten its life at a progressively greater rate. Generally, operating the thermocouple in a noncorrosive atmosphere (at any temperature) will increase its life greatly.

Limitations in a neutron environment concern the transmutation of material by neutron capture, hence change in calibration. Rhodium subjected to neutron bombardment converts to palladium, the resulting fission product decays.

Iridium appears completely useless because of its readiness to transmute. The conversion of rhenium to osmium presents some problems with this material for long term use in high flux environments.

\section{Measurements and Calibration}

Any of the standard techniques for the measurement of emf may be used as long as they have the requisite accuracy. However, at high temperatures those schemes which require drawing a current from the circuit should be avoided. This is because progressive resistance changes of the thermocouple and leads due to physical and chemical aging or corrosion must be expected. If a multiple channel recorder is to be employed it should be of the potentiometric type.

For any thermocouple, the emf vs temperature relationship can always be generated as accurately as desired, depending on how carefully the calibration is performed. However, thermocouple reference tables are most commonly used. These tables contain reference values which represent, in both form and magnitude, the nominal characteristics of particular types. Thus, even assuming that all the necessary precautions have been taken to eliminate reading and instrument errors, stray emf's, etc., there is a limit of accuracy

LMEC -Me mo $-68-10$ 
connected with all commercially available thermocouples when reference tables are used. These error limits are a function of the type of thermocouple, its wire gauge, and the temperature range and environmental conditions in which it will be used. Despite the best that the suppliers can do in the way of quality control, these errors can reach several percent (type $\mathrm{J}^{*}$ or $\mathrm{K}$ below $-100^{\circ} \mathrm{C}$ and type $\mathrm{T}$ below $-60^{\circ} \mathrm{C}$ ). More typical values are $3 / 4 \%$ for types $\mathrm{J}$ or $\mathrm{K}$ above $250^{\circ} \mathrm{C}$ and type $\mathrm{T}$ above $100^{\circ} \mathrm{C}$, and $1 / 4 \%$ for types $\mathrm{R}$ and $\mathrm{S}$ from 550 to $1500^{\circ} \mathrm{C}$.

If it is not desired to locate the voltage indicator close to the position of the measuring junction, then copper wire may be used to connect the indicator to the junctions. This is proper procedure, no matter what the materials, as long as the extension wire junctions are held at a constant reference temperature. In most industrial applications, it is customary to employ cold-junction compensation, and either a bimetallic-spring a rrangement or a temperaturesensitive resistor bridge circuit is used to compensate for changes in thermal emf occurring at this new reference junction. In this case, the thermocouple wire should be used directly where possible. If, as is often the case, the expense entailed by long runs is excessive, then the rmocouple extension wires may be used. Wires of special composition are available for types $R$, $S$, and $\mathrm{K}$ thermocouples. They provide a match for the particular thermocouple emf at the probable temperature of the.junction between the thermocouple and the extension leads. Types $J, E$, and $T$ are used as their own extension wires, although a change in wire gauge (from a number 8 to a number 18 gauge, for example) may be appropriate.

If the meter is a millivoltmeter, it will be found to consist of a galvanometer with a pointer which moves across a scale graduated in either $\mathrm{mv}$, or in ${ }^{\circ} \mathrm{F}$, or ${ }^{\circ} \mathrm{C}$. Because the galvanometer actually measures a small current (typically $50 \mathrm{\mu a}$ to $1 \mathrm{ma}$ ) produced by the thermal emf, and since this current depends on the total resistance in the circuit, the measurement is correct only if the resistance remains constant after calibration. As previously mentioned, this resis tance is quite apt to change; this phenomenon, along with changes in pivot friction, spring constant, and magnetic-field strength in the meter, will introduce a reading error. The potentiometer avoids these difficulties, and with its much

*Instrument Society of America thermocouple designations: Types S, R, J, T, $K$, and $E$. 
greater definition of scale, provides greatly increased precision. The fact remains, however, that the low cost, simplicity, and directness of temperature indication of the millivoltmeter preserves for it a very useful place in the area of industrial thermometry.

As in the case of any transducer, many inconspicuous errors in the final measurement can result from poor instrumentation practices. Thermocouples, particularly when used with electronic amplifiers, indicators, recorders, and controllers, are prone to ground-loop leakage errors, problems with stray magnetic and electric fields, etc. If proper care is taken and if accurate indicators are used in association with stable, well-made thermocouples, then it may be stated that the success attained in the measurement of temperature with thermocouples depends almost entirely upon the ability of the observer to bring the thermocouple junctions to the desired temperatures.

Figures 13 through 16 illustrate some typical thermocouple circuits used to measure temperature; they are a potentiometric circuit, differential temperature and mean temperature circuits, and a thermopile circuit.

Calibration of a thermocouple is usually accomplished by comparison with a standardized thermocouple in the moderate temperature ranges and against an optical pyrometer in the higher ranges. Calibration must be done under environmental conditions which are close as possible to those of the application, allowing the couples to come to equilibrium. Standard couples may be certified by the NBS and are usually standardized by taking a number of freezing point curves of selected chemical elements.

In using the optical pyrometer as a standard, the usual precautions concerning intervening vapors, emissivities, and collimation must be considered.

For further detail on calibration procedures and precautions to be observed in thermocouple calibration see References 1 and 4.

Measure of Thermocouple Quality by Time Domain Reflectometry. Time domain reflectometry has been investigated as a possible tool to be used to evaluate the quality of a complete metal-sheathed thermocouple.

Measurements were made with a Hewlett-Packard Model 1415 Time Domain Reflectometer plug-in installed in a Hewlett-Packard Model 140 A Oscilloscope. 

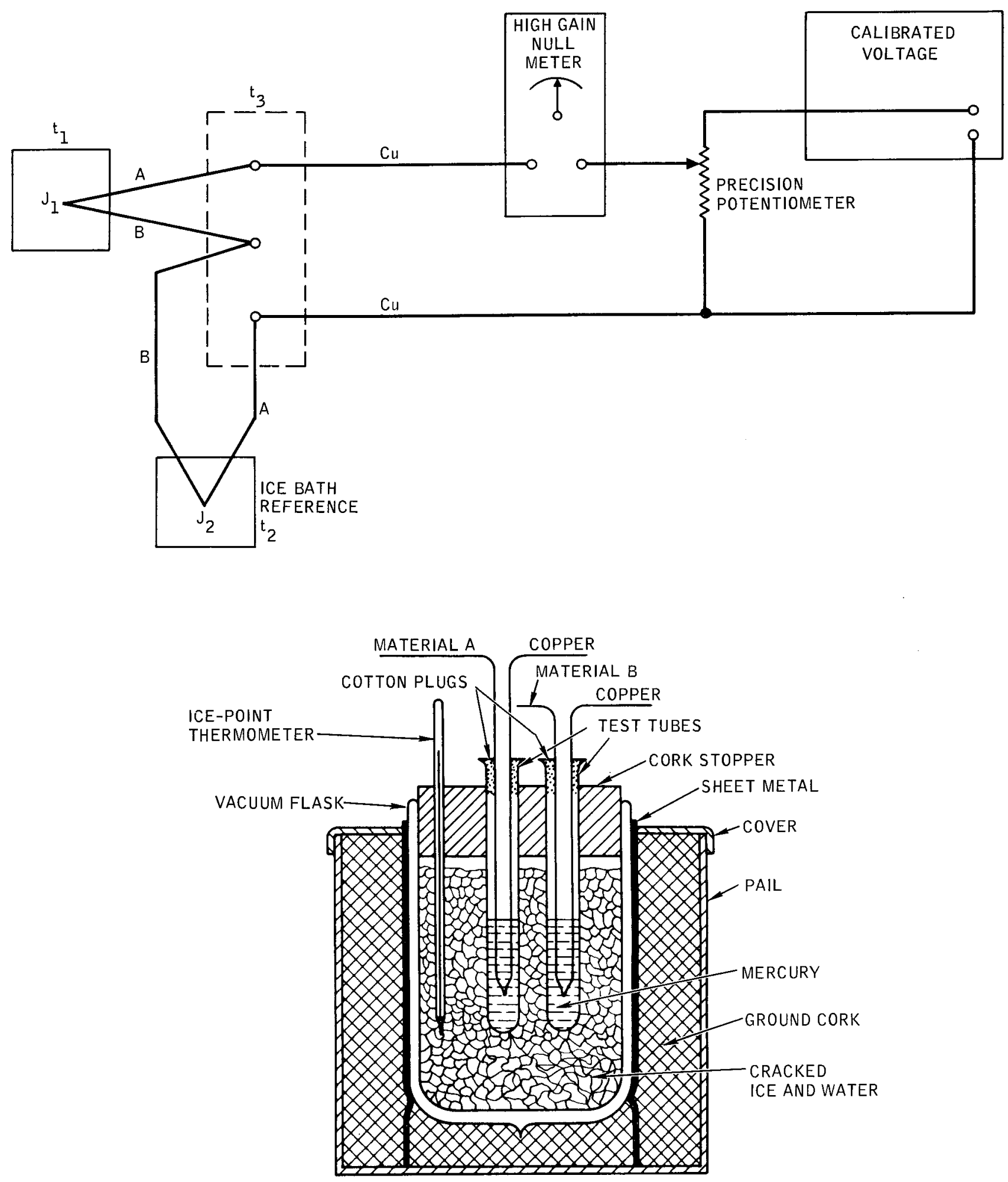

$5-2-68$

$7694-55218$

Figure 13. Typical Ice Bath for Reference Junctions

LMEC-Memo-68-10 


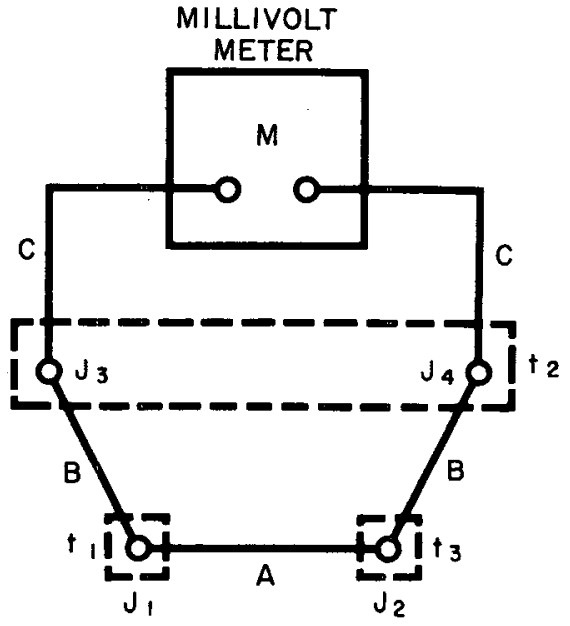

5-2-68 UNCL $\quad 7694-55219$

Figure 14. Differential Thermocouple

$\mathrm{BAB}$ and Meter M Measure the

Temperature Difference $t_{3}-t_{1}$
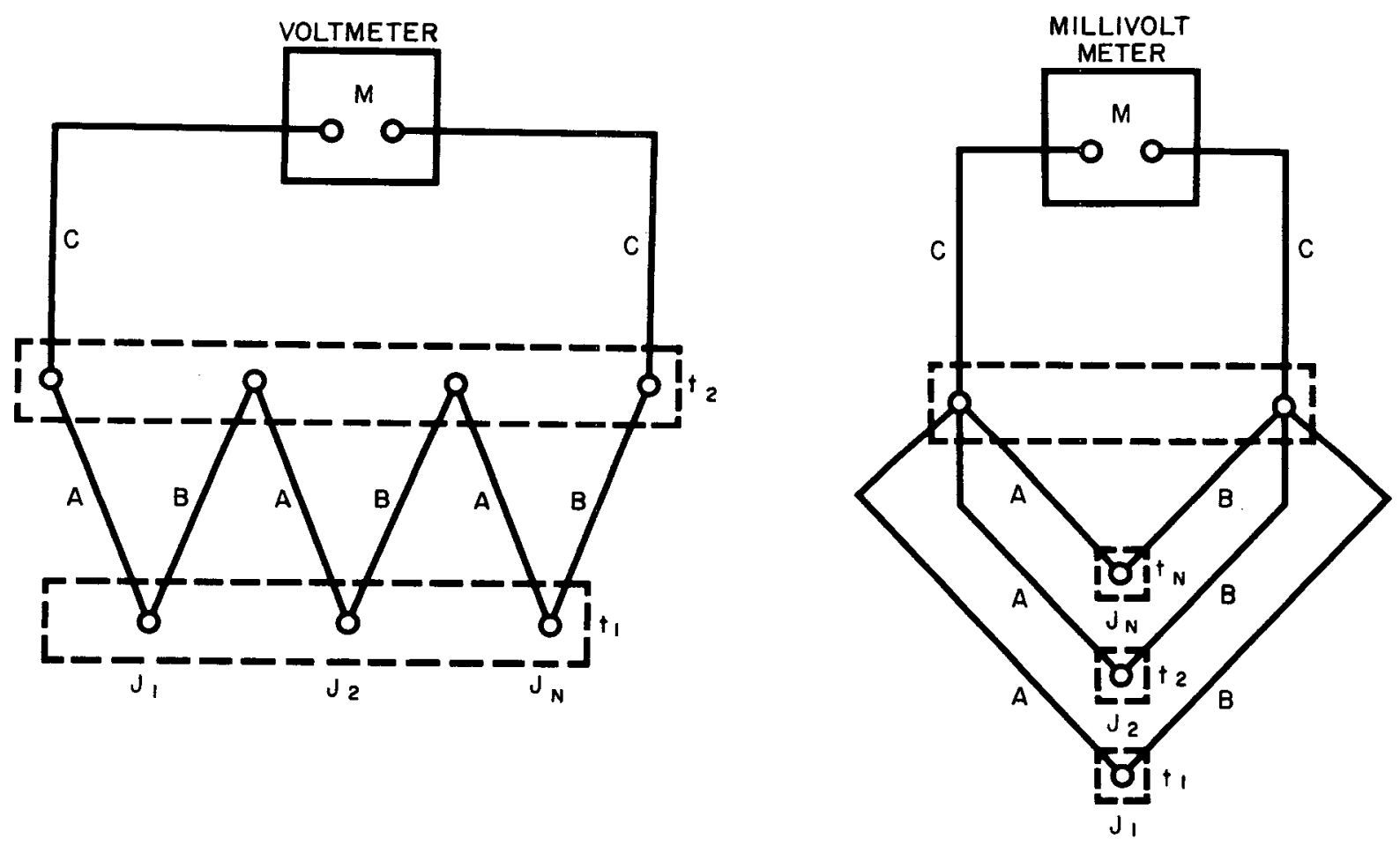

$5-2-68$ UNCL

$7694-55220$

$5-2-68$ UNCL

$7694-55221$

Figure 15. N Thermocouples in Series Acting as a Thermopile

Figure 16. N Thermocouples in Parallel Providing a Measurement of the Temperature Mean Among $t_{1}, t_{2} \ldots t_{n}$

\section{LMEC-Memo-68-10}


The technique of reflectometry consists essentially of applying an ultra-fast risetime voltage step to the system to be tested and observing the reflections. A reflection occurs each time the step encounters an impedance change or discontinuity; this reflection is added to the incident wave and is displayed on the oscilloscope. The time required for the return of the reflection locates the discontinuity. The shape and magnitude of the reflected wave indicate the nature and magnitude of the discontinuity.

Reflectometry is at its best in indicating and locating accurately gross faults such as opens and short circuits, and areas of significantly reduced insulation resistance. It is less effective in revealing fine-line fractures, particularly when definition has been reduced by intervening cable. Further details of this technique are covered in Reference 5, Section II. J.

\section{Thermocouple Fabrication}

The fabrication of thermocouples has been accomplished by almost as many techniques as are known for bonding metals together. Some of the techniques used have been soldering, brazing, welding, forging, electroplating, vapor deposition, swaging, or friction. Concentric tube and wire or rod arrangements have been used where mechanical stability was imperative. Surface temperature measurements have been made by plating or tamping thermocouples into surfaces, and a thermocouple has been made without junction, by dipping two dissimila $r$ rods into a molten metal.

In most cases precautions must be taken to prevent the oxidation of the joint and to exclude foreign materials which would weaken the mechanical properties of the joint.

In measuring high gas temperatures care must be taken to prevent radiation losses from the thermocouple. This is usually accomplished by encasing the hot junction in porous metallic shields of low emissivity. Elaborate schemes have sometimes been used to ensure the smallest radiation losses, such as installing heating elements in the radiation shields to maintain the shield and couple at the same temperature.

For high temperatures the couple elements should be so constructed as to offer less resistance to corrosion at the junction than along the elements themselves. This is to ensure that corrosion effects along the length of the couple elements will not result in parasitic emf's.

$$
\text { LMEC-Me mo-68-10 }
$$


Figures 17 through 26 illustrate some of the more common thermocouple fabrication configurations. Figure 25 is not recommended for high accuracy but rather for quick, low-cost installation.

\section{Thermocouple Installation}

Installation must be done with care to be certain that the junction is maintained at the same temperature as the material whose temperature is being measured. Heat losses by conduction of the thermocouple leads, and radiation losses to colder surroundings must be minimized. The heat capacity of the thermocouple and its appurtenances must be small enough to allow the junction to follow temperature changes in the medium at a satisfactory rate.

In addition, the thermocouple assembly should be composed of materials which will resist physical or chemical effects that would change its calib ration. At very high temperatures the problem of physical and chemical corrosion becomes of paramount importance. Most metals experience recrystallization and become embrittled. Phase changes are experienced, and chemical reaction rates increase exponentially. Protection tubes or wells to isolate the thermocouple from the environment are usually necessary. The thermocouple cannot be physically removed after installation and operation at high temperatures without injury to the components. If possible, the thermocouple should be operated in an inert atmosphere such as argon, although even argon or helium may cause embrittlement of certain metals (e.g., tantalum).

Caution should be observed in the selection of insulators for the couple elements. Even if a material is satisfactory at high temperatures for its insulating properties, it may still react with the thermocouple elements at high temperatures. Typically, some of the oxides will react to oxidize the couple elements while freeing metallic vapors. These vapors may ultimately short out the insulators.

For leading the signal from a thermocouple wire to a measuring instrument extension wires are often used. These are wires of the same relative thermal emf as the thermocouple wires. The composition of the rmocouple material and extension leadwire must have the same thermal emf relationship if spurious emf's are not to be introduced into the circuit. For high temperature applications, where the cold junction is maintained at the point of exit from

LMEC-Memo-68-10 


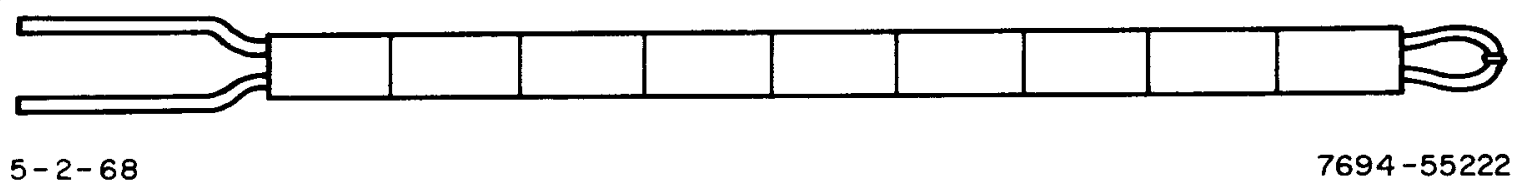

Figure 17. Single Thermocouple - Double-bore Ceramic Insulators

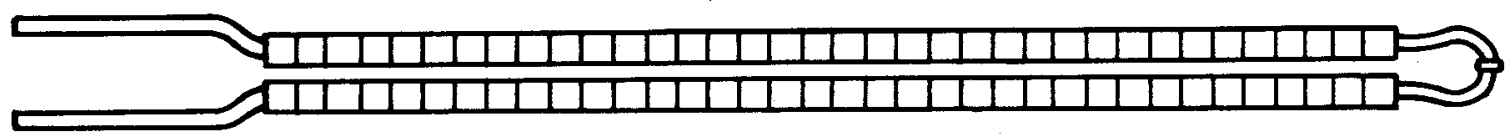

$5-2-68$

$7694-55223$

Figure 18. Single Thermocouple - Fish-spine Ceramic Insulators

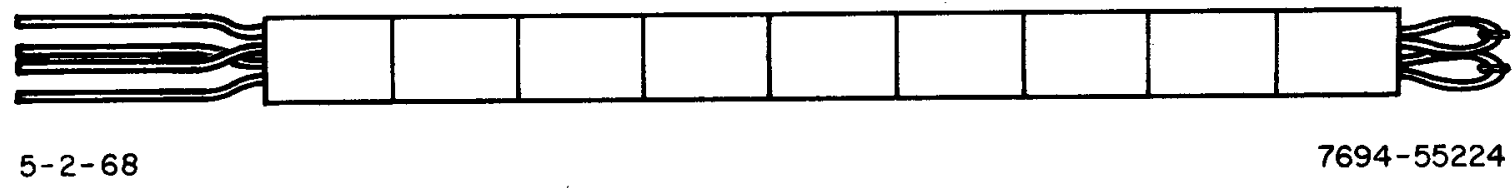

Figure 19. Double Thermocouple - Four-hole Ceramic Insulators

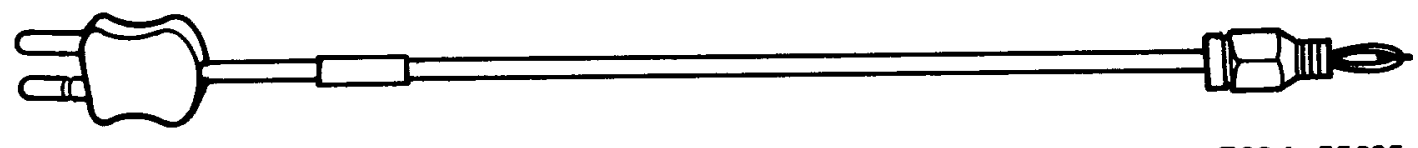

$5-2-68$

$7694-55225$

Figure 20. Exposed Loop Thermocouple

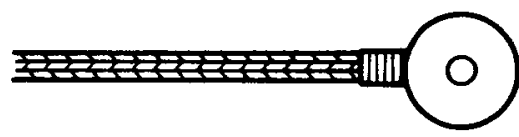

a) WITH FIBERGLAS INSULATED LEAD, NO SUPPORT

$5-2-68$

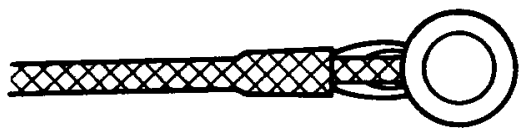

b) WITH STAINLESS STEEL BRAIDED LEAD, STAINLESS STEEL SUPPORT

$7694-55226$

Figure 21. Gasket Thermocouple

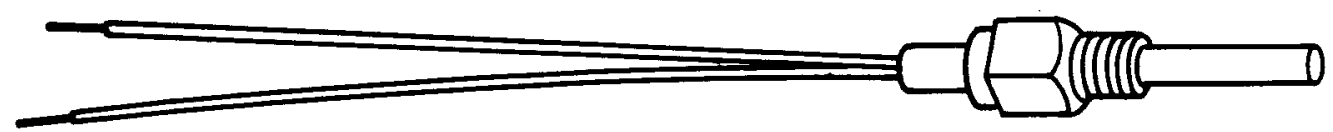

$5-2-68$

$7694-55227$

Figure 22. Mixture Thermocouple

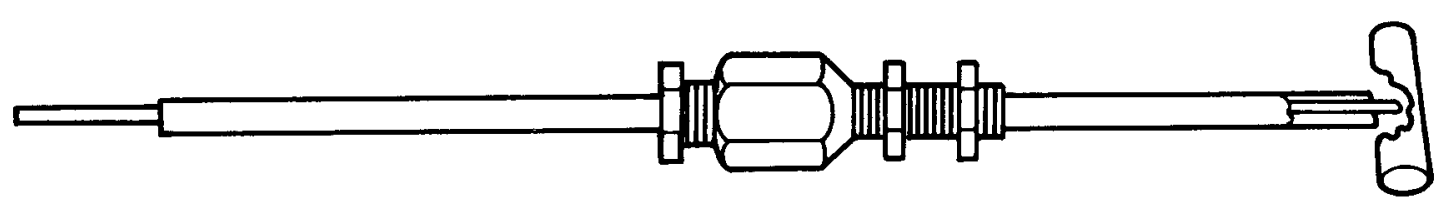

$5-2-68$

$7694-55228$

Figure 23. Shielded Thermocouple

LMEC-Memo-68-10 


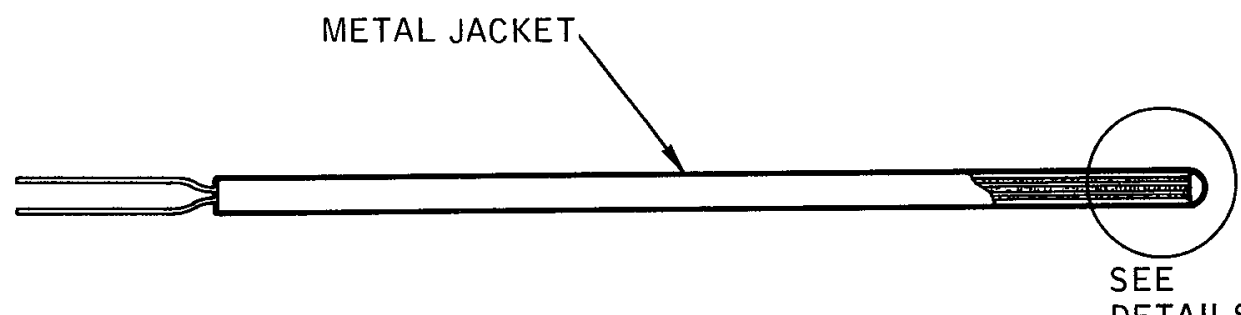

DETAILS
a) AND b)

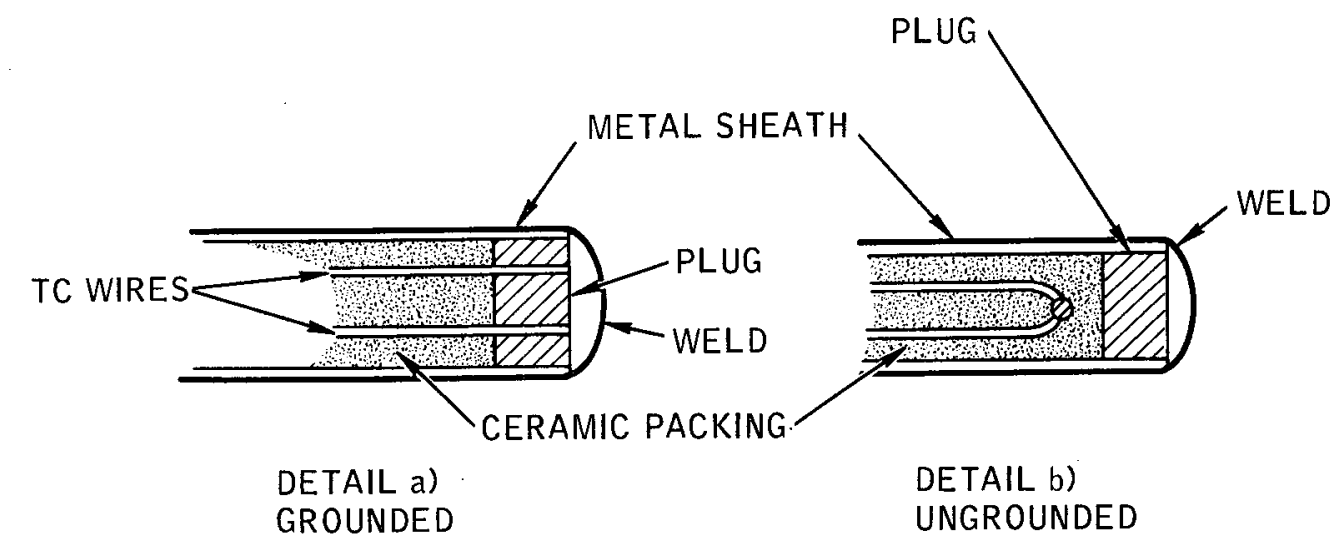

5-2-68 UNCL

7694-55229

Figure 24. Sheathed Thermocouple

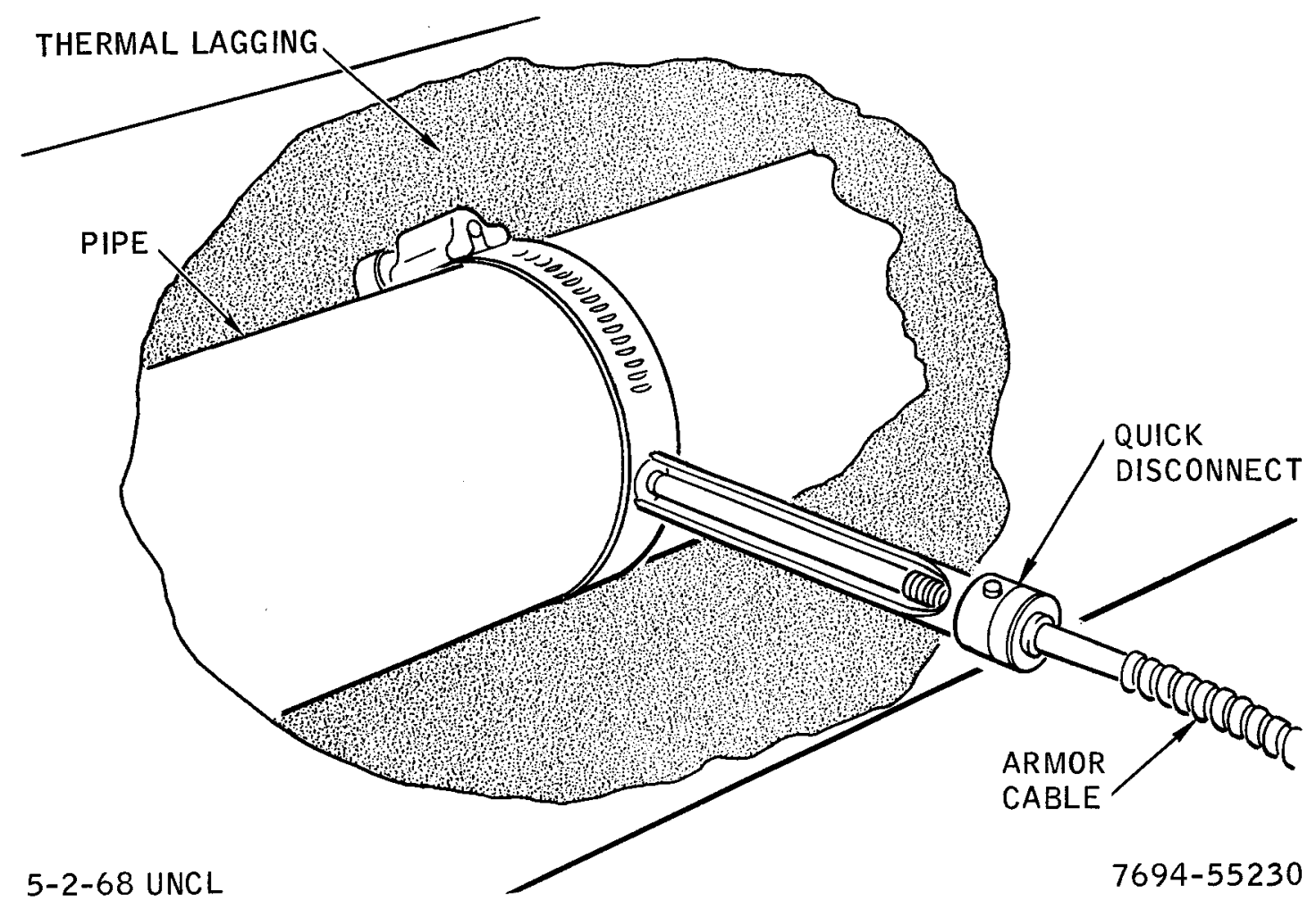

Figure 25. Thermo Electric Co., Inc., Patented Pipe Clamp Adapter (Patent No. 2, 752, 411 )

LMEC-Memo-68-10 


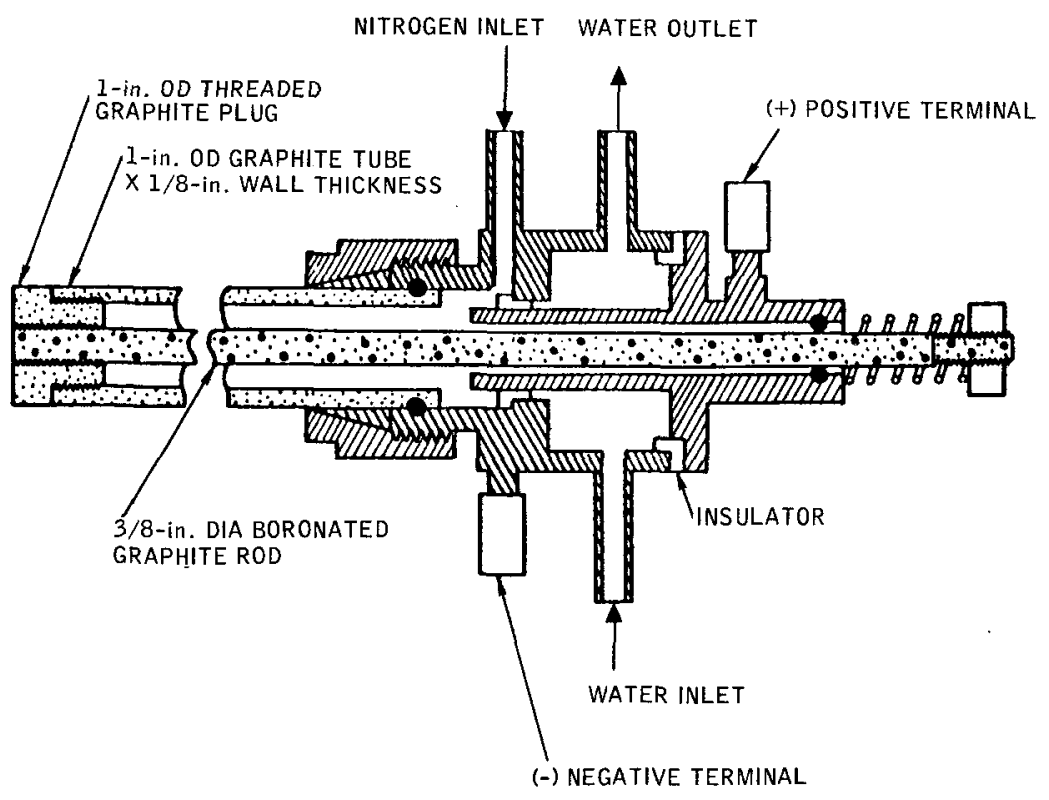

$5-2-68$

$7694-55231 \mathrm{~A}$

Figure 26. Boron Graphite/Graphite Thermocouple, Coaxial Style

the hot region by artificial cooling, ordinary copper wires will suffice for leading the signal to the measuring instrument.

In one installation on the Sodium Reactor Experiment (SRE) at Atomics International it was found that epoxy can be used successfully to seal thermocouple penetrations in the cold top region of a reactor shield plug. This technique precludes welding or brazing on the sheath, thereby diminishing a potential hazard of installation. Epoxy adhesives are available for operation to $550^{\circ} \mathrm{F}$.

For fast response, thermocouples using 0.5- and 1.0-mil wire have been spotwelded directly to the surface of the media being monitored, using a stored charge discharge welder. When tested by pulsing with a current and then recording the time to decay, a typical time constant of 2 ms was measured for a 0.5-mil Chromel-Alumel the rmocouple.

6. Thermocouple Materials

Seebeck's original discovery of thermoelectricity was based on a circuit using wires of copper and antimony. Of all the practically limitless combinations

LMEC-Memo-68-10 
of metals and alloys available since that time to make thermocouples, relatively few have been put to use. These have been chosen on the basis of their thermoelectric power $(\mathrm{dE} / \mathrm{dt})$, their stability and reproducibility, their homogeneity, relatively high electrical conductivity and melting points, ease of fabrication and cost.

The emf of any metal used as thermocouple element against any other may be obtained by integration of the thermoelectric powers of the two metals. Table 1 is a listing of metals, so arranged that each item in the list is thermoelectrically negative with respect to all those below it. For further detailed information on thermocouple materials see Reference 6 .

TABLE 1

THERMOELECTRIC SERIES OF SELECTED METALS AND ALLOYS

\begin{tabular}{l|l|l}
\hline \multicolumn{1}{c|}{$100^{\circ} \mathrm{C}$} & \multicolumn{1}{|c|}{$500^{\circ} \mathrm{C}$} & \multicolumn{1}{c}{$900^{\circ} \mathrm{C}$} \\
\hline Antimony & Chromel-P & Chromel-P \\
Chromel-P (90Ni-10Cr) & Nichrome & Nichrome \\
Iron & Copper & Silver \\
Nichrome & Silver & Gold \\
Copper & Gold & Iron \\
Silver & Iron & 90 Pt-10Rh \\
$90 P t-10 R h$ & $90 P t-10 R h$ & Platinum \\
Platinum & Platinum & Cobalt \\
Palladium & Cobalt & Alumel \\
Cobalt & Palladium & Nickel \\
Alumel (94Ni-3Mn-2Al-1Si) & Alumel & Palladium \\
Nickel & Nickel & Constantan \\
Constantan (57Cu-43Ni) & Constantan & \\
Copel & Copel & \\
Bismuth & & \\
& &
\end{tabular}

LMEC-Me mo-68-10 
The thermocouple combinations most commonly used bear the Instrument Society of America designations - types S, R, J, T, K, and E. With the exception of the noble metal thermocouples, the first named of the thermocouple pair is usually the positive leg.

For further details on thermocouple characteristics and performance see Reference 7 .

a. Type S. Scientifically speaking, the type S, or platinum-platinum $+10 \%$ rhodium thermocouple is the most important of the thermocouples now in use. Often called the Le Chatelier couple, it is used for defining the ITPS from 630.5 to $1063^{\circ} \mathrm{C}$. The interpolation equation, assuming a reference junction of $0^{\circ} \mathrm{C}$, is

$$
E=a+b t+c t^{2}
$$

where $\mathrm{E}$ is in $\mu \mathrm{v}$. The constants $\mathrm{a}, \mathrm{b}$, and $\mathrm{c}$ are determined by calibration at the freezing points of gold and silver and by a platinum resistance the rmometer reading at $630.5^{\circ} \mathrm{C}$. Although the equation is restricted to the range which it serves to define, the type $S$ couple may be used in oxidizing atmospheres for precision measurements between 0 and $1500^{\circ} \mathrm{C}$ and for short times and with special precautions to $1650^{\circ} \mathrm{C}$. Its sensitivity is about $11 \mu \mathrm{v} /{ }^{\circ} \mathrm{C}$ at $1000^{\circ} \mathrm{C}$. b. Type R. The alloy Pt87-Rh13, with its approximately $20 \%$ higher output, is used to some extent with platinum in place of Pt90-Rh10. This has been designated type $R$.

c. Type T. Copper-constantan, the type $T$ thermocouple, has been a popular sensor in industrial and laboratory applications whe re accurate temperature measurements are required in the -200 to $+250^{\circ} \mathrm{C}$ range. Within these limits, its thermoelectric power ranges from 15 to $60 \mu \mathrm{v} /{ }^{\circ} \mathrm{C}$. This sensitivity, combined with its low cost and the high homogeneity obtainable in copper wire, makes it the preferred thermocouple in its range. Above $350^{\circ} \mathrm{C}$, the copper oxidizes too rapidly to give satisfactory service. With proper calibration and suitable precautions, the type $\mathrm{T}$ can be used as low as $11^{\circ} \mathrm{K}$. It should be noted that the constantan used in this couple (known as "Adams Constantan") is not the same as that used with iron-constantan thermocouples, because of different voltage requirements.

LMEC-Me mo-68-10 
d. Type $\mathrm{K}$. Type $\mathrm{K}$ was used originally to designate only the Chromel-Alumel thermocouple. There are now two other thermocouples in this class, the Kanthal P-Kanthal N, and Tohel-Nial. The main constituent of all the type $\mathrm{K}$ mate rials is nickel, which is present in amounts ranging from $90 \%$ in the positive-leg compositions. Chromium is an important element in the positiveleg material; manganese, silicon, aluminum, iron, cobalt, and carbon are present in varying amounts in all of them. The thermoelectric power of the type $\mathrm{K}$ couples is fairly constant, averaging $40 \mu \mathrm{v} /{ }^{\circ} \mathrm{C}$. It has very good oxidation resistance, which permits its continuous use at temperatures up to $1200^{\circ} \mathrm{C}$ and, for limited times, as high as $1300^{\circ} \mathrm{C}$. However, it is subject to the same limitations as the platinum couples with respect to use in reducing atmospheres at such high temperatures. In addition, it can be used as low as $-200^{\circ} \mathrm{C}$; however, its most important industrial application is in the 700 to $1250^{\circ} \mathrm{C}$ range.

Inconel sheath Chromel-Alumel thermocouples tested in sodium have demonstrated a mean deviation of about $8^{\circ} \mathrm{F}$ at temperatures of 1100 to $1500^{\circ} \mathrm{F}$ for 4000 to $5000 \mathrm{hr}$ and a mean deviation of $20^{\circ} \mathrm{F}$ at $1800^{\circ} \mathrm{F}$ for $5000 \mathrm{hr}$. Reference 5 indicates test results of Chromel-Alumel thermocouples to $2200^{\circ} \mathrm{F}$ for thousands of hoilss,

e. Type J. The type J, or iron-constantan, thermocouple is the most widely used of all industrial thermocouples. Constantan is an alloy of copper and nickel, ranging from $\mathrm{Cu} 50 \mathrm{Ni} 50$ to $\mathrm{Cu} 65 \mathrm{Ni} 35$, but for thermoelectric purposes it has an approximate composition of Cu57Ni43. Small percentages of manganese and iron and trace impurities such as carbon, magnesium, silicon, and cobalt are also used. The relatively high thermoelectric power (increasing fiirly uniformly from about $27 \mu \mathrm{v} /{ }^{\circ} \mathrm{C}$ at $-190^{\circ} \mathrm{C}$ to $63 \mu \mathrm{v} /{ }^{\circ} \mathrm{C}$ at $800^{\circ} \mathrm{C}$ ), comparatively low cost, and its adaptability to both oxidizing and reducing atmospheres are responsible for its popularity.

f. Type E. The Chromel-constantan, or type E, thermocouple is a relative newcomer to the field. Over its range of 0 to $900^{\circ} \mathrm{C}$, it has very good stability and the highest thermoelectric power (as high as $81 \mu \mathrm{v} /{ }^{\circ} \mathrm{C}$ at $500^{\circ} \mathrm{C}$ ) of the commonly used thermocouples. These characteristics make it useful in differential temperature measurements and in thermopiles requiring high sensitivity.

LMEC-Memo-68-10 
g. High Temperature Thermocouples. For temperatures to $2500^{\circ} \mathrm{C}$ the W / W -26Re thermocouple has the highest output and sensitivity. Reference 5 indicates test results of the $\mathrm{W}-5 \mathrm{Re} / \mathrm{W}-26 \mathrm{Re}$ useful to $2800^{\circ} \mathrm{F}$ for at least $1,000 \mathrm{hr}$ and at $2300^{\circ} \mathrm{F}$ for almost $10,000 \mathrm{hr}$. Molybdenum-columbium thermocouples were developed for use in a nuclear radiation environment because of their low nuclear cross-section. Reference 5, Section II.I discusses the Mo-Cb thermocouple in further detail. For highest stability and precision types $R$ and $S$ (see preceding paragraphs $a$ and $b$ ) are used. Also, per Reference 5, the discussed thermocouples indicated operation at 1950 to $2000^{\circ} \mathrm{F}$ for $10,000 \mathrm{hr}$ in $1 / 8-$ in. OD $\mathrm{Cb}-1 \mathrm{Zr}$ alloy sheathing with alumina insulation.

h. Others. There are many other thermocouple combinations available for special purposes. In terms of everyday use, they represent but a small fraction of thermocouple applications, but there are several worthy of mention for their service at extremes of temperature. For the cryogenic range below $90^{\circ} \mathrm{K}$, gold $+2.1 \%$ cobalt vs copper or normal silver is outstanding. Iridium/iridium $40-$ rhodium 60, and graphite vs doped graphite have been used at temperatures in the 2000 to $3000^{\circ} \mathrm{C}$ range.

\section{B. RESISTANCE THERMOMETRY}

Resistance thermometers can be the most accurate of all temperature sensing devices, permitting measurements to be made within an accuracy of about $10^{-4} \circ \mathrm{C}$ at room temperature. Their operation is based on the fact that the resistance offered to the passage of an electric current by any material is dependent on its temperature. Suitably chosen and prepared materials will vary in a well-defined and calibratible manner with temperature. The resistance variation is usually measured with bridge arrangements such as the Wheatstone, Kelvin, or Mueller bridges. Potentiometric techniques (employing constant-current sources and precision potentiometers) have also become popular. There are special circuits which reduce or eliminate errors due to lead resistance and thermal emf's, produce modified versions of the $R$ vs $t$ relationship and provide automatic readout of the measurement.

Figure 27 illustrates the resistance-temperature characteristics of some materials over a broad temperature range.

LMEC-Me mo-68-10 

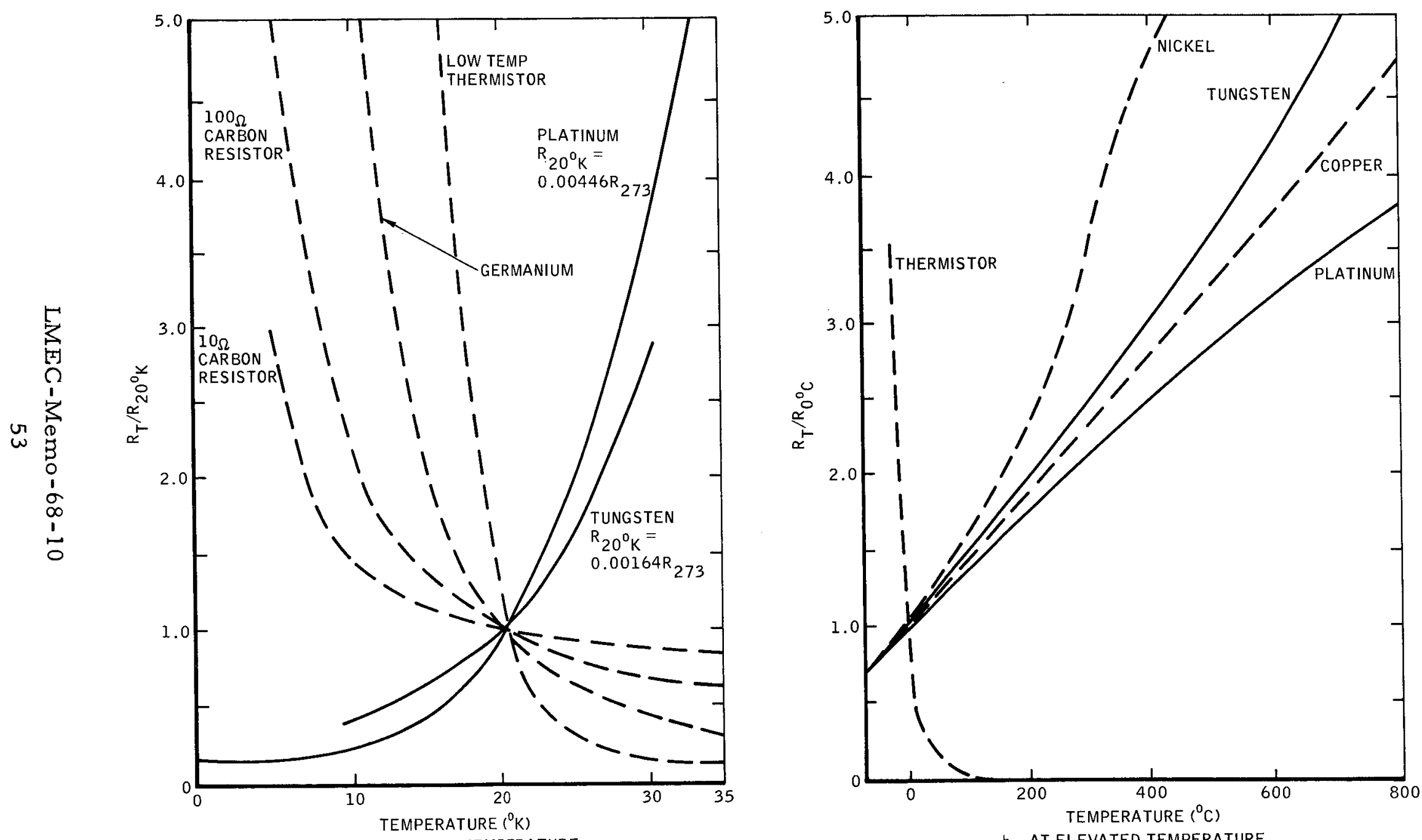

a. AT CRYOGENIC TEMPERATURE

b. AT ELEVATED TEMPERATURE

Figure 27. Resistance-Temperature Characteristics of Some Materials 


\section{Metals}

As the temperature rises, the resistance of metallic materials also rises. The main factor causing this rise is the increased interaction of electrons with atoms that are displaced from their positions in the metal lattice, resulting in a shorter mean free path for the electrons. The rise in resistance is rather small and fairly linear. Values of high temperature resistivities of some metals may be found in III. F.l of this report. All resistivities tend to converge to values a round 1 to $2 \times 10^{-4} \mathrm{ohm}-\mathrm{cm}$ at high temperatures.

Resistance thermometers, based on the temperature dependence of the resistivity, are widely and increasingly used at lower temperatures. In the range $-183^{\circ} \mathrm{C}$ to $630^{\circ} \mathrm{C}$, indeed, the platinum resistance thermometer is the international standard. Of all metals, platinum is the most appropriate for a resistance the rmometer because it is commercially available in pure form, it is easily workable and is relatively indifferent to its environmental conditions. In a pure, fully annealed and strain-free state, it has an $\mathrm{R}-\mathrm{t}$ relationship which is especially stable and reproducible.

Commercial resistance thermometers are made of copper (range -140 to $\left.+120^{\circ} \mathrm{C}\right)$, nickel $\left(-180\right.$ to $\left.+320^{\circ} \mathrm{C}\right)$ or platinum $\left(-180\right.$ to $\left.+540^{\circ} \mathrm{C}\right)$. The range can be extended upward (especially for Pt). Careful choice of insulation (highsintered or fused alumina) is said to allow the use of Pt resistance thermometers to temperatures not far below the melting point $\left(1650^{\circ} \mathrm{C}\right)$. Readings are expected to become irreproducible if the sintering point is reached or if any other irreversible changes occur in the metal.

From the preceding it is apparent that a metal resistance thermometer (using tungsten, for instance) may give service at extremely high temperatures, however, it may not be the best choice. Dimensional stability is necessary for its operation, while it shares with all electrical methods the problems of chemical corrosion and electrical insulation. Moreover, the temperature measured is an average over the length of the resistance, rather than a point temperature.

\section{Semiconductors}

In semiconductors the temperature coefficient of resistance is usually negative, and the rate of change is generally much greater than in metals.

\section{LMEC-Memo-68-10}


The effect is due to the greater relative numbers of electrons which are promoted into the conduction bands at higher temperatures. The number of conductivity electrons is smaller than in the case of metals (where it is substantially independent of temperature) and therefore the resistance, even at the upper limit of the useful temperature range, is several orders of magnitude higher than in metals.

Thermistors are semiconductors which can be brought to a highly reproducible resistance temperature curve. They are comparatively insensitive to impurities. Mixtures of transition metals ( $\mathrm{Mn}$ to $\mathrm{Ni}$ ) oxides with or without the addition of spinels ( $\mathrm{Mg}$ chromite or aluminate) can be used. Included in this category are carbon resistors, and doped germanium units, all of which have the characteristic of a resistance decrease with increasing temperatures.

However, thermistors with a positive temperature coefficient have also become available. They exhibit sensitivities up to ten times greater than that of metal resistance thermometers, although their $\mathrm{R}-\mathrm{t}$ relationship is far more nonlinear - exponential, in fact. They are available in very small sizes with rapid thermal response (in the order of ms time constants). However, the very small thermal mass leads to problems with nonlinearity of the voltagecurrent characteristic if the measuring current is not limited to values above which $I^{2} R$ self-heating of the thermistor element can occur.

These relatively inexpensive devices do not require leadwire resistance corrections because of their (usually) high resistance, and have a large energy output per degree temperature change as a favorable result of their large temperature-resistance coefficient. In order to cover a wide temperature range, several thermistors usually are required. This is an unfavorable consequence of their high sensitivity and nonlinear $\mathrm{R}-\mathrm{t}$ characteristics, which cause a given unit to swing from an inconveniently low to an inconveniently high value if the temperature span is too great.

Thermistors have most commonly been used in the region -100 to $+350^{\circ} \mathrm{C}$, but special compositions have greatly extended this range - as high as $1600^{\circ} \mathrm{C}$ and as low as $4.2^{\circ} \mathrm{K}$. Their reputation for calibration stability is poor; while it is true they cannot compare in this respect with a platinum resistance thermometer, they can be quite stable when they are properly aged before use, and particularly when this use is limited to the -50 to $+100^{\circ} \mathrm{C}$ range.

\section{LMEC - Memo-68-10}


Carbon resistance thermometers have been made in many forms and from many varieties of natural and artificial crystalline graphites, and carbons which show graphitic properties. The commercial carbon-composition resistor, in sizes from 0.1 to 1 watt, 2 to $150 \mathrm{ohms,} \mathrm{exhibits} \mathrm{a} \mathrm{large} \mathrm{increase} \mathrm{of} \mathrm{resistance}$ in the neighborhood from $20^{\circ} \mathrm{K}$ downward. Stock resistors manufactured by the Allen-Bradley Company were found to be of uniquely high sensitivity and reproducibility. A semi-empirical equation developed by Clement applies to them in the region below $20^{\circ} \mathrm{K}$;

$$
\log _{10} R+\frac{K}{\log _{10} R}=A+\frac{B}{T}
$$

where $R$ is the resistance at temperature $T$, and $A, B$, and $K$ are constants. When the constants are determined by calibration, temperature measurements in the range 1 to $20^{\circ} \mathrm{K}$ are feasible, with a reproducibility of about $0.2 \%$. At both helium $\left(4.2^{\circ} \mathrm{K}\right)$ and hydrogen $\left(20^{\circ} \mathrm{K}\right)$ temperatures, the repeatibility is $0.1 \%$, even with warming and recooling cycles between observations. About the only drawbacks connected with carbon resistance thermometers are los of sensitivity above $20^{\circ} \mathrm{K}$ and the adverse influence of $\mathrm{rf}$ stray fields on resistance at temperatures much below $4.2^{\circ} \mathrm{K}$.

In the temperature region below $20^{\circ} \mathrm{K}$, and even more so below $4.2^{\circ} \mathrm{K}$, reproducibilities of $0.1 \%$ are insufficient for some purposes. Investigation of germanium resistance the rmometers was launched with the intent of providing a possible future extension of the IPTS to very low temperatures. Both arsenicand gallium-doped germanium elements have been fabricated with the necessary precautions to avoid mechanical strain, contamination, and the effects of stray resistance. Reports from various laboratories indicate reproducibilities ranging from 0.0001 to $0.001^{\circ}$ at $4^{\circ} \mathrm{K}$. It should be noted that the former figure approaches the state-of-the-art limits of measurement. No simple universal formula is known which approximates the $R-t$ relationship of these units, so that interpolation procedures are somewhat more complex. However, the fact that the thermometer apparently requires only a single calibration, together with the availability of high-speed computers, serves to minimize this problem.

LMEC -Memo-68-10 
Commercial germanium units are presently available from several sources to cover the range from about 1 to $40^{\circ} \mathrm{K}$. While they undoubtedly will be further improved, they presently offer solid performance as either supplements to, or replacements for, other cryogenic thermometers. Investigations of silicon, gallium ar senide, and tin oxide elements are continuing.

3. Hot $-W$ ire Techniques

This is an extension of the resistance thermometer. A heated wire loses heat to the surroundings. The rate of heat loss is related to the temperature of the surroundings, and is measured by the energy input necessary to keep the temperature (and resistance) of the wire constant. Since the wire must be hotter than the surroundings, it would have to be very hot indeed to be used in liquid metal reactors. All mechanical problems applying to the resistance thermometer would thus be aggravated.

4. Thin Metallic Layers (less than 1000 A)

These exhibit resistivity properties similar to those of semiconductors at liquid hydrogen and helium temperatures. Of course they are not stable at temperatures at which the vapor pressure becomes appreciable.

\section{Oxides}

Since the temperature coefficient of the resistivity of some oxides at very high temperatures is also large and negative, it is possible to conceive of such high temperature "thermistors". Thermal deformation due to sintering, fracture due to thermal shock, changes in the resistance due to impurities and dislocations resulting from radiation damage, and chemical reaction with carbon are the adverse mechanisms which are believed to apply to such a temperature measuring device.

\section{RADIATION PYROMETRY}

It is an accepted law of nature that all substances at any temperature above absolute zero emit radiant energy as a result of the atomic and molecular agitation that is associated with that temperature. The rate of emission, or power, per unit area increases with increasing temperature and may be expressed quantitatively by the following expression:

LMEC-Memo $-68-10$ 


$$
\mathrm{W}=\epsilon \sigma \mathrm{T}^{4}
$$

watts per square centimeter, if $\sigma$, the Stefan-Boltzmann constant, is expressed in units of watts per square centimeter per degree $\mathrm{K}^{4}$ and $\mathrm{T}$ is in degrees $\mathrm{K}$. The dimensionless factor $\epsilon$, called the total emissivity or emittance, is defined as the ratio of the radiation of the surface in question to that which would be emitted by an otherwise comparable blackbody surface at the same temperature.

The blackbody surface, one which absorbs all incident radiation and reflects none, is an idealization, but some substances such as soot and platinum black do approach unit emissivity very closely. Based on considerations of thermodynamic equilibrium, it is simple to demonstrate that a blackbody is also a perfect radiator, which at any temperature emits in each part of the spectrum the maximum energy obtainable per unit time from any radiator of equal area, solely as a result of temperature. Both the total intensity and spectral distribution of the emitted energy depend only on the temperature of the blackbody radiation; this forms the basis of the thermodynamic temperature scale at high temperatures.

Absolute measurements of radiant power are difficult to make precisely. However, the measurement of the ratio of two radiant powers, say $E\left(T_{1}, \lambda\right) / E$ $\left(T_{2}, \lambda\right)$ where $T_{2}$ is a standard known temperature, could serve to define a temperature scale. This procedure was followed in establishing the IPTS above the gold ( $\mathrm{Au}$ ) point.

All classes of radiation pyrometers (optical, total radiation and two-color) are valuable instruments under any of the following conditions:

1) Temperatures are above the practical operating range of thermocouples

2) Environments exist which contaminate or limit the life of thermocouples

3) The targets are moving or not easily accessible

4) The targets would be damaged by contact with primary elements like thermocouples and resistance thermometers

5) It is desired to measure the average temperature of large surface areas.

For further details on radiation pyrometry see Reference 8, pp 69-94.

LME C-Me mo-68-10 


\section{Optical}

\section{a. General}

The measurement of the radiation from a hot body is the standard method of measuring high temperature. In most optical pyrometers the image of the hot body as seen through a telescope is projected onto the plane of the filament of an incandescent lamp. An observer matches the brightness of the image with the brightness of the filament by observing the "disappearance" of the filament. The lamp heating current is then a measure of the temperature of the body. Usually filters are employed to restrict the range of light wavelengths viewed, and a rotating sector mechanism may be used to reduce the brightness of the hot body image. The lamp filament is calibrated against a blackbody.

From Wien's law:

$$
J_{\lambda T}=C_{1} \lambda^{-5} e^{-C_{2} / \lambda T}
$$

where $J_{\lambda T}$ is the brightness at wavelength $\lambda$ of a blackbody at absolute temperature $T$. If the rotating sector transmits a fraction $X$ of the light from $a$ source at temperature $\mathrm{T}_{2}$, and this is matched in brightness against the light from a filament at $T_{1}$ at wavelength $\lambda$, then:

$$
\mathrm{XJ}_{\lambda \mathrm{T}_{2}}=\mathrm{J}_{\lambda \mathrm{T}_{1}}
$$

and

$$
\mathrm{X}=\frac{{ }_{\lambda \mathrm{T}_{1}}}{\mathrm{~J}_{\lambda \mathrm{T}_{2}}}=\frac{\mathrm{e}^{\mathrm{C}_{2} / \lambda \mathrm{T}_{2}}}{\mathrm{e}^{\mathrm{C}_{2} / \lambda \mathrm{T}_{1}}}
$$

so that

$$
\frac{\lambda \ln X}{\mathrm{C}_{2}}=\frac{1}{\mathrm{~T}_{2}}-\frac{1}{\mathrm{~T}_{1}}
$$

With $\lambda, \mathrm{X}, \mathrm{C}_{2}$, and $\mathrm{T}_{1}$ being known, $\mathrm{T}_{2}$ can be determined.

$$
\text { LMEC-Memo-68-10 }
$$


Neutral gray screens can be used instead of rotating sectors. One of the big problems in the use of this method is that most materials are not blackbodies, so that an emissivity correction has to be taken into account. Values of the emis sivity are not always well known. If the emissivity is independent of wavelength (a graybody), it is advantageous to compare the intensity of radiation at two wavelengths from the same body by means of a photocell. Filters or a monochromator may be used. The ratio of intensities at the two wavelengths is a function of the temperature (color temperature).

Thus the optical method furnishes an excellent way of measuring high temperatures. The use of this method in a reactor requires the provision of an optical path from the inside to the outside of the reactor, collimation of the light beam so that only the desired region will be seen, and absorption, contamination and scattering of light by hot carbon vapor and solid particles of condensed graphite in the optical path. Light can bebrought out of the instrument hole and through the pressure shell through a tube fitted with mirrors. It may prove to be more profitable to compare the intensity of emission at two wavelengths, rather than to attempt to measure the total emission of light. The two wavelengths method reduces absorption by carbon vapor and $C N$ to a minimum. The carbon arc spectrum suggests that $4900 \AA$ and $6800 \AA$ would be acceptable wavelengths.

A novel method of optical pyrometry has been developed by the Linde Air Products Company. It is intended for inaccessible regions. A light path is provided for emitted light by means of a sapphire (fused aluminum oxide) light guide. The light guide consists of a monoc rystalline rod which can be bent to fit the geometry of the design. The rod is fire polished and can presumably be passed through a pressure seal. Ordinary rod lengths are up to 18 in., but larger lengths can be fabricated on order. Thicknesses of the rods can be up to $1 / 4 \mathrm{in}$.

Artificial sapphire is colorless and has better light transmission than lucite. Its melting point is about $2000^{\circ} \mathrm{C}$. At $1500^{\circ} \mathrm{C}$, it is very resistant to chemical attack, though silicon produces a haze effect on the surface after long exposure (months). Thermal-shock resistance is reported to be sufficiently good to allow fire-polishing with a naked hydrocarbon-oxygen flame. Both absolute brightness and color temperature can be measured. The light can also be directed to a the rmopile.

LMEC-Memo-68-10 


\section{b. Polychromatic Pyrometry}

Another method worthy of consideration with respect to practical temperature measurements utilizes color, or polychromatic, pyrometry. The color temperature $T_{c}$ of a non-blackbody may be defined as the temperature at which it is necessary to operate a blackbody so that its radiation will match the visual color of the source being studied. In particular, if we choose two wavelengths (colors), $\lambda_{2}>\lambda_{1}$, in the 0.4 to $0.7 \mu$ range, we can measure a $T_{c}$ by taking the ratio of powers radiated from an incandescent body at the wavelengths $\lambda_{1}$ and $\lambda_{2}$. It may be shown that, in this situation:

$$
\frac{1}{\mathrm{~T}}-\frac{1}{\mathrm{~T}_{c}}=\frac{\ln \epsilon_{1} / \epsilon_{2}}{\mathrm{C}_{2}\left(1 / \lambda-1 / \lambda_{2}\right)}
$$

where $\epsilon_{2}$ and $\epsilon_{1}$ are the emissivities at the wavelengths $\lambda_{2}$ and $\lambda_{1}$, respectively. For both the blackbody and graybody, $\ln \epsilon_{1} / \epsilon_{2}$ vanishes and $T=T_{c}$. For most common materials, emissivity is a slowly decreasing function of wavelength in the visual spectrum. This means that the ratio $\epsilon_{1} / \epsilon_{2}$ is greater than, and not greatly different from, unity. Thus, $T_{c}$ is usually higher than, but not greatly different from, $T$. As an example, for tungsten, $T_{c}$ is 8 to $24^{\circ} \mathrm{C}$ higher than $\mathrm{T}$ in the range 800 to $1500^{\circ} \mathrm{C}$. (For $\lambda_{2} \sim 0.65 \mu, \lambda_{1} \sim 0.5 \mu$.) In the same range, $T_{B}$ varies from 41 to as much as $123^{\circ}$ lower than $T$. It must be realized, however, that for some important materials, $T>T_{C}$ and/or $\left(T-T_{C}\right)>\left(T-T_{B}\right)$.

There are a number of both laboratory and commercial models of two-color or ratio pyrometers. They all feature optical and electronic systems of some complexity, but with the advantages of direct (often linear) read-out and high sensitivity. Some experimental instruments have been constructed operating with three or more colors, thus requiring the measurement of multiple ratios. This scheme, along with that of shifting $\lambda_{1}$ and $\lambda_{2}$ to other regions of the spectrum (such as the infrared), has as its purpose the reduction of errors caused by excessive or anomalous emissivity variation with wavelength.

Total or panchromatic, radiation pyrometry is yet another method. Because of its nature and underlying principles, the radiation pyrometer ("total" will be understood) is the simplest to describe and perhaps the easiest to use and understand, but potentially the least accurate. As has been shown, it is possible to

$$
\text { LMEC-Memo-68-10 }
$$


measure the temperature of a source by measuring its radiant power output over some very large spectral range. This may be done by focusing the emitted radiation on an absorbing area, called the receiver, by means of a lens or mirror system. The temperature of the receiver rises until its own rate of heat loss is equal to its rate of absorption. This equilibrium temperature is seldom more than 30 to $40^{\circ} \mathrm{C}$ higher than the ambient, even for a very intense source. The significant fact is that, after equilibrium has been reached, a change in temperature of the source will produce a change in the temperature of the receiver, albeit a much smaller one, through the medium of the emitted radiation.

There are several schemes for transducing the temperature information of the receiver. Most commonly, a sensitive thermocouple or thermopile is connected to the small blackened metallic disc acting as a receiver, and the temperature changes are measured by the generated emf. The receiver can be a strip of blackened platinum or semiconducting material forming one arm of a resistance bridge, i.e., a bolometer. There are occasions when the receiver is a bimetallic spiral actuating a pointer, or a capsule in which gas pressure changes with temperature.

Speaking in more general terms, there is no need for the source power to be translated into thermal changes at all. Photosensitive detectors may be used to respond to the direct radiation impinging upon them. This class of device will have a much shorter response time and potentially higher sensitivity, but the latter varies widely with wavelength. In fact, the bandwidth of photosensitive detectors classifies them somewhere between the narrow-band optical and color pyrometers and the wide-band thermal radiation pyrometers. For this reason, these instruments are sometimes called partial-radiation pyrometers. At any rate, the thermoelectric radiation units are the most widely used in their class and have the advantages of ruggedness, relative immunity from damage by high ambient temperature and the aforementioned sensitivity over wide wavelength ranges.

\section{Emission Spectroscopy}

A typical example of emission spectroscopy involves the measurement of the relative intensity of spectral lines emitted in the optical and ultraviolet region by a radiating species of the gas or plasma. Using Boltzmann statistics

LMEC-Memo-68-10 
and the theory of atomic spectra, the relative intensity of two spectral lines from the same element is $I_{R}=k_{1} \exp \left(k_{2} / T\right)$ where $k_{1}$ is a constant involving the statistical weights, transition probabilities, and frequencies of the lines and $k_{2}$ is a constant proportional to the differences in energy levels $\Delta E$ of the states represented by the lines. A plot of $\ln I_{R}$ vs $1 / T$ will give a straight line of slope $k_{2}$; $T$ may be measured by determination of $I_{R}, k_{1}$ and $k_{2}$. Sensitivity of the measurement will depend on the value of $\mathrm{k}_{2}$, all other things being equal. It is therefore necessary to select two lines where $\Delta E$ is large, but still within the wavelength span of the spectrograph, and also within the intensity span that can be accommodated by the film emulsion and densitometer on a single exposure. Sometimes the direct method is prohibited by lack of a suitable spectrum, or for other reasons. In this event, there are the indirect determinations based on measurements of Doppler or Stark effect broadening of spectral lines, of cyclotron radiation, and using probe techniques - employing microwaves, thermal neutrons or magnetic search coils.

\section{Infrared Photography}

Where relative temperature information over a broad expanse of area is desired, such as the temperature gradations in a multitube radiator, a photographic technique can prove to be simpler, faster, less expensive and more informative than a number of thermocouples.

To obtain temperature data more easily, viewing ports were installed in the heat sink of one such radiator so that it could be observed during operation. Photographs were taken of the radiator using $9000 \AA$ Polaroid infrared-sensitive film. Results indicate that substantial temperature differences existing within the radiator unit were easily seen, and that liquid collecting at the discharge end of the radiator was detected by temperature measurement. Where there was no evidence of any substantial temperature change along or across the tubes, it was concluded that liquid had not accumulated in the tubes or headers. But where the liquid headers were no longer visible in the film, this was taken as an indication that a substantial reduction in temperature had occurred along the tube. In one case a temperature drop of approximately $125^{\circ} \mathrm{F}$ occurred across the indicated sharp color change.

LMEC-Memo-68-10 
With the use of reference thermocouples and careful control of film exposure times, a color vs temperature gradient relationship can be established.

\section{THERMAL EXPANSION OF MATERIALS}

\section{Liquid Thermometers}

a. General. Probably the most widely used temperature measuring device in both science and industry is the liquid-in-glass thermometer. This instrument, filled with a liquid such as mercury, toluene, alcohol, or pentane, depends for its operation on the relatively large temperature-dependent volume expansion of the liquid and the much smaller expansion of the glass container. The mercury unit can be used from $-38^{\circ} \mathrm{C}$ (its freezing point) to about $600^{\circ} \mathrm{C}$. This latter temperature is well above the boiling point of mercury, so an inert gas at positive pressure must be used as a filler. Furthermore, special glasses with high softening temperatures are required for such measurements. To extend the low temperature range downwards, the other liquids come into use; some pentane thermometers have been used down to $-196^{\circ} \mathrm{C}$.

Because of the generally small cross-section and short scale-length of the capillary column, various artifices have had to be developed to ove rcome reading difficulties in the liquid-in-glass thermometers. Coloring agents in the liquid or in the capillary tubing, magnification of the liquid column by a lenslike glass tubing, and minimizing of glare and reflection, have all proved to be effective. Another difficulty, separation of the liquid column into two or more parts, can usually be taken care of by proper manipulation.

Some thermometers are designed to read correctly only when the bulb and entire liquid-filled stem are exposed to the environment to be measured; others require only the bulb and a short length of the stem to be immersed. Because the latter, or partial-immersion types, are often used with stem temperatures greatly different than bulb temperatures, they are not as accurate as the totalimmersion thermometers. Emergent-stem corrections are often determined for total-immersion units used at partial immersion.

b. Differential Measurements. There are many areas of temperature measurement where the accuracy at any one temperature is not as important as the accuracy of the temperature interval. Beckmann and calorimetric thermometers

LMEC-Memo-68-10 
are constructed so as to provide accurate differential measurements in various different temperature ranges by addition or removal of portions of the liquid from the bulb. Granting that these units are more expensive and complex than others of their class, it is still safe to say that liquid-in-glass thermometers owe their popula rity to low cost, simplicity, high reliability, and long life (assuming accidental breakage to be the exception rather than the rule).

\section{Gas Thermometry}

It is possible to measure: (1) the volume change of a permanent gas at constant pressure; (2) the pressure change of a permanent gas at constant volume; and (3) change of vapor pressure in presence of the condensed phase. Method 3 is especially sensitive, but the temperature range for any given thermometric substance is correspondingly limited.

In the high temperature range and at the pressures encountered in reactors, the ideal gas law will be fairly accurate for permanent gases, so that the readings in methods 1 and 2 will be proportional to the absolute temperature in accordance with the General Gas Law:

$$
\frac{P V}{T}=\text { constant }
$$

In method 3 the vapor pressure $P$ is related to the absolute temperature $T$ by the equation

$$
\log P=A-\frac{B}{T}
$$

where $A$ and $B$ are specific constants for each material.

In principle, gas thermometry can be used at all temperatures. However, at high temperatures there are great practical difficulties. First, the gas has to be contained in a strong, rigid, gas-tight container, there are no materials which would fulfill these conditions at temperatures of the order of $2500^{\circ} \mathrm{K}$. Second, a gas thermometer measures temperature over the entire volume of the gas. In methods 1 and 2, the average temperature of the gas is measured; method 3 measures (under equilibrium conditions) the temperature of the liquidgas interface. If the proposed device is to measure the temperature of a small

$$
\text { LMEC-Memo-68-10 }
$$


region, the gas volume must be kept very small. In reactors, this means that the entire gas volume must be deep inside the reactor giving rise to the problem of how to get the signal out.

In method 1 a movable manostat, such as a piston, is needed. A gas-tight piston could be connected rigidly to a recording device in the cool region. If a piston were to move at least $1 \mathrm{~mm}$ per $100^{\circ} \mathrm{K}$ in the $2500^{\circ} \mathrm{K}$ range, the total volume of gas is of the order of $1 \mathrm{ml}$, so that a $100^{\circ} \mathrm{K}$ rise in the temperature means a volume increase of $0.04 \mathrm{ml}$. The area of the piston head is then at most $0.4 \mathrm{~cm}^{2}$. This appears feasible. The question of a gas -tight container and a gas-tight fit between piston and container is, however, more difficult. It can be safely predicted that if a tight fit is indeed achieved at low temperatures, the piston and barrel will sinter together when high temperatures are reached. Therefore, method 1 appears to be impractical. Methods 2 and 3 depend on the development of a high-temperature pressure transducer.

\section{Bimetals}

A bimetal thermometer takes advantage of the differential expansion of two solids. If the solids a re two joined strips, curvature will result which can be readily measured. Readings will be reproducible only if the elastic limit of the materials is not exceeded, so that there is little or no mechanical hysteresis. This is a condition which is difficult to fulfill at high temperatures, at which elasticity of metals is very low. Sagging and multiple bending are to be expected.

Operation to as high as $500^{\circ} \mathrm{C}$ is feasible using a high nickel-content invar vs a nickel-chromium-iron alloy. At temperatures below $-100^{\circ} \mathrm{C}$, sensitivity drops off rapidly because the coefficients of expansion of the metals approach each other. Bimetal thermometers have many advantages; they are available in both short and long temperature spans; they usually can be over-ranged without harm; they will retain their accuracy (as high as $1 / 2 \%$ ) indefinitely if handled with reasonable care, and are easy to reset if recalibration is necessary; they are easier to read, less subject to breakage and do not require stem corrections, as compared with liquid-in-glass thermometers. If the strip is coiled into a helix or spiral, then temperature changes will produce a change in the curvature of the strip. As long as the strain thus produced does not exceed the elastic limits of the metals, the change in curvature can be translated into an angular 
deflection, directly and reproducibly proportional to the temperature change. Obviously, the materials involved in the bimetal element are very important.

4. Filled-System Thermometers

Filled-system the rmometers, using temperature-induced liquid or gas expansion effects, are made up of four classes, according to filled material. The Scientific Apparatus Manufacturer's As sociation has established Class I, liquid-filled; Class II, vapor pressure (partial filling of a volatile liquid); Class III, gas-filled; and Class V, mercury-filled. There is no Class IV, and Class V is a special case of Class I. All classes are somewhat similar in appearance, construction and operation. They make common use of a bulb, a connecting capillary and a mechanism, usually a bourdon tube, which responds to changes in pressure or volume of the filling fluid. The bourdon is mounted in a case with a mechanical linkage to a pointer or pen to provide read-out on a suitable scale or chart. Some systems incorporate a compensating capillary and bourdon tube to correct for ambient changes along the capillary and at the case. Choice of a particular class depends on the application involved. Factors to be considered include maximum and minimum temperatures, size of temperature span desired, speed and linearity of response, sensitivity, accuracy and cost. As an example, the most common system, the Class I, is usually filled with an inert hydrocarbon, generally permits small bulb size, uniform scale graduation and spans as narrow as $10^{\circ} \mathrm{C}$ (but only at the expense of small bulb size, since the two are inversely related). Class I systems are usually restricted to operation in a temperature range of $-80^{\circ} \mathrm{C}$ to $250^{\circ} \mathrm{C}$, not as wide a range as Classes III and V. They require compensation, unlike Class II, but this can be done fairly accurately. They are notas low-cost or as fast-responding as Class II. From these comparisons, one can see the importance of application requirements to the choice of filled system thermometers.

\section{E. VARIATIONS IN DIELECTRIC CONSTANTS}

The dielectric constants of insulators show a marked temperature dependence, since the orientation polarization, which is due to the dipole moment of the molecule, is inversely proportional to the temperature:

LMEC-Memo-68-10 


$$
\begin{aligned}
& \frac{D-1}{D+2}=\frac{\rho}{M}\left(P_{D}+P_{O}\right) \\
& P_{O}=4 \pi N / 3\left(\mu^{2} / 3 k T\right)
\end{aligned}
$$

where

$$
\begin{aligned}
D & =\text { dielectric constant, } \\
\rho & =\text { density } \\
M & =\text { molecular weight }, \\
P_{D} & =\text { distortion polarization, } \\
P_{O} & =\text { orientation polarization, } \\
N & =\text { Avogadro's number, } \\
\mu & =\text { dipole moment, } \\
k & =\text { Boltzmann's constant, and } \\
T & =\text { absolute temperature. }
\end{aligned}
$$

This method has been used for measuring temperatures, but is especially applicable to materials of high dipole moment at low temperatures. At high temperatures $\mathrm{P}_{\mathrm{O}}$ becomes relatively insignificant compared with $\mathrm{P}_{\mathrm{D}}$; moreover, most insulators fail and become conductors.

\section{F. THERMIONIC EMISSION}

The thermionic emission current from the surface of a hot metal is highly temperature-dependent:

$$
I=A T^{2} e^{-B / T}
$$

One advantage is that the electrical signal is built in. Unfortunately, however, the method requires a good vacuum and this cannot be attained in an allhot system. In the presence of appreciable quantities of vapors, the emitting surface is poisoned and the electron path is no longer collision-free.

LMEC -Me mo-68-10 


\section{G. ACOUSTIC METHODS}

1. Velocity of Sound in Gas

The velocity of sound, $w$, in a perfect gas is related to the Kelvin temperature $\mathrm{T}$ by $\mathrm{w}^{2}=(\gamma \mathrm{R} / \mathrm{M}) \mathrm{T}$ where $\gamma$ is the specific heat ratio, $\mathrm{R}$ the universal gas constant, and $M$ the molecular weight of the gas.

A typical experimental realization of this equation makes use of two transducers, spaced at a known distance, with circuitry for continuously measuring the delay time of an ultrasonic wave generated by one transduce $r$ and received by the other. This technique thus reduces temperature measurement to a time measurement, a great advantage because of the high accuracy with which the latte $\mathbf{r}$ parameter may be determined. In addition, because the gas itself is the thermometer element, very rapid temperature changes may be followed, and errors normally introduced by thermometer elements (heat leaks, thermal lags, etc.) are absent. Of course there are the attendant difficulties: departure of the gas from ideality; the necessity for accurately determining $\gamma$; the dependence of $w$ on pressure, which must therefore be corrected; and the fact that instead of measuring point temperature, an average temperature over the path is being determined.

2. Frequency-Change ${ }^{(9)}$

A single transducer-probe penetrates a furnace, terminating in a free end. Standing waves are established in the probe by the attached transducer, the wavelength predetermined by the length and material of the probe. Attached to the transducer is a sensing crystal, the output voltage from which is fed into a power amplifier, thus producing sinusoidal oscillatory energy by the principle of electrical feedback. The output impedance of the amplifier is properly matched to the impedance of the transducer to secure maximum power transfer.

With the amplifier operating, any random disturbance in either the acoustic or the electronic system produces a transient output voltage from the crystal, which, amplified and applied to the transducer, in turn excites the crystal at higher amplitude. Since those vibrations which are at the resonant frequency of the acoustic system will be strongest, vibration of the system will theoretically be sustained at the resonant frequency.

LMEC - Me mo-68-10 


\section{Phase-Relation (9)}

Two coupler rods are attached to a transducer. One of the rods is enclosed, for part of its length, in a resistance furnace; the other is at a fixed temperature. Both rods terminate in acoustically perfect loads. If the two transmission lines are identical and if both are maintained at identical temperature, traveling waves in each will be in phase at points equidistant from the point of attachment to the common coupler. If a measured section, 1 , of one of the lines is heated, the velocity of sound in this section will decrease, resulting in a change in phase between the heated section and the load.

The phase angle between the two traveling waves is given by the relation:

$$
\varphi=2 \pi f\left(\frac{1}{c}-\frac{1}{c_{0}}\right) \text {, }
$$

where

$$
\begin{aligned}
& \varphi=\text { phase angle between the traveling wave (radians), } \\
& \mathbf{f}=\text { driving frequency }(\mathrm{kcps}) \\
& 1=\text { length of heated section }(\mathrm{cm}), \\
& \mathrm{c}=\text { velocity of sound in the heated section }(\mathrm{cm} / \mathrm{sec}), \text { and } \\
& c_{0}=\text { velocity of sound in the unheated section }(\mathrm{cm} / \mathrm{sec})
\end{aligned}
$$

If the phase difference between the signals from two sensing crystals can be measured by means of a phase detector, variation in the temperature of the heated section can be calculated from the variation in the phase angle.

\section{Spark Gap}

Another mechanism uses two spark gaps. The sonic wave from a spark across the first gap introduces a discontinuity in a discharge across the second. The propagation time for the wave to travel the intervening space thereby provides a measure of the temperature of that space. This method may be rendered impractical by the presence of ionizing radiation. Charge leakage across the spark gap and its leads would probably render it inoperative. The usual high temperature insulation and dimensional problems are also expected.

LMEC - Memo-68-10 
The amount of charge leakage naturally depends on the voltage applied and the intensity of the radiation. At high enough voltage $(1000 \mathrm{v})$ and intensities it is possible to get a total discharge when a gamma ray passes through the spark gap, an effect similar to that observed in a spark discharge counter.

\section{H. THERMOCHEMICAL}

These techniques depend on measuring an equilibrium or reaction rate, the temperature dependence of which is known. The number of reactions which have been investigated at very high temperatures is small; mostly they are gas reactions; for example, the reaction $\mathrm{N}_{2}+\mathrm{O}_{2}=2 \mathrm{NO}$. Reference 3, Section 2.5 , discusses this method in greater detail.

\section{FIXED POINT}

By their nature, these methods measure only one temperature, the one at which the phase change occurs. Although this makes them unsuitable for a continuous temperature-measuring device, the possibility of using a fixed point as an indicator of undue or catastropic temperature rise should not be ignored. Such a device could be made very simple to serve as an alarm. It may consist of a wire of arbitrary high melting point, which completes an electrical circuit. The leads can be rods of a very high-melting material such as zirconium carbide or tantalum carbide. For high temperature, the wire could be a tungstenmolybdenum alloy. Tung sten and molybdenum form a continuous series of solid solutions, with melting points varying continuously from 2620 to $3380^{\circ} \mathrm{C}$, and the desired failure point can be chosen anywhere in this range.

Practical problems for such a device resemble those encountered in a thermocouple assembly: the leads must be prevented from shorting and the wire must be protected from chemical change. It is possible that shorting could be avoided by inserting the leads through two adjacent instrument holes and passing the wire between the holes horizontally. The second condition is more difficult. Carburization of tungsten and molybdenum leads to the formation of lower-melting eutectics. If a carbide is used, the melting point may still be changed by the absorption of carbon. For instance, TaC (melting point $3800^{\circ} \mathrm{C}$ ) forms a eutectic with carbon ( $10 \% \mathrm{C}$ by weight) with a melting point of $3300^{\circ} \mathrm{C}$. If, on the other hand, a eutectic composition is used, deviation from

LMEC-Memo-68-10 
the initial composition will result in a raising of the liquidus point. However, some liquid phase will always form at the melting point of the eutectic, and it is probable that circuit failure will result. A method must also be found to prevent a spurious signal from being produced by shorting through the body of the reactor.

\section{J. PHOSPHOR LUMINESCENCE}

This method utilizes the decrease of luminescent efficiency of a phosphor with increasing temperature. This is a very sensitive technique since the efficiency may decrease by several percent per ${ }^{\circ} \mathrm{C}$. For instance, a $\mathrm{ZnS}-\mathrm{CdS}$ phosphor decreases in efficiency by a factor of 100 when heated from 5 to $40^{\circ} \mathrm{C}$. This method has no known high temperature applications because of material difficulties.

\section{K. NOISE GENERATED IN ELECTRICAL ELEMENTS}

Noise in an electrical circuit can be reduced only to a finite lower limit. At this limit the residual noise (Johnson noise) is due to the random unevennesses in electron distribution, a phenomenon analogous to the Brownian motion. The uneven distribution gives rise to a small voltage. While the time average of the voltage is zero (because displacement is equally likely in all directions), the time average of the square of the voltage is not, and is given by the Nyquist equation:

$$
d\left(\bar{v}^{2}\right)=4 k T \operatorname{Re}[Z(f)] d f
$$

where

$\operatorname{Re}[Z(f)]=$ the real part of the complex impedance $Z(f)$, a function of the frequency $f$,

$k=$ Boltzmann's constant $\left(\mathrm{R} / \mathrm{N}_{\mathrm{o}}\right)$,

$\mathrm{T}=$ the absolute temperature, and

$d\left(\bar{v}^{2}\right)=$ the contribution to $\bar{v}^{2}$ of the frequency range of width df at $f$.

The total noise is obtained by integrating over the frequency range.

LMEC-Memo-68-10 
When two circuits consisting of a parallel combination of a resistance and a capacitance are equated, it can be shown that the ratio of the integrals

$$
\int_{0}^{\infty} \operatorname{Re}[Z(f)] d f
$$

is equal to the ratios of the resistances. Thus, if the noise levels in the two circuits are equal, the temperatures of the two resistors are inversely proportional to their resistances.

In such an instrument, the resistor is typically a platinum wire welded to platinum leads, and shielded by a platinum sheet. There appears to be no reason, however, why a higher melting metal could not be used.

The use of this instrument depends, of course, on the elimination of all parasitic voltages and sources of nonrandom noise. Thermoelectric junctions, grid currents, and net thermionic emission must be eliminated. In the present case, considerable interference may be expected due to radiation effects. Since electron displacements due to gamma-radiation are large, it would seem that even a moderate dose rate would have a disproportionately great effect on the average of the squares of the displacements. The dose rate dependence of the noise could be obtained theoretically, so that the use of the noise thermometer cannot be eliminated on this basis alone.

Accuracies obtained under laboratory conditions are of the order of 0.3 to $0.5 \%$ at $700^{\circ} \mathrm{C}$. Response time is not good, as a time of the order of $500 \mathrm{sec}$ is required to attain good balance.

Even under optimum conditions, use of this method requires the insertion of a resistor wire with shielding of the same material into the instrument hole. The resistance must stay constant. Thus the noise method is not expected to be completely satisfactory.

\section{DIFFUSION}

The diffusion of gases through orifices and the diffusion of solutes through semi-porous membranes are both temperature dependent. For high temperatures, the former method is the one that is applicable.

\section{LMEC-Memo-68-10}


The number of molecules of an ideal gas hitting a surface of area dA per sec is:

$$
\mathrm{d} \mathbf{n}=\frac{3}{13} \overline{\mathrm{u}} \rho \mathrm{d} A
$$

where $\bar{u}$ is the root mean square velocity and $\rho$ the number of molecules per unit volume.

$$
\begin{aligned}
& \text { Substituting } \overline{\mathrm{u}}=\sqrt{3 \mathrm{PN}_{\mathrm{o}} / \mathrm{M} \rho} \text { and } \rho=\mathrm{PN}_{\mathrm{o}} / \mathrm{RT} \text {, } \\
& \mathrm{dn}=\frac{3}{13} \mathrm{PN}_{\mathrm{o}} \sqrt{3 / \mathrm{MRT}} \mathrm{dA}
\end{aligned}
$$

where

$$
\begin{aligned}
& N_{0}=\text { Avogadro's number, } \\
& P=\text { the pressure, } \\
& \mathrm{R}=\text { the gas constant, } \\
& \mathrm{T}=\text { the absolute temperature, and } \\
& \mathrm{M}=\text { the molecular weight. }
\end{aligned}
$$

Thus, at constant pressure, $d n$ is inversely proportional to the square root of the temperature.

A temperature probe utilizing the diffusion principle may be constructed as follows: a long U-tube of a high melting material such as tungsten would be inserted into the reactor. At the point at which the temperature is to be measured, a partition is placed across the tube and a diffusion pinhole is made in the partition. The gas pressure is maintained at a constant level on one side of the partition and is pumped down to a near-zero value on the other side. The steady-state volume of air pumped through the partition then is an index of the temperature. For example, to obtain $10^{-4}$ moles $/ \mathrm{sec}$ of gas $(2.24 \mathrm{ml}$ at STP) per sec, for $P=20$ atm, $M=40$ (argon), $T=2500^{\circ} \mathrm{K}$. Putting all quantities in cgs units, we get for $\Delta A$ :

LMEC-Me mo-68-10 


$$
\begin{aligned}
\Delta \mathrm{A}=\frac{13 \sqrt{\mathrm{MRT}} \mathrm{n}}{\mathrm{PN} \sqrt{27}} & =\frac{13 \times 6 \times 10^{19} \sqrt{40 \times 8.3 \times 10^{7} \times 2.5 \times 10^{3}}}{20 \times 10^{6} \times 6 \times 10^{23} \times 5.2} \\
& =3.6 \times 10^{-5} \mathrm{~cm}^{2} \text { or } 0.0036 \mathrm{~mm}^{2}
\end{aligned}
$$

A larger area will give a larger volume of gas, e.g., if the area of the pinhole is $0.36 \mathrm{~mm}^{2}$, the volume of gas pumped through will be $224 \mathrm{ml} / \mathrm{sec}$ at STP. Under such conditions, the pumping efficiency might be the limiting factor. For small hole area, however, the instability of the contour of the hole at high temperatures is obviously the limiting factor, especially since a small change in effective hole area can simulate a very large change in temperature (e.g., a $10 \%$ enlargement of the hole will simulate a $475^{\circ} \mathrm{K}$ drop in temperature).

\section{PNEUMATIC APPARATUS}

The volume flow rate of a gas through a nozzle (above a certain critical value) is proportional to the square root of the temperature. By comparing flow rates through two successive nozzles, the second being at a known temperature, the temperature at the first nozzle can be estimated. This method, of course, is not suitable for the measurement of temperature in small volumes.

This technique has been studied for making in-reactor high temperature measurements. Its temperature is limited by stable nozzle-flow performance, however, it should be unaffected by prolonged exposure to temperature and to radioactivity. For further details see Reference 10, Section 20.

\section{N. PYROMETRIC CONES, TAPES, AND PAINTS}

\section{Pyrometric Cones}

Pyrometric cones are ceramic compositions with specific melting behavior. The melting point is not quite fixed, but varies somewhat with the rate of heating. Each cone can be used only once and is essentially a kind of fixed point method.

Pyrometric cones and Holdcroft bars are made of such mixtures of materials that deform at reaching temperatures characteristic of these mixtures.

LMEC-Me mo-68-10 
assuming the heating is done at a specified rate. These devices are very popular in the ceramic industries, where use is made of a whole series of cones, covering the range of about 600 to $2000^{\circ} \mathrm{C}$.

\section{Tapes and Paints}

The melting points of paints, crayons, pellets, and tapes and the change in color of temperature-sensitive paints, are the basis for other methods of singletemperature measurements. They are often used as low cost, expendable temperature limit monitors.

\section{O. PYROELECTRICITY}

The phenomenon of pyroelectricity, like its better-known sister piezoelectricity, makes use of the spontaneous polarization of materials such as ferroelectrics. Where the latter depends on mechanical stress to achieve a change in polarization, the former utilizes variations in temperature to produce the same result. For a given material fabricated into a capacitor of suitable dimensions, the measurement of $\Delta t$ depends on a measurement of charge $\Delta q$ on the capacitor. With the aid of an instrument, like a vibrating-reed electrometer, to sense $\Delta q$, it is possible to measure temperature changes as small as a millionth of a degree. Such a sensitivity would be very useful in calorimetric measurements of many kinds, and for sensing elements in radiation detectors and thermometers. Furthermore, since $\Delta q \propto \Delta t$, the time derivative of temperature could be directly determined by a measurement of current in the pyroelectric transducer. Materials of high pyroelectric coefficients have been studied over the temperature range of $4.2^{\circ} \mathrm{K}$ (colemanite) to more than $1400^{\circ} \mathrm{C}$ (barium zirconium metaniobate).

\section{P. MICROW AVE RESONANT CAVITIES}

Two methods using microwaves to measure in-reactor temperature are appropriately sensitive and could be used to provide long-lived in-core temperature measurements.

Experiments with the Frequency Shift method demonstrated a sensitivity of $310 \mathrm{kHz} /{ }^{\circ} \mathrm{C}$, with a nearly linear response over the temperature range of 30 to $1000^{\circ} \mathrm{C}$. This method measures the change in resonant frequency of a 
cavity resonator as a function of dimensional changes with temperature. With current methods available for measuring $\mathrm{RF}$, a precision of $0.05^{\circ} \mathrm{C}$ at $1000^{\circ} \mathrm{C}$ is feasible.

In the Radiometer method, the natural microwave radiation from a blackbody is measured with a sensitive broadband receiver.

A common problem with both techniques is the corrosion of sensors and input waveguide at elevated temperatures. Partial solution of this problem can be provided by evacuating the sensor and waveguide. Further work must be done to establish protective measures for the exterior of the metal components. For further details see Reference 11 . 


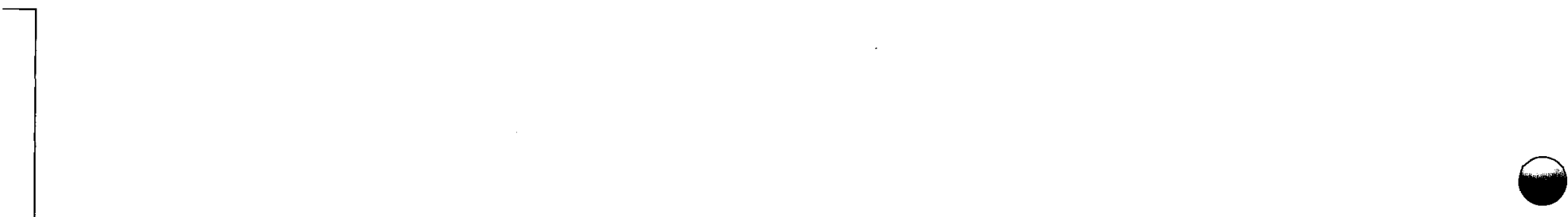

0 


\section{EFFECTS OF LIQUID METAL REACTOR ENVIRONMENTS ON TEMPERATURE MEASUREMENT INSTRUMENTS}

In addition to the chemical and physical effects of association with high temperature liquid metal there are a number of other effects on temperature devices to be considered. These are: radiation-induced changes in the characteristics of the device, radiation-induced spurious signals, vibration, erosion, and corrosion effects.

\section{A. RADIATION DAMAGE}

A high energy particle passing through solid matter may collide or interact with atoms of the solid material. This slows the particle, the energy of interaction being transferred to the atoms. These atoms in turn transmit energy by vibration to their neighbors. Thus a region of high temperature material is left in the tract of the particle, the so-called thermal spike, which may disrupt the lattice locally. Many atoms of the material may be permanently displaced from their normal positions in the lattice and come to rest at new positions, giving $r$ ise to holes and interstitials. Electrons are detached from a parent atom and are captured by other atoms creating ionizations. Neutrons may be captured, forming new isotopes which are impurities. Obviously these phenomena will affect the macroscopic properties of the medium. Thus the effects of radiation (in addition to bulk heating effects) are the production of vacancies, interstitials, impurity atoms, and high local temperatures.

These effects can be roughly grouped into displacement effects and ionization. In a good conductor, ionization effects rapidly disappea $r$ since electrons may migrate relatively freely. In insulators the ionization effects disappea $r$ much more slowly, the rates being, of course, temperature dependent. Dis placement of atoms will result in changes in the mechanical properties of all materials and especially affect the energy level configurations in semi-conductors.

The macroscopic properties most often measured as a function of radiation dosage are electrical conductivity, thermal conductivity, and hardness. The reason for measuring conductivity, which generally decreases with increasing dosage in metals, is to obtain a measure of the number of additional electron scattering centers introduced into the medium (shortening of the mean free path).

\section{LMEC-Memo-68-10}


The the rmal conductivity is affected similarly. The hardness of a material is usually a measure of the number of dislocations and the interference among dislocations existing in a medium (strain hardening).

As far as thermocouples are concerned, at a dosage of $10^{15} \mathrm{n} / \mathrm{cm}^{2}$ metals, refractory metal compounds, and insulators are little affected. However, the thermoelectric power of any couple which depends upon $\mathrm{S}_{1} \mathrm{C}, \mathrm{B}_{4} \mathrm{C}$, or $\mathrm{C}$ for one of its elements may be seriously affected. These materials have many of the attributes of semiconductors, and it is expected that their electronic properties would be more seriously changed by radiation damage.

\section{B. RADIATION HEATING}

In the thermocouple the junction and wires might be heated by the absorbed radiation at a rate different from that of the surrounding medium. If this is so then the actual temperature of the junction may be higher or lower than the bulk temperature of the medium. This type of heating is in addition to the normal methods of heat transfer to the couple. As an example, in a flux of $10^{12}$ gammarays $/ \mathrm{cm}^{2}-\mathrm{sec}$, assuming an energy loss of $1 \mathrm{mev}$ per event degraded into heat yields about $0.13 \mathrm{w} / \mathrm{cm}^{3}$ in tungsten. Heating due to fast neutrons may bring this figure up to about $0.2 \mathrm{w} / \mathrm{cm}^{3}$. At high temperatures the heat capacity of tungsten is about $1.0 \mathrm{cal} / \mathrm{cm}^{3}-{ }^{\circ} \mathrm{C}$. Thus the rate of heating is about $0.05^{\circ} \mathrm{C} / \mathrm{sec}$, which is reasonably small compared with heating rates to be encountered in the reactor, so that the normal mechanism of heat transfer to a typical thermocouple should control its temperature.

\section{DIFFERENTIAL COMPTON CURRENTS}

A spurious signal may be generated in the thermocouple leads if charge is lost differentially in the two wires. If, in the worst case, charges were lost in only one lead due to gamma interactions, for a wire $0.3 \mathrm{~mm}$ in diameter and $130 \mathrm{~cm}$ of active length, (and a radiation as in Section B., preceding) a current of $1.2 \times 10^{-8}$ amp would flow. For a total thermocouple resistance of $100 \mathrm{ohms}$ the error emf will be in the order of $1 \mu \mathrm{v}$.

\section{IONIZATION CHAMBER EFFECTS}

The passage of ionizing radiation through the gas space surrounding the wires of a thermocouple will produce free electrons and ions. If these electrons

$$
\text { LMEC-Memo-68-10 }
$$


and ions are free to move they may migrate to the wires and their movement then corresponds to a current between the wires, tending to shunt the signal from reaching an outside indicator.

A typical effect in a gamma flux of $10^{12}$ gamma-rays $/ \mathrm{cm}^{2}-\mathrm{sec}$ for a total surface area for wires of $2.5 \mathrm{~cm}^{2}$ would be calculated as $4 \times 10^{-8}$ amp (see Reference 3, Chapter IV). If the resistance of a the rmocouple circuit is 100 ohms (a high value is used to allow for thin spots which may develop), the voltage change would then be $4 \mu v$, or less than a 1 -degree error.

\section{E. THER MIONIC EMISSION}

It is conceivable that at high temperatures there will be a differential thermionic emission from the two materials of which a thermocouple is composed. Little data is available on the thermionic emission of metals under high gas pressure conditions. With no accelerating fields present the effect is very much reduced. However, this effect is common to thermocouples operating in other high temperature environments and apparently has not caused noticeable errors in readings.

\section{F. WATER CYCLE}

If water vapor is present, a complicated series of chemical reactions with the metals and insulators can be expected to occur at high temperatures. The net result is oxidation of metal surfaces. The oxide then volatilizes and is reduced at a cooler surface, freeing the metal. This series of reactions, besides perhaps inducing electrochemical potentials, would increase the circuit lead resistance, thus enhancing other spurious signals, and perhaps introduce shunt leakage paths across insulators.

\section{G. ELECTROSTATIC EFFECTS}

The reactor body will be subjected to rather large frictional and erosive forces, which may tend to create large local electrostatic potentials. These may be induced into thermocouple wires and perhaps cause ground currents, etc., which are only important here because of the necessity of transmitting a rather small emf over a large distance to an indicator.

LMEC-Memo-68-10 


\section{H. CHEMICAL EFFECTS}

As an example of a drift effect introduced by chemical action, it must be remembered that carbon will react with tungsten to form a carbide on the surface of the tungsten wire, and that the carbide is a metallic conductor. If this occurs at a thermocouple junction a new thermocouple is formed consisting of the carbide in parallel with the main tungsten wire. The emf of the $\mathrm{Mo} / \mathrm{W}_{2} \mathrm{C}$ junction is undoubtedly different from that of the Mo/W junction, so that shunting effects may occur, leading to drift in the thermocouple output.

Moreover, if the continuity of the tungsten wire is interrupted because carbide is formed all the way through the wire, the emf of the original thermocouple may not be measured at all.

\section{VIBRATION}

Vibration effects will be mainly important because the materials of which any sensing unit is made will be fairly plastic at very high temperatures. Vibration, assisted by gravity, may then deform or distort the device materials so that they might short out, or move to undesired configurations.

Local flexure, inasmuch as it effects strain hardening, fatigue, or local heat generation, is not expected to be of serious concern at high temperatures because all effects are soon annealed out.

LMEC-Memo-68-10 


\section{LITERATURE SURVEY}

\section{A. THER MOCOUPLE DEVELOPMENT FOR PROJECT ROVER, $2500^{\circ} \mathrm{C}$}

Project Rover seeks to achieve rocket propulsion through the use of a nuclear reactor to heat hydrogen propellant gas. In order to study the thermal behavior of the reactor core (i. e., heat exchanger) it is desirable to measure the graphite-uranium fuel temperatures at many locations simultaneously. Thermocouples appear to be the only practical way of doing this. The thermocouples, of lengths ranging to $60 \mathrm{in.}$ and diameters limited to about $1 / 8$ in., have to withstand hydrogen and graphite at as high temperatures as possible, in the presence of a strong nuclear radiation flux.

The thermocouples best able to stand the environment appear to be $\mathrm{W}$ vs $\mathrm{W}-26 \mathrm{Re}$, insulated by $\mathrm{BeO}$, and encased in a molybdenum or tantalum sheath. It is hoped ultimately to be able to measure temperatures in the vicinity of $5000^{\circ} \mathrm{R}\left(22500^{\circ} \mathrm{C}\right)$ with errors no worse than a few percent.

Figure 28 shows two advanced concepts for reactor core thermocouples. Each of these is to be cooled to within a few inches of its thermal junction. In the bifilar version insulators are shown staggered to increase inter -wire resistance. The coaxial version has no insulators at all in the tip region.

Ultimately it is expected that the maximum dose rates to be experienced by the thermocouples will be $\approx 2.5 \times 10^{16} \mathrm{n}_{\mathrm{f}} / \mathrm{cm}^{2}-\sec (\mathrm{E}>50 \mathrm{kev})$ or $\approx 2 \times 10^{16}$ $\mathrm{Mev} / \mathrm{cm}^{2}$-sec and $\approx 2 \times 10^{7} \mathrm{rad} / \mathrm{sec}$ of gamma rays. The integrated doses will be $\approx 10^{20} \mathrm{n}_{\mathrm{f}} \mathrm{vt}$ and $\approx 10^{11} \mathrm{rads}$ of gammas. It is believed that the se doses are not sufficient to affect materially the output of the thermocouples. As with all parts of the reactor, the thermocouples would melt if not properly cooled.

Rough calculations and a test in the Omega West Reactor have shown that radiation contributions to the shunt effect, either through gaseous conduction or ionization in the $\mathrm{BeO}$, should not be significant in comparison to the thermal shunt effect discussed in the preceeding text.

\section{B. HIGH-TEMPERATURE THERMOMETRY}

References 8 and 10 are the publications of seminars on work done in high temperature thermometry. They contain much detailed information based on fundamentals covered in the preceding sections of this document.

$$
\text { LMEC-Memo-68-10 }
$$




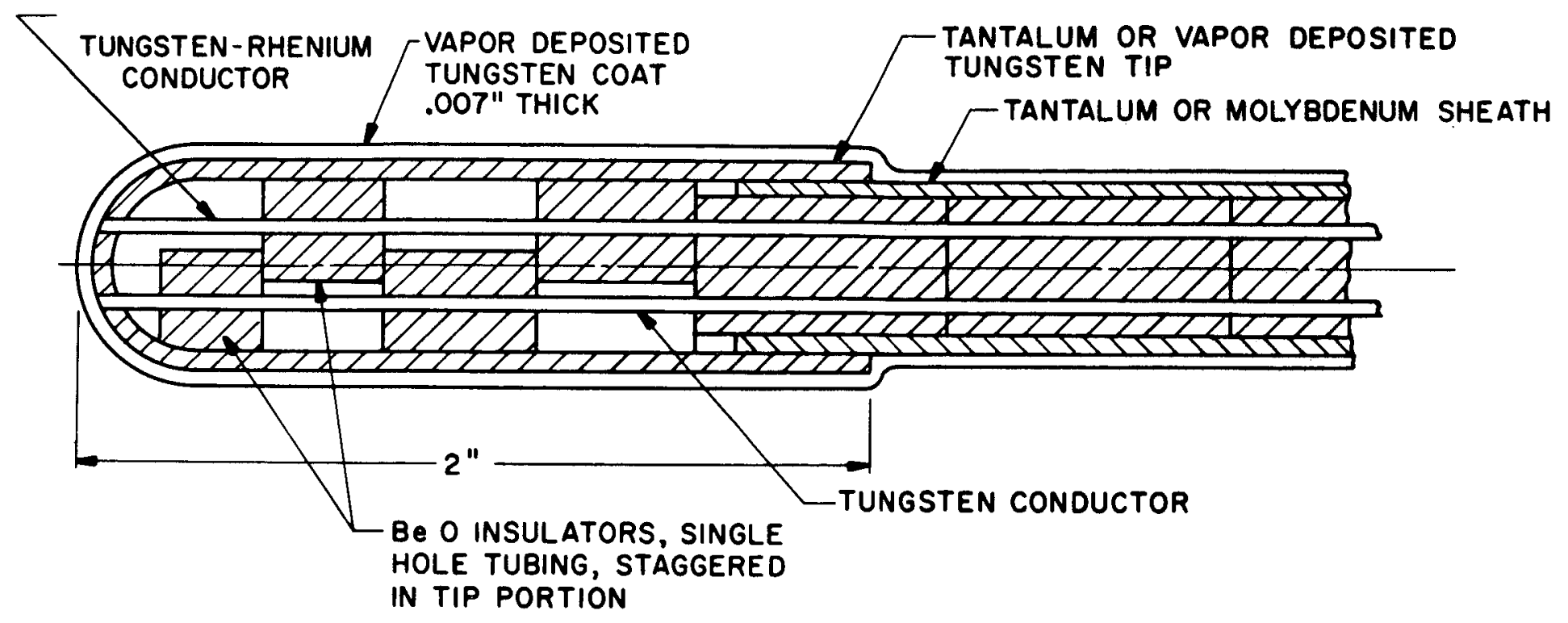

o. BIFILAR TC TIP

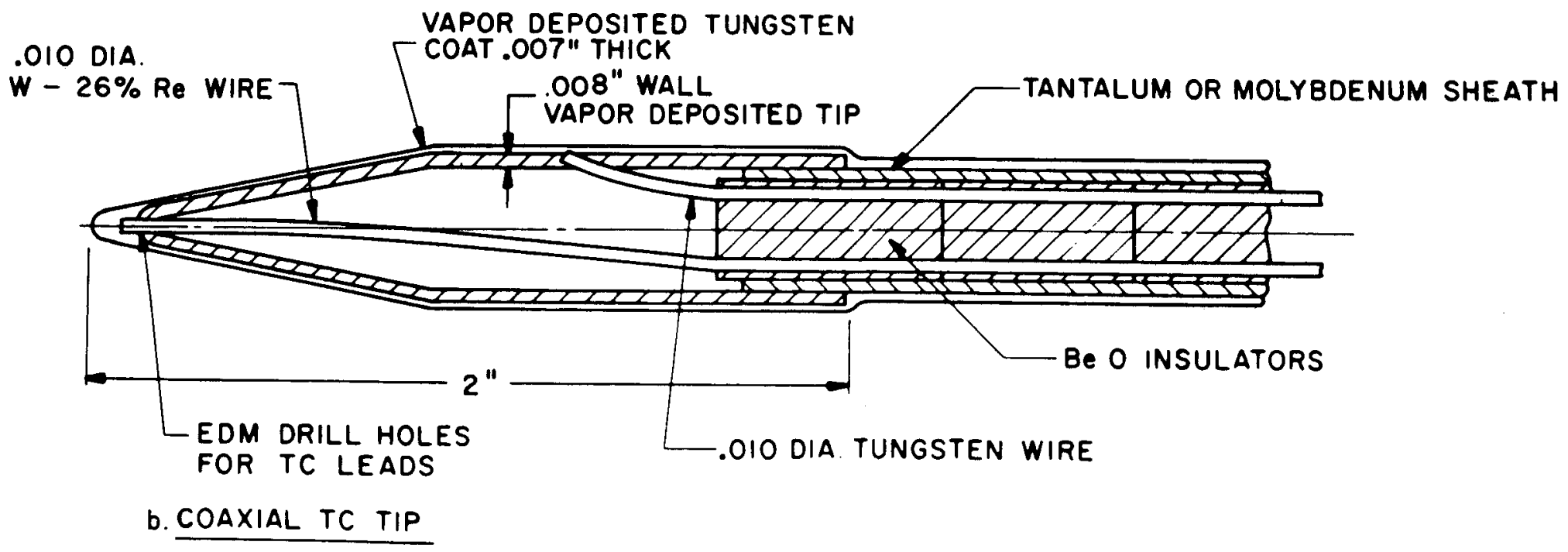

5-2-68 UNCL

Figure 28. Advanced Thermocouple Concepts 


\section{FAST RESPONSE THERMOCOUPLE}

Reference 12 describes the rmocouples made of 0.001 -in. and 0.0005 -in. wire. The 0.0005 -in. thermocouple reached a nominal 100\% of temperature in less than $1 \mathrm{msec}$ after a step function change. This represents a time constant of about $200 \mu \mathrm{sec}$.

\section{FUEL-PIN TEMPERATURE MEASUREMENT}

Reference 13 discusses the development of instrumenation and test equipment for $\mathrm{UO}_{2}$ fuel-pin temperature measurements to $2760^{\circ} \mathrm{C}\left(5000^{\circ} \mathrm{F}\right)$. Thermocouples were selected as providing the best technique, several types were tested and the cables and their insulation are discussed.

\section{E. THERMOCOUPLE STABILITY AND RELIABILITY IN LIQUID METAL}

References 14 and 15 relate specific experiences with the use of sheathed thermocouples in liquid metal systems. Essentially, the sheath material and fabrication must protect the thermocouple from the liquid metal environment while not introducing a thermal lag between thermocouple and point to be measured. A life as low as $25 \mathrm{hr}$ at $1850^{\circ} \mathrm{F}$ was experienced. Repeatabilities as good as $5^{\circ} \mathrm{F}$ at $1000^{\circ} \mathrm{F}$ after $2100 \mathrm{hr}$ in sodium were obtained.

\section{F. THERMOCOUPLE DEVELOPMENT FOR A LITHIUM-COOLED REACTOR}

Reference 16 is a comprehensive, in-depth and well illustrated report on the research, development and test of thermocouples for use in a liquid metal reactor. The primary subject of study is the $W-5 R e / W-26 R e$ thermocouple, but also, included are the following: Chromel/Alumel, W-3Re/W-25Re, $\mathrm{Mo} / \mathrm{Cb}$, and Mo/W-26Re.

\section{G. THE EFFECT OF PRESSURE ON TEMPERATURE CALIBRATION}

In Reference 17, the effect of pressure on the emf of Mo/Mo $-50 \% \mathrm{Re}$ thermocouples as compared to $\mathrm{Cr} / \mathrm{Al}$ was small, about $7^{\circ} \mathrm{C}$ at $40 \mathrm{kbar}$ and $1000^{\circ} \mathrm{C}$. It is believed that strain on thermocouple wires caused by deformation in high-pressure systems has a significant effect on the measured temperatures. For example, it has been reported that $\mathrm{Cr} / \mathrm{Al}$ the rmocouples will read as much as $8^{\circ} \mathrm{C}$ low at $700^{\circ} \mathrm{C}$ after cold work.

LMEC-Memo-68-10 
The advantage of Mo and Mo-Re alloys for use as thermocouples in highpressure dies is their ability to resist pinching off when these wires are led through gasketed systems. They have been proven to resist breaking much better than $\mathrm{Cr} / \mathrm{Al}$ or $\mathrm{Pt} / \mathrm{Pt}-\mathrm{Rh}$. Welding of Mo/Mo-Re thermocouples is dif ficult since the recrystallization temperature of the Mo is reached and a very brittle junction is formed. The problem was solved by brazing the joint with platinum. This procedure, however, limits the useful temperature to slightly over $1700^{\circ} \mathrm{C}$, but the advantage of a ductile couple junction in most cases out weighs the disadvantages. The effect on emf of the platinum in the junction was small enough so that it was not detected when precise calibration of the couples was made.

Output of the Mo/Mo - 50\%-Re thermocouple was found to be about twice that of $\mathrm{Pt} / \mathrm{Pt}-10 \%-\mathrm{Rh}$.

Investigation of a the rmocouple system that would have the above advantages and also stand direct welding led to $\mathrm{Re} / \mathrm{Mo}-30 \%-\mathrm{Re}$. This couple will retain ductility during direct resistance welding but has a smaller emf output, being about equal to $\mathrm{Pt} / \mathrm{Pt}-10 \%-\mathrm{Rh}$.

\section{H. GRADIENT APPROACH TO THERMOCOUPLE CIRCUITRY}

Reference 18 is a brief, but vital, discussion of the underlying principles of thermocouple thermometry. If not properly understood, the unwary user may introduce errors in the order of tens of degrees when making a transition from thermocouple wire to extension leadwire, even though he uses an isothermal junction block.

Another typical problem which can lead to large calibration errors involves thermocouples that have been in use a long time and are removed for a calibration check. As a result of alloy recomposition along the length of the thermocouple wire, thermal gradient emfs along one wire may result in operation which does not appear when just the couple end is inserted into a test block. The welded couple may check out to be in perfect calibration on the test rig but when placed in operation may be aided or opposed by the other emfs.

LMEC - Me mo-68-10 


\section{REFERENCES}

Material was drawn freely from the following sources:

1. "Temperature, Its Measurement and Control in Science and Industry, Vol. I, II, and III, "(Reinhold Publishing Corp., New York, 1941)

2. R. P. Benedict, "Temperature and Its Measurement," Electro-Technology, July 1963

3. B. Ragent and A. H. Samuel, "An Investigation of Temperature Measuring Techniques for Use in High Power Density Nuclear Reactors, "Broadview Research and Development, Document No. UCR L-5303, Published 1957

4. W. F. Roeser and S. T. Lonberger, "Methods of Testing Thermocouples and Thermocouple Materials," NBS Circular 590, February 1958

(Government Printing Office, Washington, D.C.)

5. "Status of Instrument Development for the SNAP-50 Reactor Test Programs," September 1965, PWAC-473, Pratt and Whitney Aircraft Company

6. F. R. Caldwell, "Thermocouple Materials," NBS Monograph 40, March 1962, (Government Printing Office, Washington, D.C.

7. "Standards and Practices for Instrumentation," published by Instrument Society of America, Section C96.1, 1964, American Standard for Temperature Measurement Termocouples

8. 'High Temperature Thermometry Seminar, ORNL October 1959," published by AEC, Division of Technical Information, TID-7586

9. "Ultrasonic Instrumentation for the Measurement of Temperature," from Applications of Ultrasonic Energy, Ultrasonic Instrumentation for Nuclear Applications, Bi-Monthly Progress report, December 1966, NYO3622-6

10. "High Temperature Thermometry, Seminar, Washington, D. C., February 1965," published by AEC, Division of Technical Information, Wash-1067

11. T. R. Billeter and D. P. Brown, "Mic rowave Measurement of High Temperatures Within Nuclear Reactors, Interim Report," BNWL-399, October 1967, Battelle Northwest Laboratory

12. G. R. Dittbenner, "Development and Application of the Intrinsic Thermocouple for Fast Response," Lawrence Radiation Lab. , UCR L-14593, March 1966

13. G. F. Popper and A. E. Knox, "Faret In-Core Instrument Development," AN L-7 161, July 1966

14. J. W. Stark, "Final Report on the Tests and Development Program of $\mathrm{MgO}$ Sheath-Type Thermocouples," Mary 1955, AEC Document, KAPL-ADM-1270

LMEC-Memo-68-10 
15. "Space Power and Propulsion Section, First Quarterly Report, September 1962 ," AEC Document, NP-12433

16. "Thermocouple Development for a Lithium-Cooled Reactor Experiment," PWAC-422, March 1964, Pratt and Whitney Aircraft

17. H. D. Stromberg and D. R. Stephens, "Effect of Pressure on the Temperature Calibration of Mo/Mo - 50\%-Re Thermocouples to $1000^{\circ} \mathrm{C}$ and $60 \mathrm{Kilo-}$ bars," UCRL-1 4993

18. R. J. Moffat, "The Gradient Approach to Thermocouple Circuitry," General Motors Research Laboratories, Warren, Michigan

19. "Temperature, Its Measurement and Control in Science and Industry, Part 2," (Reinhold Publishing Corporation, New York 1962)

20. H. D. Baker, E. A. Ryder, and N. H. Baker, "Temperature Measurement in Engineering," (John Wiley and Sons, New York, 1953) Vol. 1, Vol. II, 1961

21. K. S. Lion, "Instrumentation in Scientific Research," (McGraw-Hill Book Company, New York, 1959)

22. T. R. Harrison, "Radiation Pyrometry and Its Underlying Principles of Radiant Heat Transfer," (John Wiley and Sons, New York, 1960)

23. L. G. Rubin, "Temperature-Concepts, Scales and Measurement Techniques," Technical Memorandum T-538 is sued by Research Division of Raytheon Company

24. "Accuracy in Measurements and Calibrations, 1965," U. S. National Bureau of Standards Technical Note 262 (Government Printing Office, Washington, D. C.)

25. W. E. Forsythe, "Measurements of Radiant Energy," (McGraw-Hill, New York 1937)

26. P. H. Dike, "Temperature Measurements with Rayotubes," Leeds and Northrup Company, Philadelphia, 1953

27. P. H. Dike, "Thermoelectric Thermometry," Leeds and Northrup Company, Philadelphia, 1958, 3 rd Edition

28. Electro-Technology, May 1963, pp 113-128

29. Electro-Technology, July 1963, pp 71-86

30. International Science and Technology, Prototype Is sue, pp 18-27

31. International Science and Technology, June 1962, pp 36-53

LMEC-Memo-68-10 
32. Instruments and Control Systems, May 1961, pp 841-853

33. H. J. Metz and M. M. Yarosh, "Experiences and Development in Instrumentation for Liquid Metal Experiments," Fourth High Temperature Liquid Metal Heat Transfer Technology Conference, September 1965 


\section{APPENDIX}

\section{A. FUNDAMENTALS OF TEMPERATURE MEASUREMENT \\ 1. Definition of Temperature}

Temperature is defined as the condition of a body which determines the transfer of heat to or from other bodies. Particularly it is a manifestation of the average translational kinetic energy of the molecules of a substance due to heat agitation.

Temperature is an intensive quantity. This means that the combination of two identical objects having the same temperature will yield a new body with twice the mass and volume (extensive quantities) of each component but with the same temperature. As a consequence, any temperature measuring system must establish both a reference temperature and a rule for measuring the differences between the reference and any other temperatures. In principle nearly every property of a material which changes with temperature in a well-defined way can serve as a thermometric substance. The variety of such systems is tremendous. Although arbitrary scales may validly conform to definite test procedures, it is obvious that a truly universal scale, one which is easily and fundamentally defined, is far more desirable.

Lord Kelvin proposed a thermodynamic scale which was independent of the material used or of the specific details of the experiment. It may be explained very briefly as follows: assume a perfect reversible heat engine transferring heat from one infinite capacity heat reservoir to another. If $Q_{1}$ is the quantity of heat taken from one reservoir and $Q_{2}$ is the quantity put into the other, then the temperatures of the two reservoirs $\mathrm{T}_{1}$ and $\mathrm{T}_{2}$ are given by

$$
\frac{\mathrm{T}_{1}}{\mathrm{~T}_{2}}=\frac{\mathrm{Q}_{1}}{-\frac{1}{\mathrm{Q}_{2}}} \text {. }
$$

Or, in other words, the temperatures of two heat reservoirs are related to each other in proportion to the heat quantity contained in each. A temperature scale may then be completely defined by establishing one fixed point relative to

LMEC-Memo-68-10 
absolute zero. Kelvin chose this point so that his thermodynamic scale would be simply related to the then existing centigrade scale.

\section{International Practical Temperature Scale (IPTS)}

In 1954 the scale was adjusted slightly by choosing the temperature of the triple point of water to be $273.16^{\circ} \mathrm{K}$ exactly. This temperature, the state at which solid, liquid and vapor phases of water are in equilibrium, can be measured with a precision of a few ten-thousandths of a degree. In view of the fact that the Kelvin thermodynamic scale is identical with that defined by the gas equation

$$
\mathrm{PV}=\mathrm{RT},
$$

it is possible to reduce Kelvin's scale to practice. At the present time, the gas thermometer, filled with a perfect gas, is recognized as the primary instrument for realizing the thermodynamic scale over the range that the thermometer can be used. Although a great deal of effort has gone into this type of work, gas thermometry remains a difficult and tedious procedure, generally unsuited to the practical needs of temperature measurement. For this reas on the IPTS was originated in 1927, with important revisions in 1948 and minor changes since that time. It was established to represent, in a practical manner, the thermodynamic scale as closely as posible.

The IPTS is defined by a set of fixed points and rules governing interpolation between them and extrapolation beyond. At one of these fixed points, the triple point of water, the two scales are in exact agreement. Five other reproducible equilibrium temperatures are denoted as fixed points: the boiling points of liquid oxygen, water, and sulfur, and the freezing points of silver and gold. These temperatures, covering a range from -182.97 to $+1063.0^{\circ} \mathrm{C}$, we re assigned on the basis of gas thermometer measurements performed as carefully as the state-of -the-art permitted. Interpolation between the fixed points is arrived at by different methods for different ranges.

Thus, between the oxygen point and $630.5^{\circ} \mathrm{C}$, the resistance of a platinum resistance thermometer is used in conjunction with two equations, one below the triple point and one above. The emf of a Pt-Pt/loRh the rmocouple and

\section{LMEC-Me mo-68-10}


its associated equation defines the interpolation range between $630.5^{\circ} \mathrm{C}$ and the gold point. Extrapolation of the scale above the gold point is accomplished through the use of the Plant radiation formula, implemented by optical radiation pyrometry. No upper limit is assigned to the scope of the IPTS, but a lower limit is the oxygen point, $90.19^{\circ} \mathrm{K}$. By calibrating a series of platinum resistance thermometers against a helium gas thermometer, the National Bureau of Standards has established a provisional scale between 11 and $90^{\circ} \mathrm{K}$.

Although the IPTS is actually nothing more than a practical standard empirical temperature scale, its advantages have made possible the most significant fact of all. Any competent laboratory may now set up equipment for a thermometer calibration in terms of fixed-point standards, without reference to any other laboratory, with confidence that the results will be consistent and in agreement with all other competent laboratories. This is the most basic requirement for any measurement system.

Table A-1 provides a reference of some of the more significant temperature points.

\section{B. DEFINITIONS}

The following definitions are listed here to provide a convenient reference for terms commonly associated with temperature measurements.

1) Adiabatic - A change undergone by a body when its condition is altered without gain or loss of heat.

2) Blackbody - a body in which all the energy is absorbed for all values of the wavelength of the incident radiant energy.

3) Btu - British thermal unit, the quantity of heat required to raise the temperature of $1 \mathrm{lb}$ of water $1^{\circ} \mathrm{F}$ at, or near, its point of maximum density $\left(39.1^{\circ} \mathrm{F}\right)$; it is equivalent to 252 international calories.

4) Calorie - The amount of heat necessary to raise $1 \mathrm{gm}$ of water $1^{\circ} \mathrm{C}$ for water at $15^{\circ} \mathrm{C}$ (cgs system). The international calorie is defined as $1 / 860 \mathrm{w}-\mathrm{hr}$.

5) Heat Capacity - The quantity of heat required to increase the temperature of a system or substance by one degree.

LMEC-Me mo-68-10 
TABLE A-1

TEMPERATURE CALIBRATION POINTS

\begin{tabular}{|c|c|c|c|c|}
\hline Significant Points & $\begin{array}{c}\text { Degrees } \\
\text { Kelvin } \\
\left({ }^{\circ} \mathrm{K}\right)\end{array}$ & $\begin{array}{c}\text { Degrees } \\
\text { Celsius } \\
\left({ }^{\circ} \mathrm{C}\right)\end{array}$ & $\begin{array}{c}\text { Degrees } \\
\text { Fahrenheit } \\
\left({ }^{\circ} \mathrm{F}\right)\end{array}$ & $\begin{array}{c}\text { Degrees } \\
\text { Rankine } \\
\left({ }^{\circ} R\right)\end{array}$ \\
\hline Absolute Zero & 0 & -273.15 & -459.67 & 0 \\
\hline Helium Boils & 4.2 & -269 & -452 & 7.6 \\
\hline Hydrogen Boils & 20 & -253 & -423 & 36 \\
\hline Neon Boils & 27 & -246 & -410 & 49 \\
\hline Nitrogen Boils & 77 & -196 & -320 & 139 \\
\hline Argon Boils & 87 & -186 & -302 & 157 \\
\hline Oxygen Boils & 90 & -183 & -297 & 162 \\
\hline Carbon Dioxide Sublimes & 195 & -78 & -109 & 350 \\
\hline Mercury Melts & 234 & -39 & -38 & 421 \\
\hline Ice Melts & 273.15 & 0 & 32 & 491.67 \\
\hline Triple Point of Water & 273.16 & 0.0100 & 32.0180 & 491.69 \\
\hline Water Boils & 373 & 100 & 212 & 671 \\
\hline Tin Melts & 505 & 232 & 449 & 908 \\
\hline Mercury Boils & 630 & 357 & 674 & 1133 \\
\hline Zinc Melts & 693 & 420 & 787 & 1246 \\
\hline Sulfur Boils & 718 & 445 & 832 & 1291 \\
\hline Antimony Melts & 903 & 630 & 1166 & 1625 \\
\hline Silver Melts & 1234 & 961 & 1762 & 2221 \\
\hline Gold Melts & 1336 & 1063 & 1945 & 2404 \\
\hline Iron Melts & 1809 & 1536 & 2796 & 3255 \\
\hline Platinum Melts & 2047 & 1774 & 3224 & 3683 \\
\hline Aluminum Oxide Melts & 2293 & 2020 & 3632 & 4091 \\
\hline Molybdenum Melts & 2893 & 2620 & 4748 & 5207 \\
\hline Tantalum Melts & 3300 & 3027 & 5480 & 5939 \\
\hline Tungsten Melts & 3643 & 3370 & 6110 & 6569 \\
\hline Carbon Sublimes & 4473 & 4200 & 7600 & 8059 \\
\hline Molybdenum Boils & 5073 & 4800 & 8670 & 9129 \\
\hline Tungsten Boils & 6173 & 5900 & 10,650 & 11,109 \\
\hline
\end{tabular}


6) Heat Quantity - The amount of heat that must be added to (or removed from) a system, or substance, (expressed in calories or Btu) to raise (or lower) its temperature by one degree.

7) Latent Heat of Fusion - The quantity of heat necessary to change $1 \mathrm{gm}$ (cgs system) of solid to a liquid with no temperature change.

8) Latent Heat of Vaporization - The quantity of heat necessary to change one gram (cgs system) of liquid to vapor without change of temperature.

9) Pyrometry - In a broad sense the terms pyrometry and thermometry are equivalent. Pyrometry has become commonly associated with high temperature measurement, and even more specifically with measurement at a distance. Thermometry is the more generic term.

10) Seebeck Effect - The effect manifest in a circuit consisting of two different metals with one junction hotter than the other resulting in a current flow through the circuit (thermocouple).

11) Specific Heat - The ratio of the thermal capacity of any substance to that of water at $15^{\circ} \mathrm{C}$.

12) Stefan-Boltzman Law of Radiation - The energy radiated in unit time by a blackbody is given by, $E+K\left(T^{4}-T_{0}^{4}\right)$, where $T$ is the absolute temperature of the body, $T_{0}$ is the absolute temperature of the surroundings, and $K$ is a constant.

13) Thermal Capacity of a Substance - The quantity of heat necessary to produce a unit change of temperature in a unit mass; numerically equivalent to specific heat.

14) Thermodynamics, Laws of -

I. When mechanical work is transformed into heat, or heat into mechanical work, the amount of work is always equivalent to the quantity of heat.

II. It is impossible by any self-sustaining process for heat to be transferred from a colder to a hotter body.

LMEC-Memo-68-10 
15) Thomson Thermoelectric Effect - The designation of the potential gradient along a conductor which accompanies a temperature gradient. The magnitude and direction of the potential varies with the substance.

16) Vapor Pressure - The pressure exerted when a solid or liquid is in equilibrium with its own vapor. The vapor pressure is a function of the substance and the temperature.

17) Wien's Displacement Law - When the temperature of a radiating blackbody increases, the wavelength corresponding to maximum energy decreases in such a way that the product of the absolute temperature and wavelength is constant.

$$
\lambda_{\max } \mathrm{T}=\mathrm{w}
$$

$\mathrm{w}$ is known as Wiens displacement constant.

\section{COLOR SCALE OF TEMPERATURE}

Table A-2 is an effort to interpret, in terms of thermometric readings, commonly used expressions describing temperatures.

TABLE A-2

COLOR SCALE OF TEMPERATURE

\begin{tabular}{|c|c|c|c|c|}
\hline \multirow{2}{*}{ Color } & \multicolumn{4}{|c|}{ Temperature } \\
\hline & \multicolumn{2}{|c|}{$\left({ }^{\circ} \mathrm{C}\right)$} & \multicolumn{2}{|c|}{$\left({ }^{\circ} \mathrm{F}\right)$} \\
\hline Incipient Red Heat & 500 to & 550 & $900 \mathrm{t}$ & 1000 \\
\hline Dark Red Heat & 650 & 750 & 1200 & 1400 \\
\hline Bright Red Heat & 850 & 950 & 1500 & 1750 \\
\hline Yellowish Red Heat & 1050 & 1150 & 1900 & 2100 \\
\hline Incipient White Heat & 1250 & 1350 & 2300 & 2450 \\
\hline White Heat & $1450 \nmid$ & 1550 & 2650 & 2850 \\
\hline
\end{tabular}

LMEC-Memo-68-10 